Portland State University

PDXScholar

Summer 7-8-2016

\title{
An Interpretive Phenomenological Analysis of Long- Term Mentoring Relationships from the Youth Perspective
}

Kevin Richard Jones

Portland State University

Follow this and additional works at: https://pdxscholar.library.pdx.edu/open_access_etds

Part of the Social Work Commons

Let us know how access to this document benefits you.

\section{Recommended Citation}

Jones, Kevin Richard, "An Interpretive Phenomenological Analysis of Long-Term Mentoring Relationships from the Youth Perspective" (2016). Dissertations and Theses. Paper 3107.

https://doi.org/10.15760/etd.3104

This Dissertation is brought to you for free and open access. It has been accepted for inclusion in Dissertations and Theses by an authorized administrator of PDXScholar. Please contact us if we can make this document more accessible: pdxscholar@pdx.edu. 
An Interpretive Phenomenological Analysis of Long-Term Mentoring Relationships

from the Youth Perspective

by

Kevin Richard Jones

A dissertation submitted in partial fulfillment of the requirements for the degree of

Doctor of Philosophy

in

Social Work and Social Research

\author{
Dissertation Committee: \\ Thomas E. Keller, Chair \\ Ben Anderson-Nathe \\ Jana Meinhold \\ José Padin
}

Portland State University

2016 


\begin{abstract}
When mentoring programs are well-designed and well-implemented, young people can experience positive gains in a number of social, emotional, behavioral, and educational areas. While some of the processes underlying mentoring relationships have been explored, the voices and perspectives of participants themselves have thus far been largely excluded from the mentoring literature. The lack of participant voice in mentoring research suggests that an important source of empirical and interpretive information is unavailable to the field in the process of designing, implementing, and researching mentoring programs. This study used interpretive phenomenological analysis (IPA) to explore how youth participants in the Friends of the Children (FOTC) mentoring program experience and understand their long-term mentoring relationships.
\end{abstract}

This study used an innovative approach to IPA that combines traditional phenomenological techniques with poetry writing as a key interpretive tool to explore the interplay between the content and meaning of participants' experiences. IPA methods were used to collect and analyze interview data from 12 FOTC participants who had been in the program for more than ten years and who had the same mentor for at least the last four years. Participants were selected purposively to maximize the potential depth and richness of the data. The study included several elements to ensure trustworthiness, including a reflexivity journal, an audit trail, and member checking.

Findings suggest that for the participants in this study, long-term mentoring relationships meant: 1) unconditional support and commitment, 2) consistent and reliable help in difficult situations, 3) the chance to develop and appreciate one's own identity, 
and 4) a path to expanded opportunities in many facets of life. Subthemes within each category are described and interpreted. The poems created from the interview transcripts provide powerful and complementary illustrations for emergent themes by capturing some of the emotional content that can be lost in the process of analyzing, categorizing, and describing complex human phenomena. Key recommendations for mentoring programs and social work professionals are provided. Implications for future research are also discussed. 


\section{Dedication}

This dissertation is dedicated with love and gratitude to my life partner, Amy Salazar, and to my son, Emerson. 


\section{Acknowledgements}

First, I would like to thank the Center for Interdisciplinary Mentoring Research at Portland State University for providing funding for this project. I am also very thankful for the support and guidance of my dissertation committee members - Tom, Jana, Ben, and José-who served as thoughtful and compassionate mentors to me through the entire research and writing process. I would also like to sincerely thank my Ph.D. program cohort, a.k.a. "The Perfect Storm,” for being incredible friends, allies, and coconspirators. I owe a special thanks to my colleagues, Anissa Rogers and Alice Gates, as well as my sociology program colleagues at University of Portland, for their encouragement, advocacy, and friendship. Finally, I am eternally grateful to Amy and Emerson, my parents, brothers, and other family members who have always believed in me, and to whom I owe more than I could ever possibly repay. 
Table of Contents

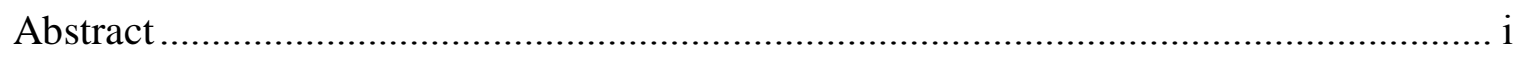

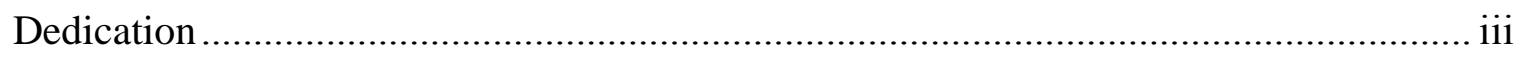

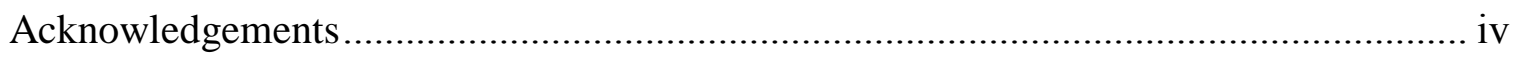

List of Tables ..................................................................................................... vii

Chapter 1

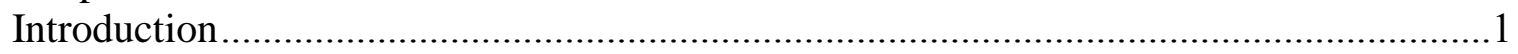

Chapter 2

Review of Related Literature ................................................................................ 17

Chapter 3

Theoretical Framework ......................................................................................4

Chapter 4

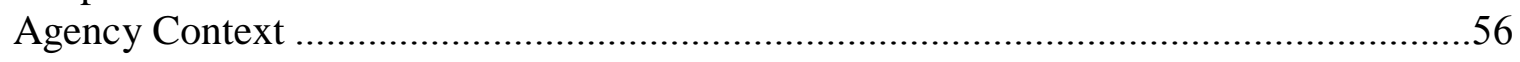

Chapter 5

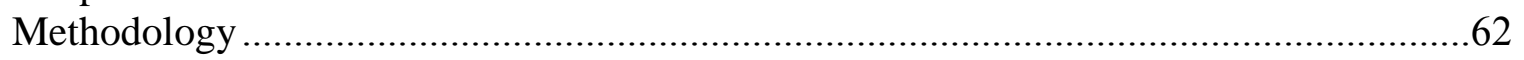

Chapter 6

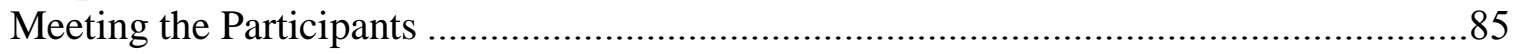

Chapter 7

"No Matter What": The Experience of Unconditional Support and Commitment...........94

Chapter 8

"Kind of Like a Guardian Angel": The Experience of Help in Difficult Situations........125

Chapter 9

"It's Okay to be Myself": The Experience of Identity Development .............................141

Chapter 10

"For Me, It Means Opportunity": The Experience of Expanded Opportunity .................162

Chapter 11

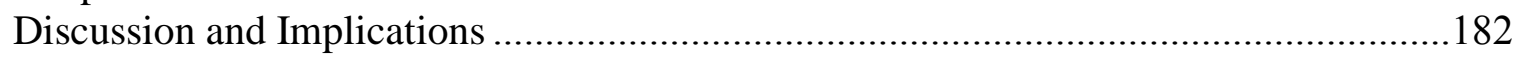

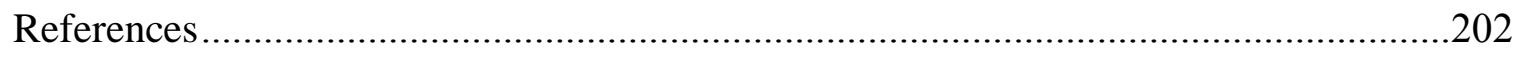




\section{Appendices}

Appendix A. Reflections on the Use of Poetry in Interpretive Phenomenological

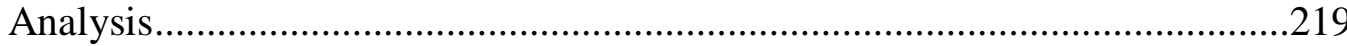

Appendix B. Parent/Guardian Consent Document .......................................223

Appendix C. Participant Consent Document ................................................224

Appendix D. Sample Interview Questions...................................................225

Appendix E. Transcriptionist Confidentiality Form ….................................226 


\section{List of Tables}

\section{Table 1}

Positive Youth Development Program Characteristics..................................................53

Table 2

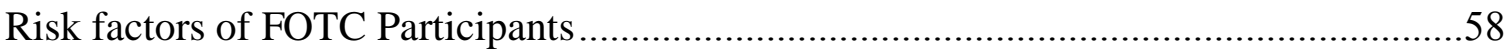

Table 3

Themes and Subthemes in Findings 


\section{Chapter 1: Introduction}

Youth mentoring has been a trusted intervention for addressing the problems of young people for more than a hundred years (Rhodes \& DuBois, 2008). In the last two decades, proponents of youth mentoring have capitalized on a wave of encouraging outcome studies and positive press to exponentially increase the number of youth mentoring programs and the number of youth served by them (Rhodes, 2008). There is strong evidence to suggest that when mentoring programs are well-designed and wellimplemented, youth can experience positive gains in a number of social, emotional, behavioral, and educational areas (DuBois, Portillo, Rhodes, Silverthorn, \& Valentine, 2012; DuBois, Holloway, Valentine, \& Cooper, 2002; Eby, Allen, Evans, Ng, \& DuBois, 2008; Sipe, 2002). Youth mentoring research to date has focused primarily on the effectiveness of programs and identifying the characteristics that seem to make youth mentoring work best. While some of the processes underlying youth mentoring relationships have begun to be explored, the voices and perspectives of the youth participants themselves have thus far been largely excluded from the youth mentoring literature. This is both surprising and significant because most mentoring programs are youth-centered in orientation and excluding direct accounts of youth experiences and youth meaning-making from consideration in program design and implementation can be viewed as antithetical to a youth-centered approach. The lack of youth voice in youth mentoring research is also notable because many other fields, such as education and nursing, have successfully integrated what has been learned from the knowledge and experiences of clients, patients, and participants to improve approaches to practice and research. The mentoring literature to date has largely neglected the topic of what 
mentoring relationships mean to participants, both mentors and youth, which suggests that a potentially important source of empirical and interpretive information is unavailable to the field in the process of designing, implementing, and researching mentoring programs.

The current study tapped into the lived experiences of youth participants of longterm mentoring relationships to discover what they experience-what they think and feel, what they remember and understand, what they want, and what they need from mentoring programs and mentoring relationships. To begin to address these largely unexamined areas, the current study used a poetry-informed approach to interpretive phenomenological analysis (IPA) to explore long-term mentoring relationships from the perspective of youth participants in the community-based mentoring program Friends of the Children (FOTC). Poetry-informed IPA combines traditional phenomenological techniques with poetry writing as an interpretive tool to explore the interplay between the content and meaning of participants' experiences, providing insight into how youth experience long-term mentoring relationships and what those relationship experiences mean to them.

This dissertation is organized into twelve chapters. Chapter One describes the purpose of the study, offers some cultural and historical context that informs how our society thinks about youth mentoring, introduces the study's specific research questions, and describes the importance of the current study for research and practice in social work. The second chapter offers a review of relevant academic literature on youth mentoring relationships and programs, including: 1) studies that address the effectiveness of youth 
mentoring in promoting positive outcomes for youth; 2) studies that describe theoretical models of how mentoring relationships work; 3) studies that describe the various roles and functions within mentoring relationships; and 4) studies that address issues of meaning in youth mentoring relationships. The literature review will provide context for the study, particularly by highlighting the ways in which an interpretive phenomenology of long-term mentoring relationships addresses significant gaps in the knowledge base that informs youth mentoring programs. Chapter Three introduces the theoretical framework for the study, which includes attention to phenomenology as a philosophy and an approach to social science research, and an outline of the principles of Positive Youth Development (PYD), the framework at the heart of the Friends of the Children program. The fourth chapter describes the agency context at Friends of the Children, providing a closer look at the program in which the study took place. Chapter Five details the study's methodology, including an overview of phenomenology and interpretive phenomenological analysis, and provides a detailed description of the selection of participants, data collection, data analysis, establishing trustworthiness, and accounting for researcher positionality. Chapter Six provides a brief introduction to each of the twelve youth who participated in the study. Chapters Seven through Ten comprise the main findings of the study, with each chapter addressing a particular theme that was central to the youth experience of long-term mentoring relationships.

\section{Research Questions}

The current study was designed to generate understanding of how youth experience and understand long-term mentoring relationships. IPA is an ideal approach 
for this purpose since it is intended "to find out how individuals are perceiving the particular situations they are facing, how they are making sense of their personal and social world" (Smith \& Osborn, 2007, p. 55). Research questions in IPA do not address hypotheses; rather, they are open and broad, allowing for a deep and detailed exploration of a particular area of concern (Smith \& Osborn, 2007). With these purposes in mind, the current study addressed the following questions:

1. What is the experience of being in a long-term mentoring relationship like for youth?

2. How do youth involved in long-term-mentoring relationships understand and make sense of those relationships?

\section{Purpose of the Study}

The purpose of this study is to explore youths' lived experiences of long-term mentoring relationships and to discover the ways in which these relationships are meaningful to youth. An interpretive phenomenological approach was used to collect and analyze interview data from FOTC participants who have been in the FOTC program for over ten years and who have had the same mentor for at least the last five years.

Participants for the study were selected purposively in an effort to maximize the potential depth and richness of the data. Thematic and poetry-based data analysis strategies were used to accomplish the study's two main goals: 1) to discover and describe what the experience of having a long-term mentor is like for older youth in the FOTC program, and 2) to interpret and illuminate the meanings that are present in youth participants' descriptions and understandings of their experiences of long-term mentoring 
relationships. Phenomenological data analysis techniques, including a traditional thematic approach and an innovative poetry-based interpretive process, allowed me, the researcher, to offer rich and resonant descriptions of youth experiences and interpret their attendant meanings in both logical/rational and emotional/intuitive ways. The prose and poems that resulted from the study provide deep, authentic accounts of what it means for youth to have long-term mentors, accounts which can inform professional practice with youth as well as future research in the fields of youth mentoring and child development.

\section{Background}

The idea that a young person can benefit from the care, guidance, and wisdom of an older, more experienced role model is an ancient one. In Homer's The Odyssey, the goddess Athena takes the form of Odysseus' trusted friend, Mentor, to guide the hero's son, Telemachus, through trials and adversity while Odysseus is away at war. As Mentor, Athena helps Telemachus navigate a ship through a storm and advises the boy on what to do in the event that his father does not return from the Trojan War alive. Through this type of mentoring, characterized by consistent and straightforward counsel, Athena provides the kind of solid advice, wisdom, and support to Telemachus that we often associate with positive mentoring relationships. Simply put, in some circumstances, “a mentor is a teacher" (Lucas, 2001).

Less well known about The Odyssey is that in addition to taking the form of Mentor, Athena also takes the guise of a shepherd, a young girl with a water pitcher, a swallow, a ship captain's daughter, and a seagull at various times in order to provide timely assistance, instruction, and encouragement that helps Telemachus make a 
successful transition from childhood to adulthood in Odysseus' absence. Telemachus' situation is a particularly perilous one. With Odysseus away, rogues run amok in the royal household and threaten Telemachus' life as they attempt to seduce his mother, Penelope. Athena uses the full range of her powers to motivate and advocate for the boy, making efforts that neither Telemachus nor Odysseus can ever fully understand or appreciate. To be a successful mentor in this particularly difficult circumstance, Athena finds it necessary to be much more than just a teacher or wise counselor. In this light, one may view Athena as something of a guardian angel (Bassett, 1920). In the end, Telemachus overcomes adversity, and after 20 years at war, Odysseus returns home to his wife, son, and kingdom.

Freedman (1999) describes several examples of mentor "mythology" that have captured the imagination of Western societies through different periods of history. In addition to the tale of The Odyssey, Freedman notes the significant influence of the Iron John fairytale from The Brothers Grimm in the $19^{\text {th }}$ century, some early variants of which date back to the $15^{\text {th }}$ century. Iron John chronicles the growth and development of a troubled young prince who receives the assistance and guidance of Iron John, a former king, to become a celebrated knight who eventually marries a beautiful princess from a neighboring kingdom. According to this "classical conception of mentoring" passed down through the centuries, Freedman (1999, p. 34) distills three common elements of mentoring relationships: "achievement, nurturance, and generativity" [emphasis in original]. Iron John, like Athena's incarnation as Mentor, possesses great—even supernatural—powers from which his mentee benefits in order to overcome adversity 
(Freedman, 1999). Freedman (1999) also notes that the "classical conception" of mentoring has not been relegated to history. He provides a recent example from The New York Times Magazine of a journalist's account of his transformative relationship with a wise and caring college professor that illustrates how the tradition of portraying mentors in idealized and heroic ways continues to this day.

From the world of literature and letters, we now shift to 1904 in New York City, where Ernest Coulter, a clerk of the court, responded to the steady stream of young boys appearing in his courtroom by calling for volunteers to serve as Big Brothers to delinquent youth (Big Brothers Big Sisters of America [BBBSA], 2011). Coulter stated that,

"There is only one way to save that youngster and that is to have some earnest, true man volunteer to be his Big Brother, to look after him, help him to do right, make the little chap feel that there is at least one human being in this great city who takes a personal interest in him. Someone who cares whether he lives or dies... I call for a volunteer.” (BBBSA, 2011).

Coulter's actions on behalf of poor and delinquent children are considered the beginning of the modern youth mentoring movement. Within a decade, Big Brothers organizations were active in more than two dozen cities, and a parallel effort to provide Big Sisters to young girls was underway.

The early Big Brothers and Big Sisters organizations were an extension of the "friendly-visitor" movement of the late $19^{\text {th }}$ century, in which volunteers visited and 
served as role models for the poor (Miller, 2007). Working from the assumption that moral deficiencies were the root cause of the troubles that poor people faced, the friendly visitors' main concern was to influence the poor to become more honest and efficient by giving them personal and sympathetic guidance (Boyer, et al., 2010). Indeed, there was widespread concern amongst proponents of the friendly visiting approach that giving money or material goods to those living in poverty, particularly those deemed “undeserving cases," would only breed dependency and laziness, in other words reinforcing the degraded character that was thought to be common among those living in poverty (Charity Organization Society, 1883).

Coulter's writings $(1913 ; 1917)$ urged against judging youth living in poverty or their families, arguing that people are largely products of their environment. At the same time, Coulter reinforced the friendly visitors' notion that poverty and delinquency are consequences of moral deficiency. Referring to a group of formerly homeless youth who were offered rehabilitation at a refuge in Delaware called Big Brother Farm, Coulter (1913) said, "These youngsters only a few months before were anaemic [sic] physically and morally. Their life at the Big Brother Farm has wrought the transformation" (p. 266). Coulter's (1917) description of the selection process for potential Big Brothers, including an assessment of personal characteristics and religious faith, further suggests that moralism played some significant role in how mentoring programs' early proponents conceptualized the problems of poverty and delinquency and mentoring's promise as part of the solution. While today’s Big Brothers Big Sisters organizations vary greatly in practice from their earlier incarnations, the front page of the Big Brothers Big Sisters of 
America website today claims " $83 \%$ of former Littles surveyed agree that their Big instilled values and principles that have guided them through life" (BBBSA, 2011), to some degree maintaining the early organization's claim that, through the mentoring relationship, youth are provided a moral compass that they lacked previously.

Ideas about youth mentoring relationships have also been shaped by developments in the social sciences, and in the evolution in approaches to addressing youth social problems over the last century. Research on adolescent development in the West has traditionally focused on adolescence as a time of turmoil and adolescents as trouble or troubled (Lerner, 2009). G. Stanley Hall (1904), widely credited with initiating the scientific study of adolescence, famously characterized adolescence as a time of inherent storm and stress. For decades, this view was reinforced by influential psychoanalytic theorists, particularly Anna Freud, who viewed the absence of turmoil in adolescence as a sign of psychopathology (Arnett, 1999). More recent research has demonstrated, however, that the storm and stress of adolescence shows wide variation among individuals, and that adolescent turmoil, and even the experience of adolescence itself, is "by no means universal and inevitable" (Arnett, 1999, p. 323). Several researchers have raised concerns about the possible negative implications of overanticipating the storm and stress of adolescence, including an increase in authoritarian parenting styles (Holmbeck, 1996), and a discounting of serious psychological and social problems in adolescence as normal and expected (Offer \& Schonert-Reichl, 1992). Yet, some mentoring programs continue to offer Hall's century-old idea of adolescent storm 
and stress as evidence of the need for more and better youth mentoring programs (Claassen, 2011; MENTOR/National Mentoring Partnership, 2004).

Popular beliefs about troubled youth led to increased federal funding and rapid proliferation of narrowly focused prevention efforts through the 1950s and 1960s. Intended to address growing concern about juvenile delinquency, teen pregnancy, substance use, and other youth problems, programs were launched that targeted one or two associated factors related to a single issue (Catalano, Berglund, Ryan, Lonczak, \& Hawkins, 1998). For example, teen pregnancy programs focused almost exclusively on addressing "promiscuity" among teen girls, while ignoring the impact of males (particularly adult males), not to mention larger societal norms (e.g. objectification of girls and women), on the rising rate of early pregnancies. The majority of early prevention programs were not based on theory or scientific research and showed little or no impact on targeted outcomes (Catalano, Berglund, Ryan, Lonczak, \& Hawkins, 1998).

Prevention science in the 1970s and 1980s began to show that a broad range of youth problem behaviors had common risk factors, and that those factors occurred across contexts and various levels of the social environment. In response, prevention scientists and practitioners shifted to more "non-categorical" approaches to youth work, promoting programs that work across social domains and address a broader range of risk factors (Catalano, et al., 1998). Additional focus was also placed on youths' positive characteristics and circumstances that can offset risk and mitigate negative outcomes. In response, some youth mentoring programs, such as FOTC, have utilized a Positive Youth Development (PYD) framework that assesses and addresses multiple levels of a youth's 
social environment while maintaining a focus on the youth's positive attributes and areas of strength. The assumptions that underlie the PYD approach to mentoring stand in contrast to many of the assumptions implicit in other ways of conceptualizing mentoring as a prevention and intervention strategy.

The evolution of how scientists, practitioners, and policy-makers view mentoring programs and relationships directly impacts how programs are designed and implemented (Coyne, Duffy, \& Wandersman, 2007). So, which perspectives are most appropriate? Mentor as teacher and counselor, or as hero and guardian angel? Instiller of values or promoter of positive attributes? Big Brother or Friend?

The way mentoring relationships are understood is shaped by many factors, including cultural lore, cultural norms and traditions, personal experiences, popular media, and developments in scientific research. Many popular and academic articles on youth mentoring as well as numerous websites and mentoring program descriptions invoke the mythical relationship in The Odyssey as a touchstone for the field. The interpretation of the relationship between Athena (as Mentor) and Telemachus as simple and straight-forward (i.e., teacher) or heroic (i.e., guardian angel) may in itself have important implications for how we conceptualize, design, implement, manage, fund, and study mentoring programs for youth. More contemporarily, there have been countless popular accounts of the power of mentoring (in film, for example, think Star Wars, Karate Kid, Finding Forrester, or even The Lion King) in which a young person is coached, encouraged, and guided by an older, more experienced person until the young person realizes a potential they never knew they had. The documentary Waiting for 
Superman offers a critique of the U.S. public school system, and proposes formal youth mentoring programs as part of the solution. The filmmakers stated that one of the main lessons they want viewers to take from the movie is, "Anyone can be Superman" if they get involved in child's life (MENTOR/National Mentoring Partnership, n.d. [emphasis in original]).

With these popular exemplars of mentoring relationships embedded in the public consciousness, to what extent do we expect adult mentors to embody the characteristics of Obe Wan Kenobe, Mr. Miyagi, or Superman? Do we expect protégés to travel similar experiential paths as the protagonists in these films - from crisis and despair all the way through to self-confidence, self-realization, and triumph? Are these expectations realistic, exaggerated, or a cultural fantasy? Are mentors indeed viewed as heroes by their mentees, or are they perceived more like teachers, or brothers and sisters, or friends, or counselors, or something else entirely? Do mentees experience long-term relationships as transformative, or supportive, or maybe intrusive? What is the mentoring experience like for youth? This final question is one that has received little attention to date, and it is the main question that the current study addressed.

\section{Importance of the Study for Social Work}

Phenomenology is primarily understood as a movement within the discipline of philosophy, focused on understanding the structures of human experience. Yet, it is important to realize that as far back as the 1940s, "there were phenomenologists who applied phenomenological methods to their practical professional concerns" including psychologists, educators, pediatricians, criminologists, and others (Van Manen, 2011, 
p.1). Today, phenomenological studies continue to make significant contributions to the advancement of practice in a number of fields, including education, psychology, and nursing (Van Manen, 2011). In education, for example, Van Manen and Adams (2009) explored the phenomenon of writing online and its implications for student expression, interaction, and learning. In reference to Van Manen's and Adams' work, Dall'Alba (2009) noted that the proliferation across education systems of web-based assignments using discussion boards, blogs, and other forums makes this effort to better understand the experience of writing online a particularly "pertinent and timely contribution to understanding learning and teaching online” (p. 2). Ehrich and Ganeson (2009) used phenomenological methods to better understand the experience of transitioning from middle school to high school, using information from student journals to reveal aspects of students' experiences that can be used to inform the ways that parents, educators, and schools support youth in this traditionally difficult period of development.

In nursing, a phenomenological study of the experience of living alone with dementia challenged the traditional practice of placing people with different levels of dementia together for treatment (DeWitt, Ploeg, \& Black, 2010). An exploration into nurses' and patients' experiences and understandings of the "caring relationship" offered potentially critical insights for nursing education and training, as well as practical information for hospital and clinic staff, including doctors, social workers, and others (Berg, Skott, \& Danielson, 2006). Professional social workers and their clients have benefited from phenomenological studies as well. Anderson-Nathe's (2010) phenomenological account of the experience of "stuckness" for youth workers provided 
insight into a ubiquitous phenomenon in the social work profession that has traditionally generated little attention in social work education and training. Based on these insights, Anderson-Nathe suggested several practical action steps to help youth workers gain awareness of and develop skills to navigate the experience of stuckness or not-knowing in practice. Likewise, the current study illuminates aspects of long-term mentoring relationships that can provide theoretically important and professionally practical information for the field.

Current theories and models of youth development and youth mentoring relationships are informed by long traditions of empirical work from multiple disciplines, including psychology, communication, and education (Barrera \& Bonds, 2005; Spencer $\&$ Rhodes, 2005). However, because minimal research exists on the youth experience of having a mentor, few if any of the current ways of understanding youth mentoring were derived directly from the experiences of mentoring program participants. The current study offers rich and detailed descriptions of what long-term mentoring relationships mean to youth, offering information for program developers, managers, funders, evaluators, and participants about what programs can do to make the relationships they facilitate more meaningful and potentially more impactful. Van Manen (1997) contends that while phenomenology does not offer us theory directly, "it offers us the possibility of plausible insights that bring us in more direct contact with the world" (p. 9). In the current study, the insights gained bring us in contact the world of youth and the unique relationships they have developed over many years with their mentors. 
While longer and stronger mentoring relationships are strongly associated with more positive academic, psychosocial, and behavioral outcomes (Grossman \& Rhodes, 2002; Herrera, 2004), virtually no research has been done on mentoring relationships that last 10 years or longer. The current study not only brings the experiences of youth front and center, it also provides one of the first explorations of long-term mentoring relationships by focusing on the participants at FOTC, which provides paid professional mentors for high risk youth from first grade through high school graduation. FOTC has utilized a third-party evaluator for several years, and the annual reports have shown impressive results in FOTC's three main outcome areas: high school graduation, avoiding teen pregnancy, and avoiding contact with the juvenile justice system (Furrer \& Kissick, 2009). Based on the strong early indications of program effectiveness, the National Institutes of Health (NIH) recently awarded a research team based at the Oregon Social Learning Center (OSLC) a five-year, \$2.9 million dollar grant to conduct a longitudinal, multi-site evaluation of FOTC program impacts. This randomized study represents an important step in gaining more information about how well the program works, and will provide significant new insights into the relative effectiveness of the FOTC approach compared to more traditional mentoring models. While the NIH study will focus on whether and how well the FOTC program works, the current study is an important contribution to the literature in that it provides insight into the participants' lived experiences of the relationships that FOTC fosters - marking "different features of the terrain" (Polkinghorne, 1989) of long-term relationships than what can be measured in an experimental study. The "insider's perspective" provided by this phenomenological study 
provides an authentic account of the youth experience and may also serve as an important complement to the OSLC longitudinal study. 


\section{Chapter 2: Review of Related Literature}

Several areas of the youth mentoring literature were reviewed to provide context and support for the significance of the current study. The first section covers youth mentoring program outcomes, including meta-analyses, systematic reviews, and largescale trials that offer evidence for the effectiveness of mentoring as an intervention approach with youth. The next section explores literature on youth mentoring relationship models, which play a large part in guiding how mentoring programs are designed, implemented, and studied. The third section deals with the various roles and functions within youth mentoring relationships that may directly influence how mentoring relationships are experienced by mentors and mentees. The last section of the review covers those studies that have explored aspects of participants' experiences or how participants make meaning in mentoring relationships. This literature review provides a foundation of support for the importance of exploring long-term youth mentoring relationships in greater depth, and for the importance of understanding how youth experience those relationships in particular.

\section{Youth Mentoring Program Outcomes}

Formal youth mentoring programs have flourished in the last two decades as research has emerged supporting the overall effectiveness of mentoring in mitigating risky behaviors while promoting positive academic performance and better relationships with peers and other adults (DuBois, Portillo, Rhodes, Silverthorn, \& Valentine, 2012; DuBois, Holloway, Valentine, \& Cooper, 2002; Blakeslee \& Keller, 2012; Tierney, Grossman, \& Resch, 1995). It is estimated that more than three million children in the 
United States have a mentor through structured programs, a nearly ten-fold increase from just 15 years ago (Sipe, 1996; Rhodes 2008). The number of outcome studies and program evaluations has likewise increased exponentially, and in the last 10 years a number of meta-analyses and systematic reviews have offered a snapshot of mentoring evaluation research to date. These effectiveness studies provide early indications that youth mentoring is indeed a prevention and intervention strategy with potential to positively impact individuals, families, schools, and perhaps whole communities, and thus they highlight the importance of generating a deeper understanding of all aspects of mentoring relationships so that programs can maximize the benefits of their efforts for youth.

DuBois and colleagues' (2011) systematic review of the mentoring literature suggests that formal youth mentoring programs have an overall positive effect on youth with regard to social, emotional, behavioral, and academic outcomes. Mentoring can have both protective and promotive effects for youth, while participants' nonmentored peers often show declines in important developmental domains. This review builds on an earlier meta-analysis (DuBois, Holloway, Valentine, \& Cooper, 2002) that found a small but significant positive effect for mentoring programs overall, and discovered that programs that were carefully implemented and closely monitored, that encouraged parental involvement, and that provided support for the mentor-mentee relationship were associated with more positive outcomes in the programs' targeted areas than programs that did not report these characteristics. The team also found that outcomes for different youth mentoring programs varied widely depending on the particular characteristics of 
the programs. Eby and colleagues (2008) reported similar results in their meta-analysis of mentoring programs. The authors hypothesized positive effects in behavioral, attitudinal, motivational, relational, career, and health-related outcomes, and findings supported all six hypothesized relationships. Effect sizes for youth mentoring ranged from .03 to .14, similar to the effect sizes found by DuBois and colleagues (2002).

A research synthesis by Jekielek, Moore, and Hair (2002) reviewed findings from ten experimental studies of youth mentoring programs. The report detailed findings from all ten program evaluations in terms of youth outcomes in four categories: educational achievement, health and safety, social and emotional development, and self-sufficiency. Findings suggested positive effects of mentoring on several academic outcomes, drug and alcohol use, violent behavior, parental relationships, peer support, and promotion of prosocial behaviors and attitudes. Sipe’s (2002) summary reviewed studies on six programs that had rigorous evaluations during the 1980s and 1990s. Programs reviewed were Big Brothers Big Sisters (BBBS), Project RAISE, Across Ages, Team-Works, Sponsor-AScholar, and Career Beginnings. These programs targeted a range of ages and populations, and had differing goals - from substance abuse prevention and improved academic performance to improved relationships with adults and increased prosocial behaviors. Findings suggested that mentors who took a developmental approach to relationship building, characterized by a focus on building trust and friendship, rather than a more goal-oriented approach, tended to be more successful in building strong and long-lasting relationships with youth. Offering further support for the findings of DuBois and colleagues (2002), the report identified several organizational practices that are 
related to program success, including screening potential volunteers, providing orientation and training, and providing on-going support and supervision for mentors and mentees. The meta-analyses and reviews of youth mentoring to date paint a consistent picture - that volunteer youth mentoring can have a positive impact if programs are welldesigned and well-implemented.

Research suggests that youth mentoring programs can be particularly effective for youth with personal and environmental challenges, such as depression, living with a single parent, or living in a neighborhood with high crime and few resources (DuBois, Holloway, Valentine, \& Cooper, 2002). These findings lend support to earlier evidence that the presence of caring relationships between at-risk youth and adults outside of the family promote resilience and help mitigate the risk factors associated with poor outcomes like behavior and mental health problems, early pregnancy, and delinquency (Rhodes, 1994). In fact, one of the three clusters of protective factors that Werner and Smith (1992) identified that differentiated resilient high risk youth from other high risk youth was "affectional ties with parent substitutes...which encouraged trust, autonomy and initiative" (p. 192).

Werner and Smith (1992) further suggested that "the promotion of self-esteem and self-efficacy in a young person is probably the key ingredient in any effective intervention process," and found in their longitudinal study of high risk youth in Hawaii that, "Most of all, self-esteem and self-efficacy were promoted through supportive relationships" (p. 205). In their recommendations for policy and social action, Werner 
and Smith (1992) were clear about the central role that positive relationships between adults and youth play in helping youth be more successful:

"...if a parent is incapacitated or unavailable, other persons in a youngster's life can play such an enabling role, whether they are grandparents, older siblings, caring neighbors, family day-care providers, teachers, ministers, youth workers in 4-H or the YMCA/YWCA, Big Brothers and Big Sisters, or elder mentors... These ties need to be encouraged and strengthened, not weakened or displaced, by legislative action and social programs" (p. 209).

Most research on youth mentoring has been conducted on volunteer-based oneon-one mentoring programs in the tradition of Big Brothers Big Sisters programs, where volunteer mentors are matched with youth and generally spend a few hours per month doing fun activities with the child either in the community or at school (Big Brothers Big Sisters of America, n.d.). This type of mentoring is more generalized in its approach and lower intensity compared to other interventions like psychotherapy, and therefore, as might be expected, shows significantly weaker effect sizes in terms of overall effectiveness (DuBois, Holloway, Valentine, \& Cooper, 2002). Across the 55 programs included in their meta-analysis, DuBois and colleagues found a small overall effect size $(d=.18)$ for youth mentoring, much smaller than the average effects for the psychological, educational, and behavioral interventions $(\mathrm{d}=.81)$ included in an earlier meta-analysis by Lipsey and Wilson (1993). There is also evidence to suggest that the modest gains attributable to volunteer mentoring may not be long-lasting (Rhodes \& 
DuBois, 2008). However, the research also points to several factors that may predict stronger outcomes for youth involved in volunteer mentoring relationships, such as experiencing more frequent contact and greater emotional closeness (Parra, DuBois, Neville, \& Pugh-Lilly, 2002), having longer relationship duration (Grossman \& Rhodes, 2002), and having a mentor with experience in the helping professions (DuBois, Holloway, Valentine, \& Cooper, 2002). These factors suggest that an approach to youth mentoring that facilitates relationships that are more intensive, longer-lasting, and that include a mentor with prior experience working with youth may hold greater potential for positive impacts on youth.

There are several youth mentoring programs that do not subscribe to the traditional volunteer-based model. A small number of programs use paid mentors to provide consistent and on-going support for participants, usually youth with significant risk-factors for substance abuse, school drop-out, or delinquency (Smith, 2004). Smith describes the use of paid mentors as a "middle ground" (p.11), a way to have some of the benefits of a professional social worker or counselor and those of having a volunteer mentor. Smith highlights three promising programs: the Children's Village WAY program, the Quantum Opportunities Project (QOP), and Friends of the Children. All three of these programs use paid, professional mentor-type adults to support and guide youth who have led difficult lives, and who are considered to be in urgent need of a consistent, caring, adult presence in their lives.

All three of the programs profiled by Smith (2004) show great promise in helping youth achieve important positive outcomes like high school graduation, developing job 
skills, and avoiding arrest, although none has yet been subject to the type of rigorous randomized control evaluation that Big Brothers Big Sisters underwent in the early 1990s to demonstrate its impact (Grossman \& Tierney, 1998). There is growing evidence that the FOTC approach is effective. Each year, an independent research firm conducts a thorough third-party evaluation of the FOTC program and its outcomes. Assessments focus on a wide range of service delivery and performance objectives, all related to the three overarching organizational goals: inspire youth to stay in school, avoid teen parenting, and avoid contact with the juvenile justice system. Evaluation data include reports from mentors, youth, parents, and teachers. Results are compared to program outcomes from previous years as well as to outcome data for the general youth population in surrounding Multnomah County. The final evaluation report summarizes findings, highlights benchmarks that were achieved and those that are in progress, and makes detailed recommendations for improving program practices in identified areas of concern.

Results to date have been overwhelmingly positive. According to the 2007-2008 evaluation report (Furrer \& Kissick, 2008), 92\% of program youth attend school regularly, $92 \%$ have avoided the juvenile justice system, and $98 \%$ of adolescents have avoided early parenting. On most indicators, FOTC youth largely resemble the general youth population in Multnomah County, which is significant given that youth in the FOTC program are selected because of the personal and environmental challenges that make them more likely candidates for delinquency and other negative outcomes than their peers. In fact, FOTC youth showed significantly better outcomes on a number of key indicators than their peers, including lower rates of initiation of cigarette smoking, 
alcohol use, marijuana use, and sexual intercourse. The report notes that a low response rate for adolescents (60\%), parents (45\%), and teachers $(47 \%)$ may have caused bias in some results, since more highly motivated youth and more highly involved parents could be more likely to complete the surveys than others. Nevertheless, the comprehensive annual evaluation of the FOTC program strongly suggests that youth in the program are achieving the goals that the organization has set as its ultimate measures of success.

The studies reviewed in this section, and particularly the evaluation reports from the FOTC program, establish a foundation for the importance of the current study because they support the contention that youth mentoring, when done well, can be an effective strategy for promoting positive development and outcomes for youth. These studies also suggest that several key characteristics of the FOTC program are predictors of positive outcomes for youth. Despite the promising evaluation results, very little is known about the FOTC relationships themselves — what they are like, what role they play in participants' development, and what importance they have for the youth who spend much of their childhoods engaged in these relationships.

\section{Mentoring Relationship Models}

Understanding how mentoring relationships operate may provide clues to discovering how participants experience those relationships. Several researchers have proposed models of mentoring relationship dynamics and development in the context of formal youth mentoring programs. The studies in this section provide an idea of how the processes of mentoring have been conceptualized in the literature to date. 
Dubois and Neville (1997) tested the relationships among characteristics of youth mentoring relationships and mentor-rated benefits of program participation for youth. Mentors were administered a questionnaire every month for six months that assessed amount of contact, feelings of closeness, and relationship obstacles, among other characteristics. In the final questionnaire, mentors rated their perception of youth benefit from the program. Results showed that mentor contacts with program staff were negatively associated with relationship closeness for both programs, while amount of contact between mentors and mentees was positively associated with relationship closeness. Amount of contact and relationship closeness were both positively associated with perceived benefits for youth. These results suggest that consistency may be an important factor in mentoring relationships, and that the development of closer relationships may yield more benefits for youth participants.

Rhodes and colleagues (2006) presented a conceptual model of the mentoring process based on theory and research in child development and interpersonal relationships. The model describes the role that mentoring may play in the areas of 1) social and emotional development; 2) cognitive development; and 3) identity development of youth. In the social and emotional realm, for example, youth mentoring relationships support the positive development of youth participants' other relationships, including relationships with parents (Rhodes, Grossman, \& Resch, 2000). This model highlights the complexity and multidimensionality of mentoring relationships, suggesting that mentoring researchers may need to expand the scope of future studies to include a 
more thorough accounting for emotional content and issues of identity, elements which are often neglected in favor of a focus on social and academic functioning.

Keller (2005a) introduced a heuristic model of youth mentoring from a family systems perspective. Within the context of a formal mentoring program (the Big Brothers-Big Sisters community-based mentoring model is used as an example), the author considers the potential impact of the interconnected relationships of youth participants, mentors, parents, and mentoring program caseworkers. The article discusses the three dyadic relationships that include the child and an adult (e.g., child $\leftrightarrow$ caseworker) as well as the twelve transitive relationships that terminate with a relationship that includes the child (e.g., parent $\rightarrow$ mentor, mentor $\leftrightarrow$ child). A fundamental premise of the model is that the success of mentoring relies not on one-onone relationships in isolation, which is often how mentoring is examined in research, but instead on the functioning of all of the relational subsystems present in the intervention. This article calls attention to the need for exploring mentoring relationships and their impacts in broader terms that incorporate the roles of other influential adults involved both directly and indirectly in the mentoring process. In other words, mentees' experiences of mentoring relationships may reflect or may be impacted by relationships to other significant people in their lives, dynamics which have been largely unexamined and may plausibly surface in a phenomenological study from the youth perspective.

Keller (2005b) also proposed a chronological stage-based model of mentoring relationship development, which includes the stages 1) Contemplation; 2) Initiation; 3) Growth and Maintenance; 4) Decline and dissolution; and 5) Redefinition. The author 
identifies the primary tasks associated with each stage, the factors from mentoring research that apply to the processes or characteristics of each stage, and program practices that are designed to address the unique opportunities and challenges that each stage presents. This model is important because it suggests that like other important interpersonal relationships, youth mentoring relationships are likely to follow common developmental paths, with each relationship simultaneously maintaining its own unique qualities. Keller (2005b) states that "every mentoring relationship has a life of its own," and suggests that "the study of mentoring relationships requires attention to normative patterns in development, individual differences in development, and variability or flexibility within a single relationship" (p. 82). While the current study does not test for normative relationship patterns or developmental differences, the information provided by youth about their experiences illuminates the importance of characteristics and processes in mentoring relationships that have been suggested previously or that have until now been unrecognized or misunderstood.

Pryce and Keller (2011) examined developmental patterns in school-based mentoring relationships and sorted relationships into four main types: progressive, plateaued, stagnant, and breakthrough. Progressive relationships, which made up about half of the matches studied, were characterized by a relatively strong relationship initiation "followed by gradual deepening and growth of the relationship" (p. 9). Plateaued relationships started strong but quickly leveled off or began to deteriorate, while stagnant relationships tended to start poorly, to exhibit conflict, and never develop the closeness of progressive relationships. A few matches experienced breakthrough 
relationships, starting slowly and with difficulty, but eventually experiencing a turning point after which the relationship flourished. Like Keller's (2005b) stage model discussed above, this study highlights the importance of understanding both the commonalities that mentoring relationships share and the ways in which they are unique. In the current study, the use of IPA to identify and interpret the themes that emerge from participants' stories of their long-term mentoring relationships at FOTC provided the flexibility to address common experiences as well as to highlight the singular experiences that occur when one individual maintains a relationship with another person over the course of many years. Liang and Rhodes (2007) draw on Strauss' (2006) The Gardening Analogy to synthesize the lessons learned about the development of strong relationships from mentoring research to date. They highlight the importance of warmth and care in the development of effective mentoring relationships with youth, and describe six key lessons for practitioners to consider, which the authors link to findings in the literature. The first lesson, preparing the soil, includes setting clear expectations for mentors and providing thorough training before the mentoring relationship begins. The second lesson, seed, describes the process of matching youth with mentors who have the potential for compatibility with youths' interests, goals, and personal characteristics. The third lesson, weed, refers to identifying and removing obstacles that may threaten the mentoring relationship in its early stages or at other times of vulnerability. Lesson four, feed, stresses the importance of training opportunities and support services for mentors and mentees through the entire lifespan of the mentoring relationship. The fifth lesson, persevere, highlights the sometimes slow and difficult nature of relationship development 
in mentoring, and encourages programs to offer support and advice for mentors who may be frustrated or discouraged by a perception of little or slow progress. Finally, the sixth lesson, evaluate, describes the importance of measuring progress for the purpose of ensuring quality and improving services for youth. The authors end by stressing that relationships cannot be reduced to formulas, but that using guidelines based on what we have previously learned offers the best chance for mentoring relationships and programs to succeed. The current study adds the youth perspective and authentic accounts of the youth experience of mentoring relationships to more fully inform guidelines for program development and practice such as these.

\section{Roles and Functions in Mentoring Relationships}

Levinson's (1978) vision of what mentors are and what mentors do expanded the popular idea of mentoring beyond the traditional roles of teacher and advisor. Dealing primarily with males mentoring males, Levinson (1978) described mentoring not in terms of the formal roles a mentor may inhabit in a protégé's life, but rather by the functions associated with their role as mentor. A mentor may be a teacher, boss, colleague, friend, neighbor, or relative that plays the part of instructor, sponsor, host, guide, exemplar, and/or counselor for a younger or less experienced mentee (Levinson, 1978). According to Levinson, these functions go far beyond simple advice and guidance to include important social, emotional, and developmental support. Goldner, Limor, and Mayseless (2008) identified the common roles of parent, therapist, friend, and teacher among mentors, and suggested that the much of the success of mentoring rests in mentors' ability to "to move freely in and out of these roles without embodying any of them" (p. 
423). Levinson also proposes that mentors have "another function, and this is developmentally the most important one: to support and facilitate the realization of the Dream" (p. 98). This "Dream" is the fulfillment of the mentee's potential, and the mentor's role as facilitator is to help the mentee create the conditions and space in which the "Dream" can be realized.

Freedman (1988) described mentoring relationships between adults and youth as falling into two types, primary and secondary. Both types of relationships exhibited characteristics such as caring, trust, enjoyment, and importance, but primary mentoring relationships reached a level of depth, commitment, and unconditionality that is not present in secondary, or less intimate, mentoring relationships. Freedman described these relationship types in part to argue that closer relationships tended to yield better outcomes for youth (Sipe, 2005). Subsequent studies support Freedman's assertions. Rhodes (2005), for example, found that youth who perceived a higher level of trust and satisfaction with the mentoring relationship showed better outcomes in academic achievement and self-esteem. DuBois and Neville (2007) found that relationship closeness was associated with greater perceived benefits for youth from the mentor's perspective. An earlier study likewise found better emotional and behavioral outcomes for children who identified their mentor as a "significant person" in their lives (DuBois, Neville, Parra, \& Pugh-Lilly, 2002). Freedman's description of the range of roles and functions in mentoring provides a menu of possible ways that mentoring relationships could be experienced by participants, opening the door for deeper explorations of these 
relationships from multiple perspectives, such as the current study's focus on the experiences of youth.

In their groundbreaking work, Morrow and Styles (1995) sought to refine the classification of youth mentoring relationships and to determine if there are any particular expectations, behaviors, or interactions associated with different types of relationships, and whether those change over time. Results indicated that the mentoring relationships studied could be generally divided into two categories, prescriptive and developmental. Prescriptive relationships were those characterized by a focus on the goals and wishes of the mentor, while developmental relationships were characterized by a focus on the changing needs and wishes of the youth, including flexibility and supportiveness. Developmental relationships tended to change over time, becoming more focused on achieving transformative goals, while prescriptive relationships tended not to change.

Differences between developmental and prescriptive relationships were also identified with regard to types of activities matches engaged in, with developmental relationships focused on fun and relationship development versus the prescriptive relationship focus on changing youth performance or behavior. At nine-month follow-up, more than $75 \%$ of prescriptive matches had ended, while approximately $90 \%$ of developmental matches were still going. These findings offer important clues about how mentors view their roles within mentoring relationships, and how those perceptions can positively or negatively impact the length and quality of the relationships. Despite subsequent support for the effectiveness of developmental rather than prescriptive approaches to mentoring, we still know little about how youth experience and understand 
mentoring relationships of any kind, limiting the potential to understand and capitalize on the particular aspects of positive relationships that make them most meaningful to youth participants.

Keller and Pryce (2010) described mentoring relationships as "mutual but unequal," referring to the dimensions of permanence and power that underlie the interpersonal dynamics as mentoring relationships develop. The mutuality/permanence aspect reflects the voluntary nature of mentoring relationships on the part of both mentor and mentee, while the unequal/power aspect refers to the relative position of the mentor as older and more experienced, and holding some degree of authority as a result. The authors reviewed a number of qualitative studies that describe the structures and functions of successful versus unsuccessful mentoring relationships, highlighting the concurrent elements of friendship (similar to a peer) and authority (similar to parent or teacher) that exist in relationships that are strong and lasting. In their earlier work, Keller and Pryce (2009) distilled 27 mentoring relationships down to four types (tutor, friend, sage, and acquaintance), which essentially reflected the main role that mentors seemed to play in the relationships.

The "hybrid" type matches in this study, which combined "friendly companionship with adult wisdom and counsel" (p. 44), were associated with the best outcomes for youth. These findings complement the work of Morrow and Styles by providing additional contextual information about how successful mentoring relationships look and operate. Yet none of these studies dives deep into the youth perspective, so an important question still remains unaddressed: What are the youth 
experiencing? Relationships last longer and appear to be more beneficial when certain factors are present, but what is it in the youth participants' experiences that makes some relationships so meaningful, useful, or transformative while other relationships fail to last or fail to have the type of impact that is expected? Using interpretive phenomenological analysis to explore youth experiences, the current study presented an opportunity to describe the unique experience of having a long-term mentor and to interpret a range of elements within those relationships that are particularly meaningful to youth.

\section{Experience and Meaning in Mentoring}

The 1995 publication of the Big Brothers Big Sisters program impact study (Tierney, Grossman, \& Resch) opened the mentoring research floodgates in the United States. Yet, while measuring program performance and outcomes has become more common, and several researchers have proposed theoretical models of mentoring relationship structure and operation, few studies have explored aspects of meaning in mentoring relationships. Even with the recent focus on positive youth development and youth empowerment approaches to youth programming, both of which emphasize the importance of youth voice and youth participation, youth perspectives have been notably rare in the mentoring literature. This section of the literature review will first look at several qualitative studies that offer the best insight to date into the experiences of participants - both mentors and mentees - in mentoring relationships. Then the one phenomenological study of mentoring relationships that was found in the literature - that of music teachers mentoring promising young musicians (Hays, Minichiello, \& Wright, 2000)—will be discussed. 
Chan and Ho (2008) conducted a mixed methods study to determine the primary components as well as primary reasons for failure of mentoring relationships between volunteer mentors and at-risk youth in Hong Kong. A factor analysis suggested that the mentoring relationships reflected two main components: relationship intimacy and relationship asymmetry. Further analysis showed that relationship asymmetry, and not relationship intimacy, significantly predicted effective mentoring as measured by the Composite Score of Effective Mentoring (C-SEM) scale. The authors then selected a subsample of youth participants $(n=50)$ to interview, and data were analyzed using thematic analysis to determine reasons for asymmetrical mentoring relationships. Results suggested four primary reasons for poor relationships: 1) mentors failing to make time for youth; 2) mentors misreading mentees' cues; 3) mentors breaking promises; and 4) mentees' time constraint due to engagement in other activities. These results suggest that youth place importance on such relationship characteristics as time investment by both parties, attunement of the mentor, and keeping promises.

Spencer (2006) explored relational processes between volunteer mentors and adolescent mentees who had been in a mentoring relationship for a minimum of one year. A sample of 24 same-sex matches $(n=48)$, half males and half females, were drawn from two Big Brothers Big Sisters programs in a Northeastern U.S. city. In-depth semistructured interviews were conducted with each pair-first mentors and mentees were interviewed individually, and then each pair was interviewed together. Using listening guide analyses, the researchers identified four primary relational processes that seemed to be important across matches: authenticity, empathy, collaboration, and 
companionship. Authenticity and empathy appeared to be particularly important elements in the early stages of relationship development, while collaboration and companionship, which represented deeper connections and greater intimacy between mentors and mentees, tended to develop as relationships matured over time. This study is significant because it provides a rare, thorough exploration of the interpersonal processes present in longer-term mentoring relationships. It also reveals the complexity and the bidirectional nature of the relational processes involved in long-lasting relationships.

Mentoring relationships that end prematurely, especially those that close within three months of initiation, may have a detrimental effect on youth participants (Grossman \& Rhodes, 2002). Spencer's exploratory qualitative study (2007a) of mentoring dyads that lasted less than six months began to uncover some of the factors related to relationship failure. In-depth interviews were conducted with 20 adults and 11 youth at two BBBS agencies, and a narrative approach to thematic analysis was used to identify factors related to the early closure of the match. Six major themes were identified, including: 1) mentor or protégé abandonment; 2) perceived lack of protégé motivation; 3) unfulfilled expectations; 4) deficiencies in mentor relational skills; 5) family interference; and 6) inadequate agency support. The author recommends future systematic research into the prevalence, nature, causes, and consequences of relationship failure. Like the study by Chan and Ho (2008) described above, the themes discovered by Spencer in her thematic analyses (2006 \& 2007a) describe participants' thoughts about what was positive and what was negative about relationship experiences, but thematic studies 
generally stop short of exploring the content and meaning present in the relationships themselves - e.g. what are they, what do they feel like, and what do they mean?

Spencer (2007b \& 2009) used a more participant-centered and meaning-oriented approach to analyze data from two subsamples - one of male mentor-mentee pairs and one of female mentor-mentee pairs-from the 2006 study described above. Using a holistic content approach, in which the researcher begins the interpretive process by reading or listening to a text "carefully, empathically, and with an open mind" until the meaning of the text is revealed and "speaks to" the researcher (Lieblich, Tuval-Mashiach, \& Zilber, 1998, p. 62), Spencer (2007b) explored the characteristics and processes found in mentoring relationships between men and adolescent boys that have lasted more than a year. Six major themes were discovered, including: 1) the importance of having an adult male role model in adolescence; 2) mentors' desires to be involved emotionally connected to mentees; 3 ) the presence of close and enduring emotional connections; 4) the relationship as a safe place for vulnerability and emotional support; 5) learning new ways of dealing with anger; and 6) maintaining a balance between sensitivity, emotionality, and more traditional expressions of masculinity. These results suggest that mentoring relationships may provide an opportunity for adolescent boys to benefit from emotional support and to learn alternative representations of maleness and masculinity. The author suggest that adolescent boys may derive positive psychosocial benefits from practicing more pro-social strategies for dealing with emotional and other types of challenges. 
Spencer (2009) also used a holistic content approach to analyze data from a subsample of 12 female mentor-mentee pairs $(n=24)$ in order to explore the characteristics and processes found in mentoring relationships between women and adolescent girls that have lasted more than a year. Three major relational processes were identified, including: 1) engaged and authentic emotional support, 2) the development of new skills and confidence through collaborations, and 3) experiences of companionship that provided relief from daily stresses. These findings lend support for the idea that successful mentoring relationships offer a context characterized by fun, emotional closeness, and support that allows matches to engage in more instrumental types of learning and guidance. Together with the study of the male dyads, this study's use of the holistic content approach that included input from youth participants offers an account that gets closer to a representation and interpretation of participants' experiences than other studies of mentoring relationships have done previously.

Nakkula (2009) explored the meaning of closeness and conflict in volunteer mentoring relationships from both the mentor and mentee perspectives. Findings indicated that participants understood the ideas of relationship closeness and conflict in different ways depending on factors such as the duration of the match, the age of the mentee, the personal and environmental challenges present in the mentee's life, and in some cases the gender of the mentee. For example, younger mentees tended to associate closeness with doing fun activities and conflict with being bored and disengaged, while older youth understood closeness as "being there" and having mutual understanding and conflict as not feeling heard or understood. Although the current study explores themes 
beyond closeness and conflict, these different ways of understanding core aspects of the mentoring relationship underscore the importance of addressing issues of meaning in mentoring research. If the meaning of closeness varies depending on the context of the relationship, then in what various ways might youth understand what a mentoring relationship is, what it does, and why it is or is not important to them? Nakkula's (2009) study also serves as a reminder that the way that older youth experience and understand long-term mentoring relationships at FOTC may be different from how youth at other stages of mentoring relationships and in other programs may experience and understand them.

DeJong's (2008) study of the presence and significance of metaphor in mentoring relationships at a Big Brother Big Sisters chapter offered some insight into how both mentors and mentees think of their mentoring relationships. Findings suggested that metaphors provide important frameworks around which both mentors and mentees define and understand their relationship with one another, although the exploration was limited to the predetermined metaphors of family (e.g. she is/is not like a big sister to me) and friendship (e.g. he is/is not like my younger friend). While the limited range of possible metaphors presented may have missed several other potentially interesting possibilities (mentors may sometimes be like teachers or counselors, for example, as suggested by Goldner and colleagues' (2008) conceptualization described above), it is important to note that both teens and adult mentors make use of metaphors to understand and describe how they think and feel about their relationship. 
For this literature review, only one study was identified that used phenomenological methods to explore the experience of being in a mentoring relationship. Hays, Minichiello, and Wright (2000) used an interpretive phenomenological approach to explore the meaning of mentoring relationships from the perspective of music faculty at the university level. Fifteen faculty members, all but one from Australia, were interviewed about their experiences as mentors or mentees and data were analyzed to define the nature of the mentoring experience, to determine the functions of the mentoring relationship, to describe the potential drawbacks of mentoring relationships, and to determine criteria for measuring the success of mentoring relationships. Findings indicated that as mentors and mentees, music faculty see mentoring as a relationship that allows knowledge, skills, and values to be passed from one person to another. Mentoring can take the form of personal and/or professional development, and can often develop into a familial-type relationship, which the authors describe as a "surrogate-parental" relationship (p. 6). Participants in the study described mentoring relationships as requiring patience, generosity of time, and a genuine interest on the part of the mentor in the life and welfare of the mentee. Important characteristics for mentors to possess were the knowledge and ability to help mentees achieve their goals as well as interpersonal qualities such as openness, care, honesty, and sensitivity to other people's needs.

Hays, Minichiello, and Wright (2000) found in the particular context of music education and instruction that mentoring relationships can serve two distinct functions, psychosocial and career-related functions. The psychosocial functions include role- 
modeling, friendship, counseling, acceptance, and confirmation, while the career-related functions include sponsorship, exposure, networking, coaching, protection, and professional training. The authors also found that the meaning that participants ascribed to the mentoring relationship depended on the particular combination of functions involved, such that the needs and aspirations of the mentee interact with the skills and other qualities of the mentor to create a uniquely important relationship environment. Challenges associated with mentoring relationships according to the study include poor communication, jealousy, and even passing on the negative traits of the mentor to the mentee. The authors conclude by offering five primary requirements that help facilitate a successful mentoring relationship: 1) developing a rapport between the mentor and protégé; 2) learning to speak and understand the same language; 3 ) understanding the psychological, intellectual and technical capacities of the protégé; 4) setting realistic goals so it is possible for the protégé to achieve his/her objectives; and 5) developing a strategy that will extend the protégé and help him/her fulfill his/her potential.

This section demonstrates that to date only a few steps have been taken down the path of trying to understand how mentees experience and understand mentoring relationships, and that those steps have so far been limited to exploratory thematic analyses, explorations of meaning with regard to specific concepts in mentoring relationship, or holistic content approaches to questions related to same-gender mentoring relationships. The study by Hays and colleagues (2000), while notable for providing perhaps the first phenomenological account of mentoring relationships, may have little 
direct application to the youth mentoring field due to its focus on adult professional musicians and music faculty.

\section{Summary}

Research on youth mentoring programs and relationships has yielded many important discoveries in the last two decades. First, it is clear that youth mentoring, when done well, is an effective approach that can help improve social, emotional, behavioral, and educational outcomes for youth. The research has also begun to uncover some of the mechanisms and processes that may explain mentoring's positive impacts. There are also studies that describe, primarily from the perspectives of adult mentors, some of the perceived roles and functions of mentors and mentoring relationships, information that hints at the various ways that both mentors and mentees may understand what mentoring relationships are, what they are for, and what they mean in the context of their lives. Finally, several studies have demonstrated that exploring questions of meaning may be important for understanding phenomena such as why some relationships last while others falter and fail, why some youth feel close to their mentors while others feel disconnected, and what it means to have a successful mentoring relationship.

Yet these studies stop short of exploring what the mentoring relationship itself means for youth. How do youth perceive this connection with an adult that was chosen for them, as in most formal mentoring programs? How do they feel about the relationship after many years? What role does the mentoring relationship play in their lives? Is it central and essential, or is it secondary and expendable? Is it like a friendship, like a familial relationship, or is it something completely different? Letting the youth 
themselves define and describe the mentoring relationship through the medium of their personal stories will provide a perspective on youth mentoring relationships that is absent in the literature, and will hopefully inspire further exploration of youth mentoring experiences in different contexts and settings. A robust body of phenomenological data could be an invaluable resource for helping to develop and improve mentoring programs and research in the future.

The current study goes beyond the initial explorations of meaning addressed by the mentoring literature reviewed here to achieve a deeper level of understanding of mentoring relationships by addressing the largely unexplored questions of how youth experience and understand the mentoring relationships they are in. By bringing the lived experiences of youth engaged in long-term mentoring relationships to life through IPA, this study provides a rich and detailed description of what these relationships are like for youth, and offers a much-needed exploration of the meanings that youth ascribe to their experiences with their Friends. The next chapter introduces phenomenology and the interpretive phenomenological approach, provides details about how participants were selected, how data were collected and analyzed, and how the trustworthiness of the findings was established. 


\section{Chapter 3: Theoretical Framework}

The current study is grounded in the philosophy and approaches of interpretive phenomenology and in the developmental theory of positive youth development. Phenomenology has developed as both a philosophy and a research methodology, and is concerned with describing, illuminating, and interpreting the essences of human experience. The current study was exploratory, and as such was not intended to test a particular theory. However, the FOTC program was designed and developed with explicit attention to the principles of positive youth development (PYD), and therefore it is appropriate to include in this chapter not only an overview of phenomenology, but also a brief discussion of PYD and its defining characteristics.

\section{Phenomenology}

Phenomenological research is a valuable and practical approach to exploring human phenomena with a well-established philosophical basis and a long history of providing important insights on human experience (Hein \& Austin, 2001). Van Manen (1997) calls phenomenology a uniquely human science designed to "question the way we experience the world" (p. 5). Phenomenology departs from the traditions of the natural sciences in that the phenomenological researcher is concerned primarily with understanding and reporting essential elements, structures, and meanings of what we sense, what we feel, what we think, what we remember, and so on—rather than with the physical or external manifestations of those phenomena (Polkinghorne, 1989). Phenomenology uses methods designed to elicit, describe, and interpret conscious (and 
sometimes unconscious) experiences and their meanings so that we may better understand what it means to be human.

Phenomenology finds its roots in the philosophy of Edmund Husserl, and later in the works of Heidegger, Merleau-Ponty, Gadamer, and others who contributed significantly to the development of more interpretive forms of phenomenological inquiry. This section offers a brief account of the philosophical principles underlying phenomenological research, especially interpretive phenomenological analysis (IPA), and will describe how IPA has been used in a number of fields to increase understanding of human experience — and in the case of the "helping professions," to inform the improvement of treatments and services for people experiencing difficult life situations.

Phenomenology is unique as a research methodology in that it begins in the "lifeworld," Husserl's term for pre-theoretical and pre-reflective human experience (Moran, 2000). Investigating the life-world, according to Husserl, means getting a glimpse of how people genuinely experience phenomena - before thought, before reflection, before other conceptualizations inevitably reshape the true experiences of the life-world into memories and other secondary reflections of experience. Husserl said, "the findings thus made are actual 'beginnings," meaning that phenomenology makes no presumptions based on science or even philosophy (Husserl, 1913, p. 33). In order to examine human experiences phenomenologically, on their own terms, Husserl argued that one must relinquish the natural attitude, the normal everyday approach to life, and take on a phenomenological attitude, in which attention is focused purposefully toward the perceptions of the experiences one wishes to examine (Smith, Flowers, \& Larkin, 1996). 
Therefore, in Husserl's phenomenology, a key to tapping into the life-world is intentionality, consciously "pointing to" the experiential objects under consideration (McIntyre \& Smith, 1989). These phenomenological objects can be real, imaginary, or conceptual, and consciousness may even be directed inward to examine internal thoughts, feelings, and processes (Hein \& Austin, 2001).

Husserl's phenomenology is generally labeled "descriptive" or "empirical" because it has the explicit purpose of describing the essential elements of human experiences, including their constituent parts and interrelationships (Hein \& Austin, 2001). In other words, the purpose of descriptive phenomenology is to describe the underlying characteristics, structure, and themes "that give form and meaning to the life world" (Laverty, 2003, p.15). Husserl's phenomenology works from two assumptions: that human experience possesses an inherent logic that is accessible to the outside observer, and that phenomenological methods hold the key to revealing the content and structure of that experience (Dukes, 1984). From an ontological perspective, descriptive phenomenology assumes that the reality being explored (the human experience of grief, for example) is knowable as a fixed and immutable entity, ready to be discovered through careful and systematic inquiry. In this spirit, Husserl called phenomenology, "genuine positivism" (Sinha, 1963, p. 562).

One key feature of descriptive phenomenology is bracketing, the process of identifying and, as fully as possible, setting aside or suspending the presuppositions, biases, and assumptions that one brings to the examination of a particular topic (Hein \& Austin, 2001). Bracketing facilitates what Husserl called "phenomenological reduction," 
wherein the researcher reduces the world under consideration from the unfiltered world of the natural attitude to only the awareness of and focus on the participant's experience of the phenomenon of interest in the phenomenological attitude (Smith, 2005). This reduction is "intended to lead the inquirer away from the distraction and misdirection of their own assumptions and preconceptions, and toward the essence of their experience of a given phenomenon" (Smith, Flowers, \& Larkin, 1996, p. 14).

Due to Husserl's distinction between information that is subject to the contamination of prior knowledge (knowledge that must be bracketed) and information that captures the unbiased essence of experience (through phenomenological methods), bracketing has been labeled by critics as a kind of "selective objectivity," and thus described by some as a relic of the positivist research paradigm, in which accounting for objectivity is often the key to a project's claim to validity (Denzin \& Lincoln, 2005). Subsequent phenomenologists, including Heidegger, Merleau-Ponty, and Gadamer, challenged Husserl's perspective on bracketing and reduction, suggesting that a critical, reflexive process of continuously exploring the impact of one's prior knowledge and prejudgments on the research process was necessary to account for the inherent subjectivity present in the researcher's perspective (Finlay, 2008).

Husserl certainly saw bracketing, and phenomenology itself, as a tool to remove the researcher from the paradigm of the natural sciences - he said, "exercising the 'phenomenological'...completely shuts me off from any judgment about spatiotemporal factual being. Thus, I exclude all sciences relating to the natural world no matter how firmly they stand there for me" (in Smith, 2005, p. 556 [emphasis in original]). On the 
one hand Husserl purposefully removed from consideration all assumptions and frameworks established by the traditions of science; and yet, in seeking descriptions of objective truths regarding the content and structures of experience, whether or not they are "pre-theoretical," descriptive phenomenology ends up relying heavily on the positivism of the natural sciences. In the end, Husserl's phenomenology suggests that any given data can give rise to only one accurate interpretation (Hein \& Austin, 2001), and empirical phenomenological methods are designed to expose that particular interpretation for others to learn from. It is important to note that Husserl himself was not concerned at all with the application of phenomenology as a research method in academic disciplines, but was rather interested in exploring the potential for humans to understand their experiences in a new way.

Subsequent phenomenologists continued to stress the importance of describing human experience as it exists in the life-world, but many rejected Husserl's contention that there is only a single correct interpretation of experiential phenomena. This led to the development of hermeneutic or interpretive phenomenology, an approach of which Heidegger, a student of Husserl, was an early proponent. Heidegger conceptualized human experience and phenomenology in terms of Dasein (translated literally as "therebeing"), which describes the inherent situatedness of all human experience within the context of the life-world (Smith, Flowers, \& Larkin, 1996). Unlike Husserl's conception of a common way of being in the life-world, Dasein is a state specific to a particular individual — and thus, exploration of human experience, to Heidegger, "must take into account the involvement of the enquirer him- or herself in the undertaking” (Moran, 2000, 
p. 197 [emphasis in original]). Every individual exists within social, cultural, and historical contexts, creating an inextricable relationship between each human being and the life-world in which they exist. In Heidegger's view, "Dasein is 'always already' thrown into this pre-existing world of people and objects, language and culture, and cannot be meaningfully detached from it" (Smith, Flowers, \& Larkin, 1996, p. 17 [emphasis in original]). Rather than setting aside assumptions and biases through bracketing, Heidegger's phenomenology calls for exploring the inherent intersubjectivity of experiences, or the ways that the overlapping relationships in the life-world give meaning to those experiences. Due to the embedded and intersubjective nature of Dasein, Heidegger saw phenomenological inquiry as requiring both descriptive and hermeneutic elements. The current study, with its goals of both describing and interpreting the experiences of youth in long-term mentoring relationships, used a phenomenological approach in this interpretive tradition.

Merleau-Ponty (1962) also contributed to understanding the individual and specific nature of human experience by describing the "embodied" (meaning literally within our physical bodies) nature of humans' relationship to the life-world. Our bodies, according to Merleau-Ponty, cannot be considered simply as objects in the world, "but as our means of communication with it" (1962, p. 106). Our existence as body-subjects has important implications for how we see others, because our perceptions are always mediated by our own physical separateness from others, while the experiences of others "belong to their own embodied position in the world" (Smith, Flowers, \& Larkin, 1996, p.19). Therefore, our interactions with others are inevitably colored by the "mineness" we 
perceive of our own experiences, and the "aboutness" we sense regarding the experiences of others (Smith, Flowers, \& Larkin, 1996). However, despite some distinction between the perceptions one has of one's own experiences and the perceptions one has of another's experiences, the distinction is not at all complete or unambiguous, particularly because each person's perception of others depends on the embodied existence of the other person, which is inevitably shaped by their sense of "mineness" and their sense of your "aboutness" (Reynolds, 2004). Each body-subject informs, shapes, and is shaped by the experience of being both embodied and other. Therefore, Merleau-Ponty does not describe perception in terms of passive observation, but rather as a "creative receptivity" shaped by the interplay of the "interiority and exteriority of psychical and physical embodiment" (Vasseleu, 1998, p. 24). Creative receptivity, then, is an active process and a tool that can be cultivated to move phenomenology beyond one-sided observation to facilitate interpretations that account for the interconnectedness of the body-subjects involved.

Gadamer (2004) emphasized and expanded upon the hermeneutic nature of the phenomenological endeavor. Like Husserl, Gadamer saw phenomenology as the best way to access "matters themselves," but Gadamer saw phenomenology as a way to understand understanding itself as well (Moran, 2000). Moran (2000) states that “Gadamer's philosophy, then, is a kind of phenomenology of understanding" (p. 250), offering insight into what it means for humans to find meaning and significance in their experiences. Gadamer (2004), like Heidegger, stressed the inherent situatedness of the observer, but highlighted the importance of history and tradition in shaping the interpretive process. 
According to Gadamer (1960), it is humans' cultivation of self (Bildung) through interactions with society and culture that creates the potential, and the perspective, for understanding human experience. For Gadamer, understanding is an inherently cooperative act, and one that reveals the dichotomy of "I and thou" to be a false one, since understanding (or misunderstanding) presupposes "a deep common accord," an agreement on a wide range of historically and culturally situated arrangements upon which any meaningful interaction depends (Gadamer, 1976). For the interpretive process, Gadamer's contributions suggest that phenomenology must constantly attend to the everchanging dynamics of self and other and society and history, being aware all the time that the entire interpretive process (even attention to context) is contextually situated and necessarily always changing.

The contributions of Heidegger, Merleau-Ponty, and Gadamer to Husserl's original phenomenological approach together suggest that the phenomenologist concerned with describing authentic human experience must attempt to account for, as fully as possible, all of the ways that the researcher and participants exist in the world (e.g. embedded in society and culture, in relation to others, historically/temporally, bodily). Van Manen (1990) contends that an individual may inhabit different lifeworlds as they take on different roles throughout the day, and that the lifeworld of a child has different experiential qualities than the lifeworld of an adult. To offer guidance to the dimensions of the lifeworld that are of particular interest in the human sciences, van Manen describes four "existentials" of lived experience that can inform the interpretive process: "lived space (spatiality), lived body (corporeality), lived time (temporality), and 
lived human relation (relationality or communality)" (p. 101, italics in original). Attention to how a participant experiences being "cooped up" in a car or "let loose" in a forest may bring the spatial qualities of the lifeworld forth, just as a "clenched jaw" (corporeality), a moment that "seems to last forever" (temporality), and "sharing a laugh" (relationality) can reveal different aspects of an individual's lived experience.

These contexts are not identical for any two people, and so the interpretation of a human phenomenon observed in the lifeworld of a research participant will be subject to a singular perspective, and one that is always in flux, always changing with each new observation and experience. Due to this partial and constantly evolving nature of being and understanding, Gadamer suggests maintaining "openness" to the texts that emerge from phenomenological inquiry, and engaging in "dialogue between what we bring to the text, and what the text brings to us" (Smith, Flowers, \& Larkin, 1996, p. 26). Openness, reflexiveness, accounting for context - all of these aspects informed the development of a relatively recent phenomenological approach called Interpretive Phenomenological Analysis (IPA), which is the specific methodological approach used in this study. A detailed description of IPA and how it was used in this study is provided in Chapter 4: Methodology.

\section{Positive Youth Development}

The Friends of the Children model is strongly grounded in a positive youth development (PYD) framework. The following brief review of PYD concepts will provide important agency context that informed the interpretive process through which the meanings of the mentoring relationships from the youth perspective were explored. 
Understanding the PYD framework is an important element in considering the "wider social, cultural, and perhaps even theoretical, context" in which the mentoring relationships under consideration exist (Larkin Watts, \& Clifton, 2006, p. 104).

Positive youth development embraces a multi-level approach to youth programming recommended by prevention researchers and reflected in the risk and resilience framework. However, PYD differs from resilience theory in that it shifts the focus away from problem identification and prevention to the promotion of youth selfdetermination and the developmental assets and skills associated with the kinds of social and academic success that youth envision for themselves (Pittman, Irby, Tolman, Yohalem, \& Ferber, 2003). PYD reflects Pittman's (1999) mantra that “problem-free is not fully prepared," a challenge to youth programs to push beyond traditional preventionfocused goals, such as reducing substance use, to embrace a more holistic and strengthsoriented approach in which each youth is empowered to set their own goals, and then offered the opportunity to develop the skills they will need to accomplish those goals. Positive youth development programs provide youth with opportunities for experiences and relationships that promote health, competence, engagement, and success. One conceptualization of the PYD framework offered by Pittman, Irby, and Ferber (2001) focuses on "The Five C's": connection, character, competence, confidence, and caring/compassion. It is notable that this view of youth success is comprised solely of positive characteristics and skills to be nurtured in youth, rather than a list of negative behaviors and traits to be avoided or prevented. 
The PYD framework is also reflected in the Search Institute's list of 40

Developmental Assets for Adolescents (Search Institute, 2006), which are divided into external assets, internal assets, and thriving indicators. External assets are environmental conditions or supports that facilitate healthy growth and achievement, such as a supportive home environment with healthy boundaries and expectations. Internal assets are individual traits, such as a positive self-concept and a commitment to learning, that are beneficial for development. Thriving indicators are prosocial attitudes and behaviors that contribute to personal growth and benefit others, like valuing diversity, helping others, and exhibiting leadership skills.

Based on their review of 77 positive youth development evaluations, Catalano and colleagues (1998) identified 15 common characteristics of PYD programs; these are listed along with their operational definitions in Table 2.

Table 1. Positive Youth Development Program Characteristics (Catalano, et al., 1998)

\begin{tabular}{|cll|}
\hline PYD Characteristic & \multicolumn{1}{c|}{ Operational Definition } \\
\hline 1. & Promotes bonding & $\begin{array}{l}\text { Focuses on developing the child's relationship with a } \\
\text { healthy adult, positive peers, school, community, or } \\
\text { culture. }\end{array}$ \\
\hline 2. Fosters resilience & $\begin{array}{l}\text { Emphasizes strategies for adaptive coping responses to } \\
\text { change and stress, and promoted psychological } \\
\text { flexibility and capacity. }\end{array}$ \\
\hline 3. Promotes social competence & $\begin{array}{l}\text { Provides training in developmentally appropriate } \\
\text { interpersonal skills and rehearsal strategies, including } \\
\text { communication, assertiveness, refusal and resistance } \\
\text { conflict-resolution, and interpersonal negotiation } \\
\text { strategies. }\end{array}$ \\
& & $\begin{array}{l}\text { Develops youth skills for identifying feelings in self or } \\
\text { others, skills for managing emotional reactions or } \\
\text { impulses, or skills for building the youth's self- } \\
\text { management strategies, empathy, self-soothing, or } \\
\text { frustration tolerance. }\end{array}$ \\
\hline 4. Promotes emotional competence
\end{tabular}




\begin{tabular}{|c|c|c|}
\hline & Promotes cognitive competence & $\begin{array}{l}\text { Influences a child's cognitive abilities, processes, or } \\
\text { outcomes, including academic performance, logical and } \\
\text { analytic thinking, problem-solving, decision-making, } \\
\text { planning, goal-setting, and self-talk skills. }\end{array}$ \\
\hline & Promotes behavioral competence & $\begin{array}{l}\text { Teaches skills and provides reinforcement for effective } \\
\text { behavior choices and action patterns, including } \\
\text { nonverbal and verbal strategies. }\end{array}$ \\
\hline & Promotes moral competence & $\begin{array}{l}\text { Promotes empathy, respect for cultural or societal rules } \\
\text { and standards, a sense of right and wrong, or a sense of } \\
\text { moral or social justice. }\end{array}$ \\
\hline & Fosters self-determination & $\begin{array}{l}\text { Increases youths' capacity for empowerment, autonomy, } \\
\text { independent thinking, or self-advocacy, or their ability to } \\
\text { live and grow by self-determined internal standards and } \\
\text { values (may or may not include group values). }\end{array}$ \\
\hline & Fosters spirituality & $\begin{array}{l}\text { Promotes the development of beliefs in a higher power, } \\
\text { internal reflection or meditation, or supported youth in } \\
\text { exploring a spiritual belief system, or sense of spiritual } \\
\text { identity, meaning, or practice. }\end{array}$ \\
\hline & Fosters self-efficacy & $\begin{array}{l}\text { Includes personal goal-setting, coping and mastery } \\
\text { skills, or techniques to change negative self-efficacy } \\
\text { expectancies or self-defeating cognitions. }\end{array}$ \\
\hline & Fosters clear and positive identity & $\begin{array}{l}\text { Develops healthy identity formation and achievement, } \\
\text { including positive identification with a social or cultural } \\
\text { sub-group that supports their healthy development of } \\
\text { sense of self. }\end{array}$ \\
\hline 12. & Fosters belief in the future & $\begin{array}{l}\text { Influences a child's belief in his or her future potential, } \\
\text { goals, options, choices; or long range hopes and plans } \\
\text { are classified as promoting belief in the future. }\end{array}$ \\
\hline & $\begin{array}{l}\text { Provides recognition for positive } \\
\text { behavior }\end{array}$ & $\begin{array}{l}\text { Creates response systems for rewarding, recognizing, or } \\
\text { reinforcing children's prosocial behaviors were classified } \\
\text { as using recognition for positive behavior. }\end{array}$ \\
\hline & $\begin{array}{l}\text { Provides opportunities for prosocial } \\
\text { involvement }\end{array}$ & $\begin{array}{l}\text { Offers activities and events in which youths can actively } \\
\text { participate, make a positive contribution, and experience } \\
\text { positive social exchanges. }\end{array}$ \\
\hline & Fosters prosocial norms. & $\begin{array}{l}\text { Employs strategies for encouraging youths to develop } \\
\text { clear and explicit standards for behavior that minimized } \\
\text { health risks and supports prosocial involvement. }\end{array}$ \\
\hline
\end{tabular}

The PYD framework also stresses the importance of youth organizing, participation, and leadership (Pittman, Irby, \& Ferber, 2001). Pittman and colleagues (2001) state, "young people have to have vehicles for organizing and speaking on their own behalf about issues that affect them directly and issues that affect the larger community and society" (p. 34). Another central component of PYD is a focus on "sparks," which is the term for the interests, activities, or topics that inspire and motivate 
youth to be successful (Benson \& Scales, 2001). Successful programs connect youth with their sparks and facilitate relationships that support youths' efforts to achieve their goals.

The FOTC approach is guided by five "Milestone Categories" that reflect core PYD principles. The five Milestone Categories are: 1) Social and Emotional Development; 2) Making Good Choices; 3) School Success; 4) Improved Health Care; and 5) Positive Plan and Skills for the Future (Furrer \& Kissick, 2009). Each Milestone Category has several specific and measurable indicators that allow the program to assess its progress toward reaching developmental goals. For example, the Improved Health Care category includes indicators related to access to preventive health care, daily consumption of fruits and vegetables, and exercise. The goal of the FOTC program, consistent with the PYD framework, is the promotion of positive attitudes and behaviors and the avoidance or mitigation of harmful ones. 


\section{Chapter 4: Agency Context}

Interpretive phenomenological research acknowledges that humans and human experience exist within particular contexts of time, place, and circumstance-in other words, people experiencing personal and social phenomena are inevitably "located" within and in relation to the world around them. Berg, Skott, and Danielson (2006), who used IPA to explore the meaning of caring relationships between nurses and patients, stress the importance of being "open to the complexity of the every-day-world in its specific context" (p. 42). For youth in mentoring relationships at FOTC, the agency context — program history, goals, policies, practices, etc.—plays a major role in shaping the experiences of youth participants. Therefore, this section seeks to briefly orient the reader to the setting and basic aims of FOTC by offering an overview of the history and development of the program and a description of its major underlying theoretical framework, positive youth development.

Friends of the Children was founded in 1993 in Portland, Oregon, with a model that broke the mold of traditional volunteer mentoring programs, like the Big Brothers Big Sisters model that dominated the youth development landscape for most of the $20^{\text {th }}$ century. FOTC was designed with the latest child development and youth mentoring research in mind. While many other mentoring programs were focused on rapid growth and expansion through increased efficiency and decreased intensity of service (Dubois \& Rhodes, 2006), FOTC founder Duncan Campbell intended to develop a program that was the ideal relationship-based intervention for youth experiencing significant life challenges, even if it meant serving just one child (Jones, 2009). To Campbell and other 
FOTC leaders, this commitment meant providing longer-term, higher intensity service than was currently available for the community's most vulnerable children. By 2013, Friends of the Children had grown to five chapters across the United States (and one in Cornwall, England) serving more than 860 youth. The FOTC-Portland chapter was serving more than 300 youth with more than 40 full-time paid mentors, affectionately known as Friends.

FOTC hires full-time Friends to form long-term, caring relationships with youth who are admitted to the program. After an extensive observation and assessment process in participating schools, youth are selected in Kindergarten and, once enrolled, are guaranteed a Friend all the way through high school graduation. Each Friend is assigned eight youth and is expected to spend approximately four hours per week with each child. At approximately 16 hours of direct contact a month, the FOTC intervention is significantly more intensive than other programs, particularly those that rely on volunteer mentors (Smith, 2004).

In 2008, FOTC added a more group-oriented and peer-oriented adolescent component to their original model. The adolescent program builds on the foundation of the interpersonal relationship formed between the Friend and the child over the first six years, but "is specifically designed to meet the developmental needs of teenagers" (Friendsnewyork.org.). Adolescent program staff offer more group outings that appeal to teens, including peers in activities at a time when friends are beginning to compete with important adults for priority in young people's lives. While the adolescent program 
provides expanded social opportunities for participants, the interpersonal relationship between each youth and their Friend remains centrally important throughout.

Youth are selected for participation at FOTC based on the identification of multiple personal and environmental risk factors by the selection team, which includes FOTC staff, teachers, school counselors, and administrators. Werner and Smith (1992) concluded from their landmark study of high risk youth that, "individuals characterized by several problem areas at an early age are more stable in their patterns of maladjustment up into adulthood than are persons with problems in a single area. They need our attention the most!" (p. 196). The FOTC program aims to serve the community's most vulnerable youth, although some potential participants are disqualified because of severe attachment disorders, autism spectrum disorders, severe developmental disabilities, or other conditions that are determined to make the FOTC mentoring approach an inappropriate intervention. Table 1 provides a snapshot of the range of risk factors that FOTC participants faced at the time of entry to the program.

Table 2. Risk Factors of FOTC Participants (Furrer \& Kissick, 2008)

\begin{tabular}{|l|l|}
\hline Risk Factor & \% FOTC Youth \\
\hline Qualify for free or reduced lunch* & $93 \%$ \\
\hline $\begin{array}{l}\text { Known to have been affected by domestic } \\
\text { violence in their lifetimes }\end{array}$ & $65 \%$ \\
\hline Known to have been raised by a single parent & $84 \%$ \\
\hline $\begin{array}{l}\text { Have at least one parent with known history of } \\
\text { substance use }\end{array}$ & $69 \%$ \\
\hline $\begin{array}{l}\text { At least one parent is known to have been } \\
\text { incarcerated }\end{array}$ & $59 \%$ \\
\hline $\begin{array}{l}\text { Have a parent that was under 18 when first } \\
\text { child was born }\end{array}$ & $58 \%$ \\
\hline At least one parent does not have a high school & $54 \%$ \\
\hline
\end{tabular}




\begin{tabular}{|l|l|}
\hline education & \\
\hline $\begin{array}{l}\text { Have lived in a home where there has not been } \\
\text { enough food to eat }\end{array}$ & $38 \%$ \\
\hline $\begin{array}{l}\text { Have had a report of abuse or neglect filed on } \\
\text { their behalf }\end{array}$ & $39 \%$ \\
\hline Has lived in foster care or with relatives & $30 \%$ \\
\hline Less than yearly contact with biological father & $45 \%$ \\
\hline $\begin{array}{l}\text { Of those youth with biological fathers involved } \\
\text { in their lives: }\end{array}$ & $65 \%$ \\
\hline $\begin{array}{l}\text { Fathers have known history of criminal } \\
\text { activity }\end{array}$ & $66 \%$ \\
\hline $\begin{array}{l}\text { Fathers have known history of } \\
\text { incarceration }\end{array}$ & \\
\hline
\end{tabular}

Because the FOTC program serves youth considered to be at high risk of delinquency, school drop-out, early pregnancy, and other negative outcomes, the original leadership team decided that professional mentors, preferably with experience working directly with youth, would offer a better chance of success than using volunteers. This strategy is supported by DuBois and colleagues who concluded, "Many of these youth are likely to be in need of relatively extensive amounts of specialized assistance, for example, a situation that is not necessarily well-suited to the primarily volunteer and nonprofessional status of most mentors" (DuBois, Holloway, Valentine, \& Cooper, 2002). While early Friends were selected for their experience and suitability for the program, FOTC now requires new Friends to have a college degree and relevant experience in education, social work, youth development, or other related area.

The mentoring relationships at Friends of the Children develop across time and in a variety of physical locations. Youth are selected for participation through a screening process that happens in the school setting, and youth often first meet their new Friends in 
the classroom. Not long after the relationship is initiated, Friends and youth start going on "outings" together — to the zoo, on a bike ride, to a park, out for lunch — and the setting for the mentoring relationships widens to include the entire Portland area and beyond.

Many youth and Friends also spend time together at the FOTC office in North Portland, which is housed in an old Catholic school building that retains much of its original character, including the lockers lining the walls in the main hallway, despite renovations to accommodate offices and conference rooms. Many afternoons the building resonates with the sound of basketballs bouncing on the polished hardwood floor in the refurbished gym, or with voices and music emanating from the basement that has been converted to a teen gathering space. FOTC also owns two houses, one in Northeast and one in Southeast Portland, that are used as spaces for youth and Friends to gather, socialize, cook, eat, and relax.

The children's homes constitute another setting that often plays a prominent role in the development of the mentoring relationships. While the program is intentional and explicit about being youth-focused rather than whole family-focused, over time Friends inevitably become enmeshed to some extent in the fabric of the youths' families and lives at home. Friends' interactions may be limited to meeting and greeting parents, siblings, and other relatives at the door when picking up children for outings, but Friends also find themselves with family members at school functions, community events, or-as one Friend described to me - at major family events like a funeral for a child's father or the birth of a new sibling. 
The diversity of settings within a single mentoring relationship over time, not to mention across the mentoring relationships of over 40 Friends and 350 youth, underscores the importance of using a phenomenological approach to explore essential elements of participants' experiences. Giving youth the opportunity to describe what has been important to them about the experience of having a mentor, and then organizing and synthesizing their personal stories in systematic and creative ways will offer a better understanding of what it is about those trips to the zoo and bike rides through the park that are important for youth participants and that may ultimately impact the way youth feel, think, and behave. 


\section{Chapter 5: Methodology}

Research questions that seek to explore the nature of human experience lend themselves well to qualitative methods (Strauss \& Corbin, 1990). Since qualitative research methods span a wide range of philosophical and scientific traditions and paradigms (Denzin \& Lincoln, 2003), selecting a methodology requires careful consideration of the purposes of the study and the specific questions asked. The purpose of the current study was to explore the lived experiences of youth who have experienced long-term mentoring relationships in the Friends of the Children program. The question of how youth make sense of these deeply personal relationships required a qualitative approach designed to reveal the meanings of subjective experience.

\section{Interpretive Phenomenological Analysis (IPA)}

Interpretive phenomenological analysis (IPA) is an approach designed to reveal how participants experience and make sense of their individual and social worlds. Consistent with the phenomenological tradition, the first objective of IPA is to understand the participants' life-world and "describe what it is like" (Smith, Flowers, \& Larkin, 2009, p. 104). However, because the experiences of others cannot be accessed directly and are inevitably mediated by the researcher's personal history, values, and beliefs, IPA involves what Smith and Osborn (2007) call "a two-stage interpretation process, or double hermeneutic," in which "the participants are trying to make sense of their world" and "the researcher is trying to make sense of the participants trying to make sense of their world" (p. 53). Due to these multiple layers of interpretation, the IPA 
researcher seeks to understand what participants are experiencing and understanding, but also what the participants may not realize they are experiencing. Smith and Osborn (2007) refer to these two types of interpretation as empathic and critical, and suggest that they should work together through sustained inquiry to offer a balanced perspective that is appropriate to the phenomenon and participants involved in the study. Finlay (2002) suggests that the self-reflective aspect of reflexivity constitutes another level of interpretation in phenomenology. Through reflexive introspection, the researcher explores his or her own reactions to the participants and their stories, and attempts to account for those responses in subsequent interpretation.

The topic of an IPA study is a human phenomenon (in this case, the long-term mentoring relationship), but the subject of an IPA study includes both the phenomenon and the person experiencing the phenomenon (Larkin, Watts, \& Clifton, 2006). For example, the current study is not concerned with an objective description of what a longterm mentoring relationship is, but rather seeks a rich, authentic account of what longterm mentoring is and means in the context of participants' lives. IPA studies are generally conducted using data collected through semi-structured phenomenological interviews with a small number of participants (Smith \& Osborn, 2007). The semistructured nature of phenomenological interview questions allow the researcher to focus on eliciting descriptions of participants' lived experiences while maintaining enough flexibility for participants to tell their stories fully. Schedules for IPA interviews may include several categories of questions, addressing aspects of the phenomenon of interest likely to be covered in the interview, and particularly questions designed to elicit lived 
descriptions of the phenomenon, For example, Smith and Osborn (2007) present an interview schedule for a study of the experience of undergoing dialysis for patients with kidney disease that includes several questions in each of three categories - the dialysis procedure itself, the effect on patients' identity, and coping strategies related to the experience. An interview schedule for the current study is presented in the appendices (see Appendix C).

While phenomenologists take a range of approaches to analysis, Smith and Osborn (2007) suggest initially coding transcripts and identifying themes that emerge from the data. Even in analyzing the first transcript, themes may be grouped into analytical or theoretical groups, reflecting connections that the researcher has identified through an iterative process of comparing themes and checking emerging ideas against the source material to ensure that the integrity of the participant's words and phrases is preserved (Smith \& Osborn, 2007). Themes may then be organized into clusters, ordered meaningfully into tables, and catalogued with supporting quotations from the transcripts (Smith \& Osborn, 2007). As additional cases are considered, the researcher looks for convergences and divergences in the data, and may drop themes that appear insignificant. A key strategy for determining whether a theme is significant or insignificant involves an interpretive process called "imaginative variation," through which the researcher explores possible meanings "through the utilization of imagination, varying the frames of reference, employing polarities and reversals, and approaching the phenomenon from different perspectives" (Moustakas, 1994, p. 97). In other words, the researcher must spend time with each piece of potentially relevant information to decide whether its 
presence or absence might change what the phenomenon means or how it is experienced, whether that experience might change depending on who was involved, and so on. If, through these thought experiments, a piece of information is determined to have no bearing on the understanding or experience of the phenomenon in question, then that element may be removed from further consideration.

The iterative, interpretive process central to IPA is often referred to as the hermeneutic circle (Larkin, Watts, \& Clifton, 2004), a term coined by Heidegger which highlights the dynamic, on-going interaction between the participants' words and understanding and the researcher's constantly evolving understanding of the phenomenon, the participants, and the data. Some critics have argued that a circle implies a closed and finite interpretive process and suggest a hermeneutic spiral, which includes movement through time and the contributions of subsequent research knowledge, as a more appropriate metaphor (Conroy, 2003).

The writing up of IPA studies is an important analytical process in itself (Smith, Flowers, \& Larkin, 2009), with a central focus on "translating the themes into a narrative account" in a way that the themes are "explained, illustrated, and nuanced" (Smith \& Osborn, 2007, p. 76). To this end, many IPA studies use prose descriptions of themes with verbatim excerpts from the transcripts to illustrate the points being made, with the researcher often providing additional commentary to lend context and perspective to the analysis (Smith \& Osborn, 2007). The current study also used poetry as a tool to analyze and present themes, particularly the deeply emotional and affective aspects of mentoring relationships that could have been difficult to communicate through prose. Although 
poetry has rarely been used in IPA, poetry has become a well-established tool in the qualitative research repertoire over the last two decades (Prendergast, 2009). IPA lends itself to a variety of analytical strategies, provided that the strategies employed are compatible with the purposes of the project and the researcher's specific aims. As Larkin, Watts, and Clifton (2006) put it:

The strategies chosen will depend upon the commitments and interests of the researcher, the research question in hand, and the more general requirement for a coherent analysis. Our point here is that the analyst has the opportunity to draw from a wide repertoire of analytic strategies, and that these may be informed by prior experience and knowledge, psychological theory, or previous researchprovided that they can be related back to a phenomenological account of the kind described above (p. 116).

The use of both poetry and prose in this study provided the opportunity for rich and dynamic representations of the experiences and meanings of long-term mentoring relationships for youth participants that would not be possible with either approach individually.

\section{Selection of Participants}

For the current study, I recruited twelve youth for participation. The size of the participant group is consistent with other phenomenological studies with youth participants (Smith, Flowers, \& Larkin, 2009). Since the phenomenon of long-term mentoring relationships is the topic of the current study, prospective participants were 
limited to youth who were 16-18 years old and in their final year or two of participation in the program, ensuring that each youth has had a mentor for at least the last 10 years. For consistency, I generally limited the participants to youth who had the same mentor for at least the last four years. However, at the encouragement of an FOTC team leader, I also included one participant who had only been with her Friend for just over two years, but who volunteered to participate and had a unique set of experiences that I thought would enhance the diversity of the participant group.

Three general criteria suggested for selecting participants for phenomenological research are that they have experienced the phenomenon being studied, that they are willing to talk about their experiences, and that the group is diverse enough that they will likely provide unique stories about the experience (Laverty, 2003; Polkinghorne, 1989). To satisfy these criteria, I used a purposive recruitment strategy in close collaboration with Friends of the Children mentors and other staff who are familiar with the youth. For recruitment, I attended two meetings at Friends of the Children-one with team leaders (who are also Friends), and one with all of the Friends who are currently matched with older youth. During the first meeting, I described the study's purpose, methodology, and procedures, and then asked team leaders to nominate youth they thought would be appropriate considering the study's approach and requirements. To provide transparency in the recruitment process, I also asked for and recorded the reasons why some potential participants were excluded from consideration.

Several youth that met the minimum criteria were excluded because they had significant challenges with verbal communication. One youth, for example, had been 
completely nonverbal for most of her childhood, and had relatively recently begun to speak with her closest family members and her Friend. Because a phenomenological interview requires extensive conversation and storytelling, students with these kinds of communication challenges were determined to not be a good fit for this study. Two potential participants had not been in touch with their mentors for several months and were unlikely to be available for an interview. One youth who initially indicated that she was interested in participating had a baby before we had a chance to meet, and then was understandably too busy with being a new parent to get together for an interview. In the end, 16 youth were identified as appropriate potential candidates for the study.

Once nominations were made, I arranged an additional meeting with the Friends to make final selections for the participant list, keeping in mind the three criteria listed above. Friends and team leaders made initial contact with the 16 selected youth to briefly describe the study, and I then arranged a meeting or phone call with interested youth to begin the informed consent process.

I used a process of informed consent to make sure all participants and their legal guardians (for youth under 18) fully understood and agreed to the terms of the study. Following Bailey's (2007, p. 17) recommendations, the informed consent agreement contained thorough information to ensure that participants understood the voluntary nature of their participation, their right to withdraw from participation at any time, the study's purposes and procedures, potential risks and benefits, and other information (see Appendix E). Of the 16 youth who were contacted by Friends, nine returned informed consent forms and were interviewed for the study. 
To reach the intended number of 12 participants, I sought permission from the Institutional Review Board to use three transcripts from interviews with Friends of the Children participants that I conducted a year earlier (with appropriate IRB approval) to pilot the methods and approach used in the current study. Permission was granted, and the three "pilot" interview transcripts were added to the contributions of the other nine participants to comprise the 12 participants of the current study.

The three participants who completed pilot interviews received $\$ 10$ gift cards as an incentive for their participation in the study. The nine new participants received a onetime \$20 cash incentive. The amount of the incentives was reasonable considering the time commitment required for participation. The cash incentive also meets ethical guidelines since the participants have no dependency relationship with the researcher, the risks of the study are not particularly high, the research is not degrading, and the incentive is not intended to compensate for a strong aversion to participation (Grant \& Sugarman, 2004). Participants who agreed to participate in a follow-up meeting for member checking or to discuss the study's findings were offered refreshments, but no additional monetary compensation was provided.

\section{Primary Data Collection}

The aim of phenomenological research is to explore the lived experience of phenomena from the participants' perspective (Patton, 1990), so semi-structured interviews guided by the study's major research questions offered a balance of focus and flexibility that was important "to get as close as possible to what [participants] think about the topic, without being led too much by [the researcher's] questions" (Smith \& 
Osborn, 2007). Since participants are regarded as experts of their own experiences, phenomenological interviews should follow the lead of participants' descriptions and stories rather than following the interviewer's line of thinking (Cope, 2005). As Thompson and colleagues (1989) put it, "the role of the interviewer is to provide a context in which respondents freely describe their experiences in detail” (p. 138).

One 90-120 minute phenomenological interview was conducted with each youth participant. Most interviews were conducted at the Friends of the Children main office in a private conference room, and the two others were conducted in private meeting rooms at public libraries. I made an effort to ensure that interviews were conducted with few or no interruptions, and in a quiet and comfortable environment in which youth felt free to share their stories openly and honestly.

Several prompts and questions guided the interviews, including: 1) Tell me what your relationship is like with your mentor. 2) What kinds of things do you do together? 3) Please describe a time when your mentor was particularly important to you. 4) How did it feel to have a mentor in that situation? and 5) Please describe a time when your relationship with your mentor was difficult. These prompts and questions were designed to get participants started talking about their experiences in the mentoring relationship and were not meant to be prescriptive. Smith and Osborn (2007) highlight a few key components of the interview process in IPA, including building rapport with participants and allowing participants room to tell their own stories and introduce topics of discussion that are most important to them. "In this relationship," Smith and Osborn (2007) state, "the respondents can be perceived as the experiential expert on the subject and should 
therefore be allowed maximum opportunity to tell their own story" (p. 59). Follow-up questions depended largely on the direction and tone that each individual interview took, although I was intentional in trying to keep each interview focused on participants' lived experiences - thoughts, feelings, perceptions, and memories related to their experiences in the mentoring relationship.

Interviews were audio recorded using a digital recording device. I personally transcribed the first two interviews in order to facilitate immersion into the data and the analytical process. All remaining recordings were then transcribed by a third party transcriptionist. When the transcripts were complete, I listened to each interview again while reading the transcripts to ensure accuracy and consistency, and also to further connect with the youth's stories and to better remember their personalities. The completed transcripts were transferred from Microsoft Word documents to document files on ATLAS.ti Version 5.2 qualitative data analysis software for analysis.

\section{Data Analysis}

Data were analyzed using an iterative process that incorporates a number of stages common to interpretive phenomenological analysis (IPA) as described by Smith, Flowers, and Larkin (2009). The authors describe the analytical process in interpretive phenomenological research as an "inductive cycle" (p. 79) that is "multidirectional; there is a constant shift between different analytic processes" (p. 81). It is important to note that analysis in IPA is often flexible and creative rather than formulaic, and the researcher's decisions most often respond to the intersubjective meanings that emerge at each stage of the research rather than to predetermined steps or procedures. IPA is 
marked by many subjective elements and processes, but "at the same time that subjectivity is dialogical, systematic and rigorous in its application and the results of it are available for the reader to check subsequently" (Smith, Flowers \& Larkin, 2009, p. 80).

Despite the need for flexibility, it is also important for researchers using interpretive approaches to be explicit about the strategies used and their purposes. Several specific analytic techniques that were used during the current study are described below. They include reading and annotating the interview transcripts; identifying units of meaning and emergent themes within the material; writing individual poems using participants' words as they appear in the transcripts; presenting the individual poems to participants for reaction, clarification, and additional input; and constructing a prose description of the themes that emerge from the analytic process.

\section{Reading and Annotating the Transcripts}

To become intimately familiar with the interview data, I read each transcript several times while listening to the corresponding audio recording. As I read and listened, I made notes in the margins of the transcripts to record my initial thoughts and impressions of the experiences each participant chose to share in the interviews. This annotation process was accompanied by regular entries in my reflexive journal about the things that were surprising, expected, or otherwise notable based on my prior knowledge and experiences. The goal of this initial reading and annotation process was to begin to identify how the mentoring relationships were experienced and understood by each 
participant, as well as to begin to describe the meaning that each participant ascribed to the experience in this particular context (Larkin, Watts \& Clifton, 2006).

\section{Identifying Meaning Units and Themes}

After all transcripts were read and annotated, I began a process of identifying and labeling units of meaning - individual statements that relate directly to the phenomenon of interest (Groenewald, 2004). This was done in the Atlas ti program using the open coding function, and additional thoughts and noted related to the coding process were recorded in "memos" that can be attached to any passage for future reference. Next, themes and patterns were identified among the meaning units that suggested important commonalities or differences among the concepts and meanings implicit in participants' experiences. At this stage, general themes and more subtle nuances within themes emerged, and larger chunks of data were represented by concise statements that "speak directly to the psychological essence of the piece," and that "contain enough particularity to be grounded and enough abstraction to be conceptual" (Smith, Flowers \& Larkin, 2009, p. 92). Maintaining a balance between detail and abstraction was important because it allowed me to remain in touch with the concrete and visceral components of individuals' stories while simultaneously constructing a preliminary map of the phenomenon of interest in which all of the details are meaningfully related to each other. Themes were labeled and managed in the "families" function of ATLAS.ti, which allows segments of text across documents (transcripts) to be linked to each other by larger conceptual categories. Any apparent relationships between themes were illustrated using the "networks" function in ATLAS.ti, which provides a number of options for 
representing conceptual relationships visually. ATLAS.ti automatically organizes themes in an accessible format, with supporting quotations from the interviews attached, essentially providing a catalogue of themes at each conceptual level highlighted by the excerpts that support each category.

\section{Writing Poems Using Participants' Words}

One way the current study differs from most phenomenological research is the use of poetry as a supplementary method of data analysis. Raingruber (2009) contends that "good poetry captures the truth of an experience" (p. 261); and indeed capturing the truth of experience is what phenomenological methods are all about. In fact, the poet David Whyte considers writing poetry to be a phenomenological process (Reece, 2000). The emotional and associational qualities of the data that was collected through the interviews lent themselves well to the particular way that poems are constructed. The poet Matthew Dickman said, "Ecstatic love and devastating sorrow and grief destroy language. Poetry takes the rubble of human experience and puts it back together. Poetry offers the tools to do that" (personal communication, April 17, 2010). In other words, poetry is an ideal medium for describing, sometimes metaphorically, the elements and the deep emotional content of important life experiences.

This study used a technique called "poetic transcription" (Richardson, 1993) to create poems from verbatim fragments and phrases of the interview transcripts (i.e. meaning units). The products of the poetic transcription process have been called “interview poems" (Furman, Shears, \& Badinelli, 2007) or “transcript poems” (Luce- 
Kapler, 2004). The idea of poetic transcription is to use the poignancy of participants' words, along with the power of poetic devices and poetic form, to discover and communicate aspects of experience that may not be fully accessible through other modes of analysis. The sociologist Laurel Richardson (1993), one of the pioneers in utilizing poetry as inquiry in the social sciences, suggests that "by settling words together in new configurations, the relations created through echo repetition, rhythm, and rhyme let us see and hear the world in a new dimension. Poetry is thus a practical and powerful means for reconstituting worlds" (p. 705).

The poetic transcription process used the meaning units to construct poems that describe and interpret aspects of experience that are central to the mentoring relationship. In a process that is simultaneously analytical, intuitive, interpretive, and artistic, I combined the sentences, phrases, and fragments that constitute the meaning units to create lines, stanzas, and whole poems that are hopefully "spare, economical, rich, and resonant" (Neilsen, 2004, p. 42). Some poems reflect and/or expand upon themes identified earlier in the inquiry process, while some explore other events, ideas, memories, and emotions conveyed through the interviews that represent something experientially significant for the participants but that were not apparent in the thematic analysis. While the thematic analysis relied largely on finding logical, explicit connections or divergences within the data, the poems were constructed to present emotionally and intellectually resonant interpretations of the experiences of the youth and the meanings associated with those experiences. 
I used the participants' words with the intention of creating poems that incorporate elements of "concreteness, voice, emotion, ambiguity, tension, and associative logic," that are present "to a greater or lesser extent in any strong poem" (Butler-Kisber, 2009, p. 5). Using poetry allowed me to convey "the sense and texture" of mentoring relationships without relying exclusively on "summative language...that can over-sterilize or even deaden the aliveness of the shown phenomena" (Todres \& Galvin, 2008). Most importantly, though, I believe the poems illuminate the participants' experiences in a way that honors the voices of the youth and enhances understanding of what it means to have a long-term mentor.

\section{Presenting Poems to Participants}

Once the poems were written, I intended to share my work with as many participants as possible to solicit their responses and feedback, and ensure their thoughts and experiences were accurately represented. Due to a long delay between conducting the interviews and writing the poems, however, I was only able to reach two of the twelve original participants. All of the participants had graduated from the program, and many had gone away to college or had not been in touch with the organization for quite a long time. Despite only reaching a pair of participants, I had the opportunity to spend more than an hour with each of them discussing my findings and sharing drafts of my poems with them. I read the poems to them, and gave them an opportunity to ask questions about the content, structure, and meaning of the poems, and gave them ample time to respond with comments, concerns, endorsements, and any other feedback that came to mind. Butler-Kisber (2002) recommends sharing research poems with participants for two 
reasons: "As in all qualitative work, getting a response from the participant(s) helps deal with ethical issues, but also contributes to crafting the product" (p.235). Consistent with these dual purposes, the process of sharing the poems with youth allowed me to make sure that the poems presented fair representations of the experiences shared by youth in the interviews (Lincoln \& Guba, 1985), and it also give me the opportunity to edit the poems based on the participants' feedback and additional comments. Overall, I believe the process of sharing the poems with youth, listening to their impressions, and considering their feedback as I revised and refined the poems ultimately yielded poetic interpretations that were more true to the experiences of the participants and ultimately to purpose of the study.

\section{Establishing Trustworthiness}

The subjective nature of qualitative inquiry requires that the researcher establish the trustworthiness of the research process and findings (Lincoln \& Guba, 1985). What constitutes trustworthiness in qualitative research depends to some extent on the paradigm or underlying philosophy of the researcher and her methods (Morrow, 2005). Post-positivist approaches, for example, differ from constructivist and interpretive approaches in their criteria for rigor. In constructivist and interpretive research, including the current study, researchers seek to maximize "authenticity" and "fairness" in the process of collecting and analyzing data (Guba \& Lincoln, 1994). Authenticity is a multifaceted construct that refers to a number of aims that depend on the nature and purpose of the research, but might include "ontological authenticity" (when a study addresses the perspectives of participants as fully as possible) and "catalytic authenticity" 
(when a study inspires action) (Guba \& Lincoln, 1994). Morrow (2005) also argues, however, that several elements of trustworthiness are so fundamental that they transcend paradigmatic boundaries. These include the imperative of the researcher's immersion in the data being analyzed, as well as the need to embrace subjectivity and reflexivity as core perspectives and processes.

Establishing trustworthiness increases confidence that the researcher's analyses and interpretations are sound, appropriate, and believable, and that participants' voices were heard, which is particularly important when exploring and representing the experiences of marginalized populations (Lietz, Langer \& Furman, 2006). The current study included several components, including reflexivity, an audit trail, peer debriefing, and member checking to ensure that the study's findings are, in the words of Lincoln and Guba (1985), “worth paying attention to" (p. 290).

Reflexivity

Reflexivity is an active and continuous consideration of the ways that the researcher's identities, experiences, and beliefs intersect with those of participants and influence the research process (MacBeth, 2001). This process of "situated reflection" occurs throughout the study, from conception through reporting of findings, and can take place in individual thought or in dialogue with others (Kogler, 1996). For this study, I used a reflexive journal to keep a running account of my thoughts and feelings regarding my relationship to the topic of youth mentoring relationships, the participants, the research process, and other elements that affected my decisions in the course of designing 
the study, collecting and analyzing the data, and reporting the findings. The use of a written method for reflexivity helped ensure that my ideas and perspectives, especially with regard to how they affected the decisions I made over the course of the study, were available for review and critique.

\section{Audit Trail}

An audit trail is a detailed account of the steps taken in the research process (Rodgers \& Cowles, 2007). Maintaining an audit trail is important for justifying research decisions that are made throughout qualitative studies, particularly when flexibility and creativity are important components of the process (Lietz, Langer \& Furman, 2006), like in arts-based approaches. Establishing a clear and consistent process for recording procedures and decisions allows readers to critically review how and why data were collected, organized, analyzed, and reported in certain ways. The rigor demonstrated in an audit trail makes a stronger case for the findings of a study to be viewed as credible and valuable, particularly in the social science community (Akkerman, Admiraal, Brekelmans \& Oost, 2008). The audit trail for the current study is contained primarily in the coding records, notes, and memos in the Atlas ti files. The remainder of the information that reflects the analytical and logistical decisions that were made throughout the study is contained in the reflexive journal.

\section{Member Checking}

Member checking is the process of taking research data, interpretations, and findings back to participants to solicit their input and reactions (Creswell, 1998). Lincoln 
and Guba (1985) consider member checking to be the most important strategy for establishing the credibility of a study. As I mentioned briefly in an earlier section, I had intended to engage each participant in the member checking process to solicit their responses to the categories and themes identified in the findings as well as to share and discuss the transcript poems. Due to the extended period of time that lapsed between the interviews and the completion of the manuscript and poems, I was only able to reach two participants to conduct member checking sessions. While this is clearly a limitation of the study, the two participants who agreed to participate in member checking provided comprehensive and thoughtful feedback for all of the findings chapters and the majority of the poems included herein. Detailed notes were taken during the member checking sessions to ensure that all participant reactions and concerns were acknowledged and considered before the products of the research were presented or shared.

\section{Ethical Considerations}

In an effort to minimize the potential for harm to participants, all guidelines provided by the Institutional Review Board (IRB) at Portland State University were followed for the duration of the study. These include provisions for informed consent for parents or legal guardians of participants as well as written assent for youth; protection of participants' privacy; and the right for participants or their parents to withdraw their consent for participation at any time. All participants and their parents or guardians were informed of the purposes of the study and data collection procedures both orally and in writing. Participants were notified that names and other identifying information would be omitted or changed prior to publication to protect privacy. Participants' assent was also 
attained prior to each interview being conducted. Participants and their parents or guardians were provided contact information for the investigator and for the IRB in case concerns or questions arose at any time during the study.

Another assurance that the study was conducted ethically was the process of member checking results with participants prior to publication. As a researcher who asked youth and their families for permission to record, analyze, interpret, and publish accounts of deeply personal experiences, I have the obligation to make sure that youth's stories are fairly represented before they are shared with others. Through the member checking process, youth were given the opportunity to review and provide commentary on findings prior to publication. In order to be inclusive of different perspectives on the topics under consideration, I used participant commentary as additional data to be considered in the analytical process. Participants were also given the opportunity to decide to exclude at their request any details they may have provided in the interviews; that is, they may remove from consideration any thoughts or stories that, in hindsight, they wish they did not share.

\section{Researcher Positionality}

Before presenting the findings of this study, I think it is important to take a few minutes to describe some of the ways that my personal experiences, interests, identities, and beliefs have influenced my approach to the topic of long-term youth mentoring for youth who have had particularly challenging lives. According to Muhammed and colleagues (2014), researcher positionality "encompasses both societal ascribed and 
achieved identities that confer status on an individual researcher, such as race/ethnicity, or level of education attained," as well as the "relationships between academics and community members" that can affect how research projects are designed and conducted by the researcher and experienced by participants (p. 8). Accounting for positionality does not ensure fairness, nor does it ameliorate the power differential between an academic researcher and, in this case, young people with many identities and experiences that put them at a distinct disadvantage with regard to access to opportunities and resources. However, accounting for positionality can help a researcher become more aware of their own privilege and biases in the research process, and to take steps to increase the opportunities for participants' voices to be heard, their perspectives to be valued, and their agency to be recognized and maximized. I hope this section contributes to those aims in the current study.

I come to this project as a social science researcher, but also as a graduate student, a teacher, a poet, a social worker, a parent with a young child, a mentor, a mentee many times over, and a person of great privilege in having been born white, male, and middle class in a society where all three of these characteristics are afforded undue value. My interest in pursuing this study as a dissertation comes in part from my frustration that the struggles of youth born and raised in difficult circumstances - many of whom have been my clients, students, mentees, and friends — are so often pathologized, categorized, calculated, analyzed, and explained without an honest effort to account for the true nature of their personal experiences. This project also reflects my commitment to helping 
improve mentoring programs and practices so that more youth will have the chance to enjoy the benefits that strong, authentic, and positive relationships can provide.

Although I have faced few of the struggles and barriers that youth in formal mentoring programs have encountered, I have been fortunate to benefit from a number of mentors I have met in the course of my schooling and employment. To me, a mentor is a person who takes an extraordinary interest in the development of another person who benefits from their wisdom, guidance, and support. One mentor helped me raise my educational aspirations and formulate a plan to meet my long-term career goals. Another mentor has provided years of moral support, opportunities, advice, and collaboration as I have developed my knowledge and skills as a social work educator and researcher. While many others have been kind, helpful, and encouraging, it is my mentors to whom I can honestly say, "I couldn't have done it without you."

As such, I feel compelled to return the blessing of mentoring as a mentor to students and as a researcher dedicated to making the mentoring experience as beneficial as possible, particularly for those youth who have found few natural mentors to guide them. As a parent, I feel the responsibility to work to make our communities as healthy and just as possible for the benefit of those who live here now and those that will follow us in future generations. As a person born with many privileges, I am compelled to use those privileges to expose injustice, and to use the power that I have to work for the empowerment of others through active engagement in community service, politics, teaching, and through a profession that is dedicated to establishing and maintaining just and equitable social systems. 
As a researcher, I make a commitment to account for the role my privilege plays in all aspects of my work because I believe not doing so would represent a step backward from acknowledging my own personal and professional responsibilities and intentions in undertaking this project in the first place. Instead, consistent with the interpretive tradition and using reflexive techniques described below, I have tried to account for my privilege, position, process, thoughts, and opinions the best I could throughout the research process, with the hope that this additional data adds to the trustworthiness of the findings as they are reported.

As a poet, I make sense of the world through verse - through musical, magical fragments of language that, when arranged in just the right way, offer the reader or audience immediate and visceral access to another person's world. In this study, I asked youth participants to think and talk about the experience of having a Friend, a mentor who promised that they, or another caring professional person at Friends of the Children, would be with them throughout their childhood. I asked them to trust me with their thoughts, feelings, memories, beliefs, and their voices so that I could make sense of them in my own unique way, hopefully illuminating rather than diminishing the sparks of meaning in their stories. It is my hope that as I present these words and their meanings as poetry, and as social research, to the academic and public worlds that others will become more aware of and responsive to the lived experiences and very real needs that underlie the statistics about high risk youth. 


\section{Chapter 6: Meeting the Participants}

The current study was designed to illuminate the experience of long-term mentoring relationships from the perspective of 12 youth with unique lives, personalities, backgrounds, and beliefs. Some of the work of phenomenology is finding similarities and themes that transcend individuals and resonate among the diverse lives explored through the work. Phenomenology is not about any individual, though, nor is it necessarily about the group; rather, phenomenology is concerned with the nature of the lived experience itself. However, in order for a researcher to genuinely connect with that experience, a certain level of honor and respect must be afforded to the people who have offered themselves and their stories for interpretation and analysis. To understand the varied lives that yielded the rich experiences the 12 youth participants shared with me, I had to get to know them. I had to understand, to whatever extent I could in the short time we had together, what was most important to them, how they viewed the world and the people around them, what they wanted for their lives, among other things.

In order for the findings of this study to make as much sense to the reader as they do to the writer, I thought it would be helpful to introduce readers to the participants, and hear a little bit about each one of them, as I got to know them during our time together. This section provides a very brief introduction to the six young women and six young men who shared their stories with me for this study. Although time has passed since their participation and each of these young people has moved on to new stages in life, I describe them here as I met them the day of their interview. All names have been 
changed to protect confidentiality, and participants were given an opportunity to select a pseudonym of their choice.

\section{Gabriel}

Gabriel is a sixteen year-old youth with an artistic streak. He plays and produces music, works afterschool at a non-profit center for the arts, and is teaching himself video editing. Gabriel is very close to his mother, whom he lives and works with. When discussing the importance of having a consistent, long-term mentor in his life, he said, “It's really nice to have a Friend, 'cause you know I didn't have too many friends...it's really just me and my mom." Gabriel's father abused drugs and left the family when Gabriel was young — "it was really tough at home to the point where we had to leave for a while...we were in a shelter for a little bit, you know, kept switching schools and stuff like that. That was rough times." Gabriel described a lot of yelling and fighting in his household, and the toll it took on his mother. "Mom told me not to worry about it, but things were still hard. Especially hard on Mom."

Gabriel has had two mentors during his 11 years at Friends of the Children. He was matched with Paul in first grade at the age of six, and then at 11, he switched Friends and was matched with Emmett. Gabriel remembers warming to the idea of having a mentor very quickly, "I got to brag about my awesome new friend to a lot of people. He took me to movies, buy me lunch, and yeah, it was good." Switching mentors after 5 years wasn't difficult, Gabriel said, because he already knew Emmett from group activities with other Friends and youth, plus he was able to keep in touch with Paul, who 
was still connected to the organization. Gabriel is looking forward to studying computer science in college, but is also focused on taking more responsibility in the household in order to help out his mom, “...trying to pay bills, things like that. It doesn't look too scary to me as it would to most people, and I don't plan on moving out from my mom yet 'cause we both kind of need the money. And then, you know, also she's my mom."

\section{Candice}

Candice is a confident 18 year-old who excels in school but has had her share of challenges with family, friends, and the pressures of being a teen. Describing her elementary school years, Candice said, “Around that time my mom wasn't around, she was incarcerated. I actually lived with my grandma until $8^{\text {th }}$ grade year, before I moved out and went with my mom... I'm actually really close to my grandma now, but she's really strict, my grandma's one of those people who doesn't really listen to you, you don't listen to a child, you're supposed to be seen and not heard. She's really traditional, so it was kind of hard when I was little.”

Candice has had two Friends during her 12 years in the program, meeting Robin in her $1^{\text {st }}$ grade classroom, "My caseworker kinda dropped it on us. She was like 'Oh yay, you guys are getting a mentor.' I was like, 'Well, what do they do?'” When her caseworker described the program and the Robin's role, Candice remembers asking, "So, do I have to do this?" She tried coming up with different excuses to get out of it, but finally gave in and tried it out. When she switched mentors in $5^{\text {th }}$ grade, she wasn't thrilled about the shift. The first time she met Naomi, she recalls, "I was kind of 
indifferent. My mentor had gotten pregnant and she was moving to Dallas. She had a baby, so she was moving to Dallas...we butted heads sometimes, but I really missed her." However, Candice and Naomi formed a quick bond, and Naomi was surprised to find that Naomi was one of the rare people with whom she never "butted heads." Naomi thinks back, "She seemed really nice, she seemed pretty cool...We got along really well."

Candice describes herself as outgoing, kind, and caring, who "just started hanging out with the wrong people" around $9^{\text {th }}$ grade. "By the end of my freshman year, we'd drink and smoke every day. Just partying every day.” Candice would sometimes go to school drunk or high, and eventually stopped going altogether. During this period she started dating a guy who was a gang member, and they spent a lot of time around other gang members. She remembers feeling overwhelmed: "They were all in it, and that's what they do - they party and do crazy things." Now, Candice has earned her GED, and is attending an alternative school program to complete her high school diploma. She is applying to college and hopes to major in history. Even during the most difficult periods in her life, Candice remained connected to Naomi, often telling her friends that they would have to wait, "We actually had a day set. It was Thursdays. That was the day I'm going with her, and I spend time with her on that day. That was my day with Naomi. I remember, they'd be like 'Do want to go here?' and I'd be like, 'Nah, I have to go somewhere today,' and they're like 'Are you serious?' I was like, 'Yeah.' I would be like 'Later I'm available, but I have to go with my mentor for the day,' and I remember they all used to get jealous, 'Ah, we want to do this'... Those were the days I looked forward to." 


\section{Hugo}

Hugo is a seventeen year-old high school junior with an interest in science, and more specifically how the human body works. "I thought it would be really cool to be a surgeon of some sort," he said, and is also considering being a paramedic or a firefighter. Hugo also wrestles on the varsity team at his high school and plays the guitar in band with some friends. "The summer going into sophomore year I was in Mexico for a while... and my cousin had an acoustic guitar. During the day, he would go to school, so when I would wake up I didn't really have much to do and I was spending a lot of time messing around with the guitar." Hugo has had two mentors during his 11 years in the Friends of the Children program, Paul for the first six years and now with Derrick for the last five.

Hugo lives with his mother and two of his four siblings. Hugo's family has struggled with poverty throughout his childhood. "My mom hasn't had too good of a steady job, so mostly we were on welfare. That's how we were paying our bills, with what our dad gave us, the child support, and the food stamps and stuff like that was a lot of what helps us get by." For a period, Hugo and his mom and siblings were homeless. He said, "It was actually all of us... my mom had a van and we'd have most of our belongings in it, and then at night we would go to a shelter and sleep there and then eventually my mom had us move in with some friends." After moving homes and schools several times over the next few years, Hugo's older siblings started helping out with bills, and things smoothed out a bit. Even though Hugo continued going on outings with his Friend during this period, he was reluctant to share too much, "The whole time when we 
were homeless, I think I was like, at that age, I wouldn't, I wouldn't think it was something to share just 'cause I think I would have thought I would get us in trouble or something like that."

\section{Jacquie}

Jacquie is a 17 year-old three-sport varsity athlete. She excels in basketball, volleyball, and track, and plans to go to college with scholarships for throwing the javelin and shot put. She has had two mentors in her 11 years in the Friends program-Michelle during $1^{\text {st }}$ through $6^{\text {th }}$ grade, and then Sharon for the last five years. She remembers the first time she met Michelle, “My mom was like, 'You're getting a mentor,' and I was like 'What's that? I don't want one,' and she's like, 'No, it's fine, like they'll help you with school,' ‘cause I was like really struggling. My mom was working two jobs so-so she came over and she brought this Dragon Tale coloring book to my house and I was like, 'How does this lady know I love Dragon Tales?' and then I just sat down and colored and we talked and she told me all this stuff that we were like going to do and I was like, 'Oh, okay this will be cool.",

During elementary school, Jacquie loved making crafts, especially bracelets, and attending church events. Even though she has always been close with her mother, Jacquie recalls arguing a lot with her brothers and sisters, which affected her to the point that she attempted to run away from home twice. "My sisters were always gone," she said, "they didn't come over a lot. I didn't see them, and when they did come I would argue with one of them all the time. She made me so mad one day I wanted to run away and I was like 'I don't want to be in this house.' It just, it was mainly just family problems." Jacquie also 
developed some anger problems that presented challenges in the classroom. "My teacher, she just couldn't handle it anymore so I had to go talk to the counselor once a week."

These days, Jacquie's schedule is packed, with practices year round, plus a demanding school schedule that includes three AP classes-English, Government, and Art Studio. Her favorite subject right now is History, but she plans to pursue a career related to law. With such full days, it can be hard for Jacquie to connect with Sharon as regularly as she used to, but the pair makes it work. Sharon "comes faithfully" to Jacquie's games, “If I have two games a week she's at least at one of them. She makes time, and she'll tell the girls like, 'Well, we're going to Jacquie's basketball game so if you want to go see a basketball game then you can come. If not, I'll pick you up another day." Even without scheduled times to meet, Jacquie and Sharon manage to see each other every week, and they still attend church events and retreats together. "We just never have a dull time," Jacquie says with a smile, "We always have something to talk about."

\section{Sarah}

Sarah is a 16 year-old with significant literary skill and experience. "I enjoy English, writing, art and stuff like that. Short stories. I've wrote an entire book. And some poetry....most of my poetry is about what the characteristics that come out a lot are like. First, I start off a point with like, 'this is really depressing' and talking about my past, and then I keep going and it gets brighter and it's like, talking about how I grow constantly." Sarah has had four Friends over the years, and for the past five years has been matched 
with Becca. She also has a boyfriend who she has known for six years, and who she considers her best friend, "It's actually a really good relationship because he's kind of broken 'cause of a bunch of things that happened in his past - and so was I, still kind of am-but when I'm with him it's like together we're growing and being there supporting one another, you know?"

Sarah has had her share of struggles, too, including one traumatic life event that is still too painful for her to talk about. Sarah's home life has been difficult, she said, since early childhood and she prefers to spend time with her friends at the arts center she attends or hang out with her boyfriend and his family. When talking about what it's like to be at her house, Sarah says, "It's just dysfunctional and no one really talks to each other, and if they are they're insulting each other or doing something else that's just not nice at all...I feel kind of scared, hurt, like scared and hurt and just, alone." However, Sarah sees art as a way to help herself heal and grow, and to help others who are having a difficult time. She said, "What I really want to be able to do, like when I'm older, is I want to be able to take that art and poetry, somehow get out of the hole that I was in, keep going up, and then show people that it's not impossible and try to inspire them to keep trying."

\section{Dante}

Dante is an 18 year-old high school senior who writes and performs music and poetry, has already secured several scholarships for college and is in consideration for several more. He is a voracious reader and a big fan of all kinds of music, from Johnny 
Cash to Childish Gambino to Killswitch Engage, and he puts a lot of thought into how his clothes reflect his personality. He said, "I like to color coordinate. It makes me feel like I'm on top of the world. It makes me feel like I'm in control of myself...color represents my mood during the day, so I'll be like, 'Okay, I feel kind of red right now." Dante plans to use his skills and creativity to become a video game designer. Video games have been an important outlet and escape for Dante during difficult times, which have come way too often for him over the years. "You get to be led into a character's perspectives of his journey," he said, "so it's kind of like, okay, so I'm kind of away from everything that's going on with me right now when I play this game. And from there I'm entranced with the story, entranced with the plot, entranced with the characters. I'm feeling what the characters are feeling, and it's made me forget what was going on for that moment in time, so it kind of helped me out through tough times."

One of the major challenges in Dante's life has been his experience in foster care. "I really didn't have childhood," he said, "and the reason why I didn't have a childhood is because my mother wasn't really there — and that's why I'm in foster care." Dante described experiences of being locked out of his own house, of being punished by withholding food, and of being physically threatened by his mom's husband. Dante also shared that "something really bad happened to me before sophomore year," and that traumatic event and his mother's unwillingness to believe or protect Dante was what led to his removal from his mother's home. "I can't verbalize it," he said of his mother's response to the situation, "It was completely off the chart...completely polar opposite of what I needed. I wanted a mom, who would have been there, came up to me and said, 
'I'm sorry, Dante, this happened to you,' gave me a hug. No, she just completely blew that off like she didn't care about me at all."

Dante has found strength in self-expression through his music, a sample of which he shared with me during the interview. He got out his laptop, queued up a song, and played a smooth instrumental track from the performer Pretty Lights, overlaid with his own impressive rap performance that conveyed his personal vision with references to pop culture, other artists, and some historical and political figures. The line that stuck out to me most during my first listen was one that almost burst with double-meaning, "That's me/'cause I'm a G/express yourself/take a shot/like Martin Luther King." There was a poignant mix of hope and struggle in Dante's music as well as in his own personal story, and as he looked forward to the next chapter in his life, he clearly wondered whether his experiences would finally tear him down, or would they be something that in the end helped to set him free.

Dante has had three Friends in his more than 12 years in the program; first was Travis for four years, then Eric for four more, and now he has been with Jesse for almost five years.

\section{Danielle}

Danielle is a high school senior who is very involved in her community, volunteering regularly for organizations like the food bank, Meals on Wheels, and a retirement community to help feed people that are hungry. She is looking forward to studying social work in college and then working with children, maybe as a counselor. 
Danielle is also a multi-sport athlete who enjoys football, wrestling, basketball, and running track. She is positive and optimistic despite having faced some significant challenges in her life. She has had difficult family relationships, challenges with peer pressure, and was sometimes left to fend for herself at a young age. She has not always enjoyed school, but has made use of tutors and other resources, many provided by Friends of the Children, to make it through to graduation.

Danielle has had one mentor, Maria, for the entire 12 years she has been in the program. Danielle says that her relationship with Maria was particularly important during a move from the city to a more rural community, "I lived in [the city] my whole life and I moved here in seventh grade and when I moved here, I wanted her to be a part of my life because I love her, like she's like my aunt or something."

Danielle recently reconnected with her biological father and sister after not seeing them for most of her life. Although the conversations with her dad did not go well, and she has since ended communication with him, her relationship with her biological sister has blossomed. Danielle talks to her sister almost every day now, and plans to visit her for the first time in person in the next few months. "She is the closest person in my entire family to me...relationship-wise," Danielle said, clearly enthusiastic about this new relationship and positive family connection.

\section{Karin}

Karin is an 18 year-old high school senior who plans to become a high school history teacher. Her childhood and road to graduation have been difficult, starting with early childhood experiences of neglect and sexual abuse. Although she has only vague 
recollections of her early years, she remembers her mother being depressed and unable to find work. She started in the Friends of the Children program in first grade, just as she was moving from the custody of her mom to the care of her aunt. After that, she recalls, “I really didn’t really see my mom and my grandma anymore." Life with her aunt was not much better, as she and her siblings endured physical violence and other challenges, like her aunt often yelling and pitting one sibling against another. Just last year, Karin's aunt kicked her out of the house, and Karin spent more than three months homeless, moving among friends' houses, and experiencing a significant drop in her academic performance from which she still hasn't fully recovered.

Karin identifies as a lesbian and has struggled with the difficulties of coming out to her family members and peers. When she connected with a group of other LGBTidentified friends in high school, she felt like a social outcast and was often the victim of harassment. She said, "We had people come up to us and be like 'Oh, do you think I'm sexy in the locker rooms?' And there was this one time, some kid poured Gatorade all through my clothes, my gym clothes, so that I didn't change and then I'll get knocked down points... And there were a couple times when my friends got pushed down the staircase or something - it was really harsh stuff."

Today Karin has self-confidence and direction, and is working with Therese to develop an independent living plan for when she turns 18, which includes support for finding housing and other vital resources. Karin mentioned that she recently wrote a letter to the founder of FOTC thanking him for providing this program for youth, "because 
without it, I'd just be in such a different place." Karin has had three mentors during her time in the program, and has been matched with Therese for the last three years.

\section{Alex}

Alex is an 18 year-old high school senior with a strong interest in mechanics, engineering, and technology. He has been excited about reading since his Friend, Travis, who he has been matched with for more than 12 years, first took him to browse books at a book store. An initial preference for Mad Magazine and Garfield eventually gave way to an interest in Popular Mechanics and Popular Science. When I asked him about his latest reads, he said, "Manuals on machinery and engineering, stuff like that...you know, aerodynamics, propulsion systems." Alex is also very intersted in robotics, computer programming, and military technology, including defense and weapons systems, and recognizes the earning potential of expertise in these highly technical fields. As he continues to develop his knowledge and skills, he would like to own a machine shop, and use that space to invent and market new products.

Alex spent some of his early childhood moving in and out of foster care. He said his mom has struggled with mental illness, and has been confined to institutions a number of times. He remembers her being "dragged away" one time, and "that's when [Child Protective Services] got involved, the foster homes, and stuff like that.” Alex describes his dad as "a good man" who is important to him, although Alex is also aware of some of the more dubious lessons he learned from his father along the way. "Let me give you an idea of me and my dad's relationship," Alex said, "When I was nine years old, he taught 
me how to throw knives." In addition to taking five years of taekwando and kung fu, Alex adds that his dad also "taught me to fight dirty." Although Alex sums up his dad's interests as "cigarettes and cold beer and fast cars and stuff like that," Alex appreciates the limited time they do spend together, "It's cool. We hang out. We watch TV from time to time."

Alex's grandmother eventually adopted him and has been his primary caregiver ever since. These days Alex takes on many adult responsibilities around the house, including building a fire each day, carrying heavy things for his grandmother, and doing the laundry each week. Alex clearly takes pride in his domestic contributions and in his knowledge and talents. He appreciates the ways that Travis has actively supported his learning, and he knows that Travis is proud of him, too. Alex had a big grin on his face when he said, "Yeah. He's proud that I'm intelligent. Not many 18 year olds can tell you about hydrogen fuel cell technology." "That is very true," I said.

\section{Deion}

Deion is a high school senior with one English class to go before graduation. Deion plays basketball and football and would like to explore flight school after graduation. He has had three mentors in the FOTC program, the first two for three years each, and now he's been with Emmett for the last six years. Deion's main goal in life, he says, is to have "a nice family... a nice house, a nice daughter, and a wife. I want life to be easy." Deion's life so far hasn't been easy at all. His mom, he says, "is super bipolar. She's always happy and mad all the time. We have a love-hate relationship. At times it 
will be cool, next one will be bad. She yells a lot." After Deion's $8^{\text {th }}$ grade year, his mom moved to Louisiana and he stayed behind to live with his grandparents.

Deion's father was absent for most of his life, but has recently started calling Deion to try to reconnect, which has been both good and difficult. "Me and him, I don't know. He's weird... I know his my dad technically, but there's a difference from being a dad when I needed a dad. I don't feel comfortable calling him dad." Even with the uncertainty, Deion said he knows his father is trying, and "I can tell he's trying to build a relationship...he's getting better." Deion spend his free time doing the things that many teenagers do, "hanging with friends, hanging out with my girlfriend, playing video games, and all that." He remembers very clearly his first summer in the FOTC program, when his new Friend helped enroll him in a summer school program and, "and then every day after summer school he'd pick me up and we'd go to Jack's Chicken. We'd get chicken nuggets every day. I remember I called him every single day. Saw him every single day. It was crazy." After his second Friend left the program to become a helicopter pilot (a career Deion is considering), he was matched with Emmett, who has been his Friend for six years

\section{Sean}

Sean is a high school senior who wants to train to be a firefighter, or "something that positively impacts someone's life...I wanna be someone that someone says 'wow' and looks up to." Sean enjoys exploring new music, and says that music is one thing that he remembers being important through every stage of his life. Another thing that is 
important to him is food-“"Just food. Good food. Food is my thing. I love food. I know so many good food places." One of his favorite things about Portland is the variety of foods and restaurants that are available. Sean lives with his parents, with whom he has a close relationship. He describes himself as a "momma's boy" and says his dad "is the chillest dude you'll ever meet." In the last few years, he has begun to appreciate the time that he and his parents spend together. He said, "I've been trying to just hang out with my parents as much as I can whenever I see them. I make sure I spend extra time. Okay, I got 20 extra minutes to spare, I'm gonna use those 20 extra minutes because anything can happen at any moment." With this kind of caring personality, it is not surprising that Sean says he makes friends easily and can connect with people in almost any group or situation.

Sean got his first Friend a few years after his sister started in the FOTC program, so he was ready to get started, too. "From the beginning I was like, this guy looks awesome. I'm definitely gonna get along with him," Sean told me, "I was really stoked at the fact that [he] was African-American, big mustache and handle bar, just really thick, and then he had a huge 'fro and I was like wow...this guy really looks goofy, got really big brown eyes. He's just a really friendly person, approachable...I was like sweet, I'm excited to see what this guy has in store for me." For the last seven years, Sean has been matched with Jesse, who Sean remembers teaming up with to play video games on their first official day together. He said, "It was me and him versus Jeff [another Friend] and this other kid. This was my new mentor so we're bonding over it. We're a team now and we were just destroying and really out there — standing up, like 'in your face,' really 
getting down on this game and stuff. We still make jokes and reference back to that day. It was big. It was a really good start."

\section{Kianna}

Kianna is currently enrolled at a local community college in a program that will allow her to finish her GED and take courses she will need to enter a two-year degree program. Although she is not sure what career she is headed for, she is happy to just be back on the right track after several years of being disconnected from school. Kianna dropped out of high school during tenth grade when her son was born, and several attempts to get reengaged didn't work out. But now her son is her main motivation to get back in school and finish a degree. She said, “Now it's like, I'm no longer a kid. I don't really have my parents to take care of me and do this. I've kinda been doin' it on my own forever. I just have to finish, because I have a son, and I have to get a good job. I have to finish school and maybe things will be easier for me. It's the only way I feel like things will get any easier. So that's like one of my main focuses. If I finish school, then I'll be alright because I can get a good job and I can take care of my son like I want to. That's like my main motivation."

Kianna grew up in a home with her mother, a single parent who often had two or three jobs in order to support her family, and her three older sisters. Kianna remembers her mom, "was never home," and even as early as second grade, Kianna remembers being discouraged by her mom's lack of recognition of her accomplishments. She also said that her family often told her she wasn't smart and wouldn't amount to much, and 
her sisters teased her and made fun of her when she succeeded and did well in school. Now Kianna has renewed determination, and has good self-awareness about some of her challenges, including an inclination to quit when things get difficult. She told me, "To this day, I sometimes I feel like I'm just going to give up and quit because things just get so hard. I'm good for quitting. I am. I've done it before, but I get back up and I'll try it again. And then maybe I'll quit again, but I'll just keep doing it over and over again. I'm never consistent, but that's what I'm working on this year-I'm trying to be consistent and more responsible and get into school and finish.”

Kianna has had two mentors during her time at FOTC, and has spent the last 10 years with Trayvia, who Kianna says has been there for almost every important event that she can remember. "Unless I done it with her..." she said, thinking back to trips to the zoo, the movies, and shopping, "then I never done it before." Kianna said that over time she has developed confidence in her interactions with other adults, "Everywhere I go, I form some type of relationship with somebody. I don't know what it is, but I'm very friendly, and nobody forgets me, and I don't really forget them either."

\section{Introduction to the Findings Sections}

Chapters 7 through 10 present the main findings of the study. The findings have been divided into four major categories, which constitute global or overarching themes that were centrally important in the participants' experiences of their long-term mentoring relationships. The four themes are:

1. The experience of unconditional support and commitment; 
2. The experience of help in difficult situations;

3. The experience of identity development; and

4. The experience of expanded opportunity.

Within each category, several subordinate themes are described that represent a particular aspect of the global theme. The subthemes are presented as subsections in each chapter, and are outlined in Table 3 below.

Table 3. Themes and Subthemes in Findings

\begin{tabular}{|l|l|}
\hline Theme & Subthemes \\
\hline Unconditional support and & - Just being there \\
commitment & $\begin{array}{l}\text { - Personal characteristics of Friends } \\
\text { - Logistical support } \\
\text { - Financial support }\end{array}$ \\
\hline \multirow{3}{*}{ - Challenges related to unconditional support }
\end{tabular}

Quotes directly from the participants are provided throughout the findings sections to help illustrate the themes and categories that have been identified. Some of the quotes in the following chapters are quite a bit longer than quotes found in other 
phenomenological studies. I believe including the longer quotes in these cases provided important contextual information that made the "meaning units," the words or phrases that best describe the essence of the lived experience under consideration, even more poignant. In the cases of longer quotes, I bolded the text of the meaning unit to draw explicit attention to those particularly illustrative words and phrases.

In addition to the description of the themes and the corresponding participant quotes, three interpretive elements are included in the findings chapters to help the reader get a better sense of the researcher's perspective on the concepts being introduced as well as the depth and character of the participants' responses as the interviews were being conducted.

The first interpretive element is additional commentary provided for each theme and subtheme, which is intended to deepen the discussion beyond the surface to identify more complex meanings behind participants' experiences. The commentary offers my personal perspective and observations to complement participants' statements by highlighting connections between multiple participants' experiences and describing conceptual links between themes and subthemes.

Each chapter also begins with a poem that I created using verbatim words and phrases from participant interviews that highlight, in a different way than prose can, the emotional experiences of participants related to their relationships with their Friends. The poems are themselves interpretations of experience, and thus are not subjected to further analysis or explication. Instead, the poems are meant to speak for themselves, to evoke responses in the reader that can only be achieved through the power of poetry and its 
creative rhythms and devices. I believe the poems also offer a compelling point of departure for the analyses and interpretations that follow in each chapter. 


\section{Chapter 7: "No Matter What":}

\section{The Experience of Unconditional Support and Commitment}

Me and Him

At Powell Butte with the kids, just biking up there, around a corner and they take a left straight down the hill.

If I lose my footing I'm done for.

There's jagged roots coming out of the ground, I lose my footing, I'm like this, flying all the way down the hill.

At the end of it is a log and I hit it, front wheel. I go soaring about ten feet, land in a bush of stinging nettles, bike lands on top of me and I get up.

We were all there, just dying.

I've got blisters from stinging nettles, But I don't feel it 'cause of the adrenaline rush.

He gets some ferns and if you rub ferns on stinging nettle blisters, it'll actually numb the pain.

We just sat around for a couple minutes, cracking up. I got my breath, kept on biking for another three hours, all the way around that place.

A few tears of pain but mixed in with the laughter.

That's me and him right there.

I get hurt but we laugh about it. 
In the current study, one of the most common experiences among participants related to their long-term mentoring relationships was the sense that their Friend was there for them unconditionally, or as Sean put it, "We're definitely friends for life no matter what." The experience of unconditional support and commitment manifested itself in many different ways, and in the following sections I will attend to some of the most important ways this support was understood by participants in this study.

\section{Just being there}

One of participants' central experiences related to unconditional support was the feeling or sense that a Friend is "there" at all times. "Being there" of course does not imply physical presence, nor does it even mean that Friends are always available in a literal sense. Rather, participants perceived friends as perpetually and existentially "there" - in the form of a permanent resource that transcends defined boundaries and constitutes (to borrow a concept from Gabriel Marcel) "extravagant availability” (see Macquarrie, 1973).

Gabriel described the presence of his Friend like this: "Any day of the week, I can count on them. It's good to have someone to fall back on. It's good to have someone who's going to have your back...Having someone to back you up. You're always going to have a friend with Friends of the Children. It's definitely something powerful on its own. Always going to have someone you can trust, always having someone you can go to and talk to, always having a resource." 
In this case, when I asked Gabriel to describe what was it was like to have someone to fall back on, he said for him it was important because, "again, you know, I didn't have too many friends," and "my dad was in the hospital a lot," so Emmett's presence "pretty much cheered me up...brightened my mood if there was problems going on. It helped a lot." The experience of having a Friend was a positive boost in a difficult time, when there was no one else available to help Gabriel take his mind off his problems and feel better for a little while.

"Having” someone's "back," as Gabriel and other youth put it, is a sign of loyalty and trust. It suggests that one person is looking out for and protecting another. When someone has your back, you can move confidently forward without fearing that the unexpected might ambush you from behind. For youth in this study, family turmoil, educational challenges, depression, PTSD, and substance abuse were among the dangers that threatened their well-being, that threatened to catch up to them and possibly overwhelm them if there was no one there to have their back. Sean was struggling in school, for example, but said that Jesse "still kicked it with me as if I was getting straight A's, and was still encouraging me to be better...He still had my back."

Candace's involvement with gangs was the thing that threatened to catch up with her. "It was crazy," she said, "I felt like I was in over my head." Even for the couple of years she was involved with a gang, Candace still met with Naomi every Thursday, and "those were the days I looked forward to" Candace said. Like Emmett did for Gabriel, Naomi was the consistent positive presence during a time when she felt like she was in danger of being overwhelmed. 
The sense that Friends are "always there" is illustrated by several participants" descriptions of extreme hypothetical situations in which they would be confident of their Friend's availability. Danielle said that she and her mom sometimes got in fights, and that, “...if I called [Maria] — and I live far away from her — and if I wanted her to pick me up at two o'clock in the morning, she would, no matter what. I'm pretty sure if I was in jail she'd bail me out of jail too, but, having someone, another adult there for me that actually cares about me..."

I asked her, "Did you ever call her at 2:00 in the morning?"

She said, "No, but I could."

Even without having the actual experience of these hypothetical situations, Danielle had the very real experience of feeling supported "no matter what," of knowing that an adult "actually cares about me," of understanding that her relationship provided support in a way that would otherwise be unavailable. Danielle then shared explicit promises that Maria made to her that reinforced this point, "She always says that if I ever get knocked up or whatever, that I could call her and we'll figure out what to do. I would never get an abortion, but if I wanted to then she would support me-or if I wanted to have the kid, she'd support me..." Again, in this case it is not important what the hypothetical situation entails, but rather it is Danielle's experience of full faith and confidence in her relationship that reveals something significant about what a deep and long-lasting connection with a mentor provides. 
While participants used extreme hypothetical stories to indicate the extreme level of trust and confidence they had in the support of their Friends, in fact many extreme situations did arise for youth in which the help and support of Friends was essential. For some youth, that trial by fire was necessary; Friends had to prove over time that they were truly committed in order to gain the trust and respect of youth. For others, though, it was never necessary to encounter extreme situations to experience the utmost level of confidence in their Friend. Over time, day by day, and eventually year by year, the genuineness and consistency with which most Friends engaged with youth translated into an unshakable confidence in their relationship.

Danielle also experienced the power of being able to trust her Friend despite growing up in an environment that caused her to generally distrust adults:

When I was a kid, I had a really bad trusting problem and I expected her to tell my parents if I did something wrong. I expected her to tell my parents and I didn't necessarily want that, so I kind of like hid things from her. But now she's the only person in the entire world that I can talk to and I absolutely know...she will always be there for me, even when I'm thirty years old and I'm like 'Hey, want to go out for coffee?' She's going to be around. Now I have no problems with having a mentor.

One transformative experience Danielle described involved smoking a cigarette with a peer when she was around nine years old. Danielle said, "Sally'd be like, 'You can tell us anything,' and I told her... and I stopped because she was worried; she's like, 'I 
don't want you smoking." Danielle realized that Maria's care and support was not threatening, that she would not get in trouble for telling Maria about her choices, and that she could trust Maria to be supportive and helpful in difficult situations.

As Danielle indicated, knowing that Friends would be around long-term, not just as mentors in a program, but as important life-long allies, gave youth a sense that the investment of time and emotion in the program would be worth the effort. Karin also identified the long-term investment Therese has made in her life as an essential component for her developing trust. She said:

\section{So, if you know somebody is limited, you're not going to put your effort into}

that as much. If you think it's forever or for even 12 years or more, then it's like, 'Okay, yeah.' But if you think of, 'I'm willing to have you for like 3 months or 2 years,' there's going to be this block. You're not going to want to go the distance all the way. If you have somebody who's there for 12 years, like 'Uh, fine. If you're gonna be around for 12 years, I might as well put some effort into this.'

In addition to the general sense that Friends are consistently present and available, there were several other important elements of these long-term relationships, including some of the specific personality characteristics displayed by their Friends, that participants identified as being particularly important to their experience of Friends' support and commitment. 


\section{Personal characteristics of Friends}

Participants identified several personal characteristics of their Friends that helped facilitate the development of a sense of trust and commitment in the relationship. One characteristic was responsibility. Gabriel said, "They will always be on time all the time, they'll always be responsible. If there's a delay, they'll call the parent-even for parents like, parents worrying about their kids leaving with a stranger. There is no problem at all. All of these people are really hand-picked, you know?" Gabriel experienced Emmett's dependability and responsibility in several situations when he needed a ride to an important commitment — he mentioned specifically dentist appointments and getting to a job. Gabriel also felt that Emmett and his previous Friend were firmly committed to his academic success. He said, "If I'm having a problem I can't figure out, 'How does this work?' you know, 'How do you flip the equation?' or whatever...they'll sit down with me step by step...they will work it out with you as long as it takes."

In Gabriel's words, one can hear the sense of confidence in Emmett's level of responsibility as well as an expectation of this high standard of conduct. Friends are not good people just by chance - they are selected for those qualities that youth need and appreciate, and Gabriel was not the only one to express this view. Other participants described reliability and dependability as particularly important qualities that their Friends exhibited. Karin shared a story about her aunt calling up her Friend, Therese, and "yelling at her" because her aunt thought their weekly outings were interfering with Karin's chores at home. Karin feared that this experience would threaten the stability of her relationship with Therese, but, "She didn't go away. I was really afraid that she 
would go away then. And she didn't — so okay. So, it really is important for me in the trust issue." Support, for Karin and others, meant that Friends would maintain their commitment to the mentoring relationship even in situations that challenged both the Friend and the youth.

Although being responsible, reliable, and dependable are qualities that one might reasonably expect from a professional mentor, especially given that these characteristics are important and to some extent expected in most professional settings, it is important to consider under the circumstances the duration, intensity, and inherent challenges involved in the relationships at FOTC. One would imagine that there would be an endless amount of risk for disappointing youth, of not being there when they are needed, of letting someone down in some way. While disappointment certainly happens sometimes, participants very rarely mentioned any of these instances, and they never described these events as typical or particularly noteworthy. Instead, youth were much more likely to say things like Gabriel said, "I don't think I've ever been angry at a Friend for anything they did."

Participants identified other personal qualities that facilitated meaningful connections in their relationships as well. Gabriel, Sean, and Alex all said that sharing a sense of humor was a central aspect of their relationships with their Friends. Gabriel said, "We share the same sense of humor and sense of sarcasm. We watch and read a lot of the Onion News Network. Man, that's funny, we will sit there and crack up for five minutes at a time... and we talk the same, well not maybe the same, but..." 
"You influence each other in that way?" I suggested.

"Yeah," Gabriel replied.

Sean said that he and Jesse have developed a sense of humor together over time, and he sees their shared sense of humor as an indication of greater similarities, "We have the same sense of humor. As I grew up we started making jokes, the same things, kinda thinking the same way. It was pretty cool." A shared sense of humor for Gabriel and Sean suggests a deeper connection, one in which each youth has a partner who can relate to them, understand their perspective, and appreciate what they think and what they say. Youth with this connection can see that their Friend, a successful person whom they look up to, is not so different from them.

Shared interests developed into a sense of deep connection for many youth, and while a shared sense of humor was the entry point for some, others found connection through a shared love of art, music, video games, food, animals, and other things. For Jacquie, a shared spiritual faith has been a cornerstone of her relationship with Sharon, "I do a lot of church activities with Sharon because we're both Christian...we talk about church a lot." The faith that Jacquie and Sharon share provides an outlet for Jacquie to discuss topics that are important, and sometimes confusing, to her. When she learned about evolution in biology class and discussed the Scopes trial in history, she thought, “Oh my gosh, this doesn't go with my faith...everything I learn in my faith, nobody does this anymore...so I really just talk to her about that, we talk about that a lot, like which one is true." Even in these deep and sometimes difficult conversations, Jacquie has no 
doubt that she can trust Sharon to be honest and supportive. "There's definitely no holding back when it comes to talking to her, like if I'm going to talk to her, I'm going to talk to her and I'm going to tell her everything. And I know she'll tell me how she feels about it."

Sean said that he and Jesse initially bonded over a love of music, and that led to the pair exploring and finding other interests in common:

Just recently we went air softing with air soft guns. This weird tactical adventure kind of thing. It was cool. We had a nice little bonding... we had layers and layers 'cos we were running around in the forest and stuff but it was really cool 'cause he's on my team. We got to act all tactical and stuff, and both of us were getting into it like we're on this real-time war kind of thing. Like making little hand gestures and stuff in the woods. It was a really cool experience.

The airsofting experience for Sean revealed multiple layers of connection between him and Jesse, layers that go deeper than shared interests to reflect a sense that he and Jesse are a team, that they share a secret language, have the same goals, and are "fighting" together to succeed in their mission.

Given the Positive Youth Development foundation of the FOTC model, it is not surprising that the experience of connecting with a mentor through shared interests was common across youth in the study. The PYD "thriving" framework used by FOTC was developed by the Search Institute (Benson \& Scales, 2009), and includes specific attention to helping youth find their "sparks," the gifts and interests that motivate youth 
to pursue their goals. However, even though the program model includes attention to the "sparks" of participants, youth experienced the implementation of this strategy as a real and genuine personal investment by Friends into their lives. In other words, even though one can discern the programmatic influence that focusing on "sparks" had in these longterm mentoring relationships, the lived experience of connecting to Friends through their "sparks" was a rich and organic process that revealed a deep sense of trust and personal connection.

\section{Logistical support}

Along with the listening, validating, sharing important interests, offering advice, and other intangible aspects of "being there," youth also described the experience of being able to count on Friends for many concrete forms of support. Friends often provided transportation to offer youth access to all kinds of resources and opportunities, from medical and dental care to extracurricular activities. Gabriel said:

Having Emmett around or having Paul around really, really helps when you need something. Anything really. Anything, they'll answer the call. If I need a ride somewhere, if I need a ride to a dentist. Any day, any day of the week, if I need to go to a gig, a deejay gig-I deejay for school dances, you know? Any day of the week, yeah, I can count on them. It's good to have someone to fall back on.

For youth experiencing poverty, sometimes seemingly small inconveniences can translate into major challenges that mean the difference between playing a sport or not, attending social functions with peers or not, getting an after-school job or not. Friends 
"being there" for youth in this instrumental way bolsters feelings of trust and unconditional support, as Gabriel mentioned, but it also facilitates another aspect of the long-term relationship that participants identified as centrally important in itself - the experience of expanded opportunity—which will be discussed further in Chapter 10.

Sometimes instrumental support went beyond expanding extracurricular opportunities for youth - sometimes it was a matter of life and death. When Hugo was going into eighth grade, he started to experience blackouts:

It kind of happened a few times and then it happened more regularly, so we made an appointment at a clinic, and then me and my mom went and then they told us to go to this other place to get an MRI scan. Yeah, and then Derrick took us there, and then he would just give us a lot of rides when we needed it — and I guess I had a tumor in my brain. I didn't know what it was doing, but that was the cause for my blackouts, and I had to have surgery to get it removed.

After the surgery, Derrick continued to help out in very practical ways. "We don't have a car at home," Hugo said, "and Derrick sometimes helped us, going to get groceries or giving us a ride somewhere...just staying on what I need to be doing or checking and getting my check-ups and stuff like that." Hugo then shared that he would "feel a little weird" asking for help from his family members, and that Derrick is "the main person to go to." 


\section{Financial support}

Friends were also able to provide financial support through the FOTC program to make a variety of opportunities possible for youth that would have been out of reach otherwise. Deion described this financial assistance as one element among many that created a sense of being fully supported, “If there's something, he'd just share with you. Always talk about school. Help me with homework, teachers, come into the classroom a lot. Yeah, make sure we had everything. Just like today he paid for my permit when I got my permit today. We always talk about school, then he'll ask me about how my mom's doing. How's our family doing?"

Deion's quote illustrates how intricately woven are the physical, social, and emotional elements of care and trust that constitute the sense of unconditional support participants felt from their Friends. When Deion said that Emmett made sure his family had everything, he made no distinction between being physically present to support him in class, asking about his family, or paying for his driver's permit. It's all helpful, it's all supportive, and Deion knows he can count on Emmett for any of it, anytime. Importantly, participants often identified the individual Friends as the source of financial support rather than the organization (e.g. "today he paid for my permit"). Regardless of which bank account the money came from (and Friends did sometimes use their own funds to pay for food and activities), youth experienced the relationship with their Friend as their supportive foundation, the entity they could count on when they needed help. 
Hugo also considered financial support as a genuinely helpful supplement to the other kinds of support he received from Derrick. He recalls several significant opportunities that were made possible by his Friend:

I also remember...he signed me up for some art classes at, I think it's called YArt. Yeah, and then I just remember he would take me there 'cause I really enjoyed art I guess. I liked drawing and stuff, and sometimes he would take me to the southeast house and we would draw. He just helps me out with stuff, like this year at school I started wrestling, and it was my first sport, and Derrick helped me out a lot with that. He got a check from Friends of the Children and they paid for the fee to sign up for it, and then Derrick also was the one that bought me some shoes for wrestling and stuff like that. So I thought that was really helpful honestly.

Danielle and Jacquie both mentioned the importance of Friends paying for sports fees and equipment. Jacquie said that although it may not seem like much, the money that Sharon is able to provide for sports is invaluable:

We have to pay fees for sports, so she'll tell me, 'Well, I know you play three sports,' and they're not really that costly_ 'cause I'm on free and reduced lunch right now — so they're only like forty dollars and sometimes there will be times where I can't get the forty dollars when I need it, so she'll be like, 'Well, just let me know when and I'll talk to Friends of the Children and see if they can pay that part for you,' you know? It's like 'Okay, good,' 'cause I really can't do it right now — especially during basketball, we gotta pay for our basketball shoes, we gotta pay for our little jumpsuits, we gotta pay for this... same thing for 
volleyball, they want us to have these shorts and these shoes, and these shirts, and these kneepads.

Just as Daniel described the importance of assistance with what might seem like minor logistical concerns, Jacquie made it clear that the $\$ 40$ here and $\$ 40$ there that Sharon is able to provide through Friends is not something she takes for granted. In fact, for her it makes the difference between being able to participate in the activities she loves and being left out. And with the multiple college scholarships that Jacquie has earned as a top student athlete, the consistent support from Sharon as Jacquie's number one fan and as someone who can provide financial resources when necessary has been nothing short of life-changing.

Danielle said that Friends of the Children has given her the opportunity to play sports that would have been too expensive for her otherwise, "We never had money for me to play sports or anything, and I've always loved track and basketball and football and wrestling and a few more sports. And if we couldn't necessarily pay for that, they would help us - they would give us the money that was needed." Danielle, Jacquie, and Gabriel all indicated that their participation in organized sports was transformative. In Jacquie's case, varsity sports led to college scholarships and will likely save her tens of thousands of dollars over the course of her college career, not to mention that Jacquie's identity has clearly been influenced by her athletic aptitude and achievements.

Sometimes the financial support from Friends went beyond enrichment activities and sports to include essential items that youth and their families needed. Hugo mentioned that Paul was able to provide some emergency funds while his family was 
homeless. Hugo's mom sometimes didn't have money for food or clothes, and Derrick would request help for the family through the Friends program. Hugo said he's grateful for the things Derrick is able to provide through FOTC when his family is in need: “Another thing that he's done for me, something I'm really grateful for, is the clothes he gets me. He bought me these shoes and he's bought me a few pairs of pants and he got me this sweater and some other stuff-I think these piercings he got me too, so..." He paused and laughed, "So a lot of the stuff. Yeah, Derrick's been really helpful 'cause my mom doesn't really have time or money to take me clothes shopping, so there's a lot more opportunities to go with Derrick if we need it... when it gets cold or something, he's always buying us clothes, too, if we need. I guess for me it'd be a lot more difficult or complicated without Derrick. I think Derrick helped us out when we needed, like with giving us food, not food but gift cards, gift cards and stuff like that. He'd give us those and we had money for stuff we didn't usually have money for." Although this material support was made possible by the FOTC program structure and resources, Gabriel experienced receiving the food, clothes, and other necessities as an element of the mentoring relationship, one that was at times centrally important to Gabriel and his family.

\section{Challenges related to the experience of unconditional support and commitment}

Clearly the unconditional support of long-term mentors was an overwhelmingly positive experience for youth, but there were also several exceptions and challenges related to unconditional support that are important to note. First, a couple of youth mentioned that they sometimes chose not to disclose difficulties to their Friend because 
they did not want to worry or disappoint a person who has invested so much to help them be successful. When someone believes in us, we want to live up to their expectations. When someone genuinely cares about us, we don't want them to worry. So, when Karin got kicked out of her aunt's house and was moving from one friend's house to another, she chose not to be fully honest with Therese about her situation, "I wasn't really as open as I should have been with her about it because I didn't want her to worry about anything." Karin feared being a burden for Therese, a sign of her intense respect for their relationship. Karin knew Therese was there for her: "She always said like, if you ever need a place to shower or something that her house is always an option. She's always really supportive of the fact that I was going through a lot." So the hesitancy to use Therese as a resource, to take advantage of the unconditional commitment that was available to her, was a matter of respect for the relationship rather than doubt that her Friend would be available or helpful. In other words, this kind of challenge did not compromise or undermine Karin's experience of "unconditionalness" in the relationship at all, but caused her to withhold information in order to protect the feelings of her Friend,

Kianna said that when she gets into difficult situations, she tends to hide and avoid Trayvia. When Kianna found out she was pregnant, "I was just scared of disappointment...so she didn't hear from me, and she came to my school a couple times, but she still didn't hear from me. I just kinda hid - hid myself — and I kinda did that with my family, too. I was just scared.” So, while having a mentor who is consistently and unconditionally supportive can be a source of comfort, confidence, and resources for 
youth, it can also cause stress when a youth encounters a situation that they feel might worry or disappoint their Friend. Again, similar to the case of Karin and Therese, there was no sign in Kianna's case that she doubted the support of her Friend. Rather, she was scared to face the unknown consequences of disclosing the information to others.

Another challenge youth reported related to the unconditional support and commitment of their mentors was the confusion or disappointment they experienced when a Friend left the program. Sean said:

I was just kinda getting in the groove being in the program and it was 'Wow, now I got a new mentor.' I wasn't sad or anything. It was a lot of why questions... Was it something that I did? Was it something that he did? Why would they break us up? That kind of thing. I was just kinda confused. I was little and I was, 'Wait, I thought he was supposed to be mine forever,' coz my sister had hers. She's been consistent with the same mentor so I was like 'This is weird.' I just didn't really know what to expect.

Jacquie shared a similar feeling, "It was kind of hard...I wasn't fully okay with it." Jacquie found solace, however, in knowing that she would transition to Sharon, a new Friend but someone she was already familiar with. She said, "I was more comfortable going to Miss Sharon 'cause I had been around her a long time — and some of the girls that I hung out with were Miss Sharon's girls so it wasn't like she was brand new. I was kind of like worked into her little system and stuff." Despite some initial uncertainty, Jacquie's experience of switching mentors did not shake her confidence that the 
foundation of trust she had developed with her first mentor would also be established with her new one. 


\section{Chapter 8: "Kind of Like a Guardian Angel":}

\section{The Experience of Help in Difficult Situations}

\section{A Long Story}

Laughing. Silliness.

It's important.

Why?

Well, that might be a week-long story.

Something bad happened to me and I want you to hear this.

Something had to be done, and she didn't listen.

It's like the polar opposite of what I need.

Like she didn't care about me at all.

I wanted a mom

who would have been there,

come up to me and said,

"I'm sorry, son, this happened to you."

Instead she said, "My husband's coming."

So she had backup and that was the worst thing.

He was like, "Let's fight."

He was like, "I'll beat you up."

Sometimes she wouldn't feed me for a couple of days.

"You should at least feel unconditional love for me,"

I thought. "But you don't care about me."

Something really bad happened to me

But I didn't have a way to tell people.

There was no concrete evidence.

There were no witnesses.

They all hated me, so I was alone.

I was actually clinically depressed.

I actually was. No one really was listening. 
I attempted suicide a couple times, which is, I guess, what would happen.

I just have to tell you now-

I won't survive much longer if I don't tell anybody about this.

From all the stories I told him, he understood.

He understood something had to be done.

He's my friend. I told him

"I know as long as I'm with you I'm fine."

He was there as my support, but also witnessing.

He put things in motion.

I'm still here, so something must be said.

I guess I'm not supposed to die yet.

There's something I have to do-

I'm excited for that.

I learned to be myself.

I'm making music,

I make songs,

I make poems.

We laugh and just be silly.

We also talk about serious stuff.

We just basically do everything,

which is cool.

The reason why we laugh a lot

is because I really didn't have a childhood.

What does it mean to be a friend?

Well, that might be a week-long story.

Every participant described difficult moments or situations in which they felt their mentor was absolutely essential. Usually, these were major life-changing events, like being moved into foster care, suffering abuse, becoming homeless, or getting expelled 
from school. Several participants described difficult situations with peers that Friends helped them navigate successfully, while others encountered serious challenges with family members that needed to be addressed. These critical situations tested the limits of these long-term mentoring relationships, and participants were, without exception, pleased to find that the bond between mentor and mentee was strong enough to persevere and to help them make it through even the most difficult times.

\section{Difficult peer situations}

Sarah said that her relationship with Becca helped her gain perspective and confidence when she encountered difficult situations with peers. She said, "I was having this problem with a friend because he was always planning things with me and then something would come up and then he wasn't able to, and after a while it seemed like he was doing it on purpose. And then Becca was telling me how I needed to talk to him to tell him how this is hurting me and stuff."

“And how did it work out?” I asked.

Sarah responded, "Pretty well because then the next time we planned something he followed through. I think if she didn't, it might have continued. And then I would've just kept being disappointed over and over again.”

As Sarah continued to describe what her relationship with Becca meant to her, she admitted, "I still have some issues with confronting situations 'cause I don't want to end up hurting anyone's feelings if I tell them they're doing something wrong, and I know that a lot of people if you try to tell them even calmly they will scream and yell 'cause 
they don't want to accept it, so I have some problems with that, but because of Becca I have an easier time expressing those issues to them." Through the mentoring relationship, Sarah experiences confidence and an ability to confront problematic situations that would otherwise go unaddressed and unresolved.

Like Sarah, Alex experienced an inner strength through his mentoring relationship that allowed him to resolve problems more effectively. Unlike Sarah, however, Alex was the victim of regular bullying in elementary and middle school, and rather than ignoring or avoiding the problem, he sometimes considered using violence as a response to his victimization. Alex said:

At the time...even before I was going to get thrown out, things were bad, you know. People were picking on me plus with my prior and all that, combat tactic skills, weaponry. That kind of scared me a little bit, like I didn't want to do nothing, but at the same time, I want to make the son of a bitch pay, you know. But it just passed, you know. I still want to flip him off whenever I see him...but the sweetest revenge of all is to live. That's my goal. That's what keeps me sane. That's what keeps me doing what I do, doing what I love. Yeah. That's when you really appreciate solid relationships.

Me: I'm so tempted to describe your relationship in some sort of metaphor like...you and Jack interacting in these ways that, you know, have resulted in him being a certain way and you being, it sounds like...pretty successful. 
Alex: That's something that I've definitely developed. I didn't always have this sort of resilience.

Alex was clearly pushed to the point of considering drastic measures to stop his tormenters from continuing their bullying and abuse, even considering the use of weapons as an option. However, with Travis there to help him navigate this potentially grave situation, Alex was able to persevere, and to find ways of channeling his energy into positive activities instead of destructive ones.

For example, when Alex started middle school, at a time when the bullying was particularly severe, Travis started taking Alex to the gym to exercise and lift weights. Alex lost weight, felt strong, gained self-confidence, and managed to successfully overcome the experience of being bullied without harming himself or anyone else. He said of that difficult period:

That's when we went to the gym a lot. That kind of helped me get out of my head as well...Just go exercise and just forget about it, you know, because like I said, I used to be kind of the fat kid. Now, as you could see, I'm kind of, you know, big. Yeah, I'm not bad off. I actually got better physically. Along with physical fitness, you can also like - I don't know. Physical fitness has some sort of effect on your mind that it also tunes up your mind, you know. Helps your brain to function.

Me: So you think all of that worked together like to build your self-confidence? Alex: Yeah, pretty much, and my psyche. 


\section{Problems with drugs and alcohol}

Several youth discussed their use and abuse of alcohol, drugs, and other substances, and described the role that their relationships with Friends played in supporting them and helping them to make healthier life choices. Danielle described her experience with smoking cigarettes at age 9 or 10, just when she had met Maria. "When I first met Maria," she said, "I met a girl named Erika, and she became my best friend "til sixth grade, and her family was not a good example of like, they did drugs and drank all the time and stuff, and as a nine year old my friend started doing it. She persuaded me to start smoking and do what she was doing, and when I moved out here, we were still best friends...she was ten years old, she had already been pregnant twice, and did major drugs, and Maria was just like, 'You don't need that life.' I loved my best friend, yeah, but I need to make my own life. I need to have a life.”

I asked what role Maria played in that decision making process and Danielle said, "She would like talk to me about what I could do, asking her like, 'Will you please not try to make me do the stuff you want to do?' or try to make her not peer pressure me, and saying what I should say to her. Or she would talk to my friend and say, 'Well, I don't think you should be doing that, but it's your life. I can't decide what you do, but you shouldn't be causing harm for anyone else, but you're doing it."' For Danielle, this intervention by Maria on her behalf gave her a chance to end that friendship, and Danielle said, "We haven't talked in like three years and I'm glad, 'cause I'd probably be messed up and in jail or pregnant." 
Candace struggled with the pressure to drink and do drugs as she entered high school. As mentioned in Candace's brief introduction above, there was a time during her transition from middle school to high school when she drank and smoked every day, sometimes skipping school and sometimes going to class drunk or high. She said, "At the end of my $8^{\text {th }}$ grade year, that whole summer I pretty much ended up getting introduced to just everything, drugs, yeah, all of that. I had already kind of been drinking before that, but then...it was pretty much the beginning of a new stage because by the time my freshman year was over, I was drinking a lot." Not surprisingly, Candace's drug use negatively affected her academic performance, until "by the end of my sophomore year it got worse, it was getting a lot worse, 'coz I was dropping out by my sophomore year."

Candace's Friend Naomi was a constant and consistent presence throughout this difficult period in Candace's life. Unlike Maria's direct advice and intervention with Danielle, Naomi did not directly confront Candace or the group of peers with whom she was using drugs and missing school. Instead, she just made sure she was there when Candace needed her, and through her presence demonstrated that the kind of commitment that was really helpful and truly important for Candace was the kind provided by a loving Friend. After having a fight with several peers, Candace called Naomi who picked her up and gave her a ride to the hospital where Candace's mom was in labor. Candace remembers Naomi bringing her home and staying with her for the night before bringing her back in the morning to see the birth of her sister. "She was there when my brother was born, too," she added with a smile. With this story and smile, Candace was telling 
me that her relationship with Naomi meant much more than an occasional presence during a difficult time, and much more than a ride to the hospital. Naomi was as close to family as it gets. "It made a huge difference," Candace said, thinking back to her struggle to stop using drugs and get back in school, "I think because I was so close with her...she was understanding about everything, you know?" Although the approaches may have appeared different, both Danielle and Candace experienced concern, care, and commitment from their Friends during very difficult periods in their lives.

\section{Problems with family}

Alex said the most difficult period in his life was when he was removed from his home by child protective services and entered the foster care system. Over the next few years, he lived with his godparents and two different sets of aunts and uncles. This experience affected how he felt about relationships, even with Travis at the beginning. When he and Travis first met, he said,

I was just kind of getting situated back at my house. So you know, after three foster homes plus being torn away from your family at a young age, it was a little hard to trust people. It was a little hard to know who was what, plus I was also really young. So I didn’t know much, didn’t expect much. I wasn't sure who was my friend, who was my enemy, stuff like that. It was kind of like ingrained in my personality. I just kind of got, yeah, I struggled at school...But you know, Travis kind of...He kind of got me out of the house and out of my head and out of my thoughts and stuff like that, and that was always good life experiences like rafting and stuff like that. I never would have done that without him. 
Alex's experiences in the child welfare system had him wondering if there was anyone he could trust. Adults who seemed to care and who wanted to help came and went. With Travis, Alex found not only consistency and commitment, but an opportunity to escape from the turmoil of his home life and a chance to try new and interesting activities that were not possible before. With Becca, Sarah not only had an opportunity to get away from the fighting and arguing that took place at her house, she also had an ally and advocate when she needed to talk to her mom about serious issues. Sarah said when she felt like her mom wasn't listening to her, Becca would, "sit there in the room and help me tell her and express it to her.” Becca also communicated directly with Sarah's mom when necessary, "She's able to express things to my mom 'cause my mom won't listen when I tell her stuff, or she gets offended because I brought up something 'cause she doesn't want to believe it. She like freaks out, so Becca's helpful with me being able to express things to her."

For Sarah, having Becca's support meant the difference between feeling silenced and feeling heard, and she said, “that feels amazing because my mom's actually listening to me, like when she's listening to me and she's hearing my thoughts, and I'm being heard...since Becca's my mentor, she won't freak out or show any of the things she does when she's not around."

Danielle said Maria helps her deal with all kinds of difficult relationships, “...family problems, and friends when I was a little kid, and still now like boyfriends...me and my mom don't get along, and me and my brother don't get along, and my mom's fiancé or something doesn't get along, and my entire family just doesn't 
talk to each other - and she kind of helped to be like, 'You have to call them in order for them to call you, too,' like I can't just expect them to want to be a part of my family without me giving the time to be a part of theirs. And helping me figure out what to do with my mom with my life-like how to survive and solve the problems that we're having."

Danielle's situation demonstrates how Friends help youth explore multiple perspectives when faced with difficult situations. When youth were able to take a step away from the stress and pain of the relationships that were causing them so much trouble, they were able to think about and discuss possible courses of action that were unlikely to occur to them in the heat of an intense moment. Again, as with other kinds of support that Friends offered participants, assistance during crisis situations varied widely depending on the context of the situation. Sometimes help meant support in taking a challenge head on, while other times it meant finding healthy ways to escape temporarily from intense and uncomfortable events. Regardless of the details, youth always experienced the support of Friends, particular during crises, as reliable, consistent, and just plain helpful.

Candace said that the support of her Friend was particularly important while her mom was in prison, "It was somebody to talk to, "cause I was pretty much raised as an only child. I have an older brother-we were really close, but he ended going back with his dad, so I was pretty much raised an only child. The only thing I had was a dog. It was nice to have someone to talk to, and you just spend the time with them." Just spending time with a Friend, as Candace said, meant the opportunity for a close human connection 
when family members were not present. Just spending time also meant having a relationship in which being together was the idea and the purpose, without the demands and expectations of relationships with counselors or teachers or caseworkers.

Other youth found it comforting to have a Friend to turn to when parents were unavailable. Deion never knew his father, so when he was little, he saw his Friend, "like a dad. I lived with my mom. It was only me, my mom and my sister so I just looked at him as a dad or like a big, big super brother." Then Deion's mom moved across the country when he was in eighth grade, leaving him to live with his grandmother, and living on and off with an aunt and uncle. When problems arose in any household, Emmett was always available. Deion remembered after one particularly bad argument with his aunt in the middle of the night, Emmett "drove all the way out there. He picks me up at 1 o'clock. We went through a drive thru. We got Burgerville drive thru. We got something to eat and then talked about it and he still remembers."

I asked him, "So what kinds of things did he say or did you talk about?"

Deion said, "I told him what happened, and he just tried to talk me through some stuff, like what to do next time or what I could do and should do, and just keep my cool instead of trying to - even though she's wrong or something - just try to walk away, try to avoid it. He's giving me helpful tips." In addition to this experience further supporting the point that Friends offer support during times of crisis, it is also notable that Deion emphasizes that Emmett still remembers that night, suggesting that Deion experienced the event as mutually significant, as a moment that defined in some way an essential 
component of the relationship - being there no matter when and no matter what, and valuing that time enough to remember it years later.

\section{Difficulties at school}

When I asked Danielle about Maria's influence on her academic performance, she was unequivocal, “Yeah, without her I'm pretty sure I wouldn't make it, or wouldn’t have made it this far."

So I asked, "What were some of the barriers that would have gotten in your way?"

She said, "Schooling in general, like I don't like school. I don't like high school. And she helped me through it. She supported me, and I was doing really bad in math and she helped me get a tutor and she just stayed on me, trying to make me do my work...it was good knowing that I had someone there just to help me with school, and that she stuck with me until—this is my senior year." "Making it" for Danielle means high school graduation and being able to pursue her dream of becoming a social worker, while her relationship with Maria was experienced as persistence, encouragement, and a chance to "make it" when she would have otherwise given up.

Helping get work done was a common theme. When Kianna was overwhelmed by the amount of schoolwork she had, Trayvia would step in to help get her going, "I would have a backpack full of homework I wouldn't do, and she'd come over there and my mom and them would make me do it—all of it, and it was a lot." Kianna would also try to skip school by hiding in her bedroom, pulling the covers over her head on the top bunk bed until her mother left for work. Trayvia was the one who would check on her, tell her mom, and make sure she made to school. This type of support, Trayvia holding Kianna 
accountable for school responsibilities, was challenging for Kianna at first. She said, “Then I was probably always mad about it, but now that I'm older, I appreciate a lot of the things that [Trayvia] has done, because I'm more mature. Of course when I'm a kid, I'm gonna be mad that I have to do all this stuff I never had to do before. Now that I'm older, it benefited me in the long run and I appreciate it."

Sarah and Sean both mentioned specific ways that their Friends helped them with school. For Sarah, it was math and history, her two most difficult classes. Sean remembered a long list of requirements that came with his senior project assignment, which included visiting colleges and preparing for post-graduation. Sean put it off for a long time until Jesse helped him get organized and moving in the right direction. "For a while," he said, "I was in danger of not graduating. I was like, 'Hey man, can you help me with some of this college stuff?' He was on it. The next day we sat down, went to his house, he helped me fill out OSAT, helped me fill out FAFSA and all that kind of stuff. It just helped me so much."

Hugo was thankful for the motivation that Derrick provided along with some very practical assistance that helped him stay on top of his school work, "Well, he kind of motivates us, reminds us we need to be like successful, 'cause he knows that — and we know that also - that we don't want to be stuck at a crappy job or doing something we don't like to do, so checking up with our counselor or whatever, seeing our grades. That helps a lot 'cause, even though I could do it, sometimes it slips my mind or I just don't feel like it, or I just get lazy with homework and I can't really ask anyone at home for help—so Derrick's the main person to go to." Like in Deion's case, Hugo's Friend 
provided assistance and support right when it was needed; their mentors were availablenot just metaphorically this time — at a moment's notice, in the middle of the night, the very next day, when it really mattered most. Also, similar to Candace's experience, Hugo's Friend was the one person available in this moment of need to provide support. For both Candace and Hugo, their relationship with their Friend was critical; their Friend was "the main person to go to."

Along with academic support and motivation, Friends were also able to step in when youth had disciplinary issues. Alex said having Travis there for him when he got kicked out of school was the most important time of their relationship, "It was definitely that [school] situation. Because I mean really, at that point, I was just a high school dropout. Nothing more. Nothing to do. No resumes. No job. Just a dead beat pretty much. And I probably still would be if it hadn't been for him. Kind of like a guardian angel."

A guardian angel does not stand beside you and hold your hand every step of the way through life. The idea of an angel is that they are not often visible, but are watching over you at all times. However, although not visible, they are always available, always ready, and always willing to answer a call for help in dire situations, in those moments when you know you cannot make it alone. Like guardian angels, Friends are not physically present all the time, but youth know that they are there, and that they can be counted on, without question, to step in and help when life is most difficult. 


\section{Challenges related to having a mentor in difficult situations}

The presence of a long-term mentor in times of crisis or in particularly difficult situations was almost always experienced as beneficial for the youth in this study, but there were a few reservations that a couple of youth expressed about the dynamics of their relationship during these periods. Hugo said that having Derrick involved when he is making a difficult decision doesn't always lead him to make the right choice. For example, Hugo said that when he goes to a party where there is alcohol, he is aware that Derrick would not want him to drink, but he said, "In some ways I guess I listen to him, and I understand what he's saying, but there's also a lot of the time I just don't care too much - but it still kind of has a bit of an impact, but it doesn't really exactly change my mind." In other words, having a long-term mentor is not magic, and the guidance provided by the mentor is not always heeded. Difficult choices that teens face continue to challenge them, and even with the support that "has a bit of an impact," the decisions are still the youth's to make.

Dante said something similar, and added that Jesse can sometimes "be a nag." $\mathrm{He}$ added, "I get that you're trying to help me and I appreciate it, but dude, I got this." Dante was sensing that his own confidence and skills were not being fully recognized and appreciated by Jesse, suggesting that maybe Jesse could play a less active role in situations that are within Dante's capabilities to handle independently. It is important to point out that Dante does explicitly state that "I appreciate it," and that none of the participants went so far as to say that the presence of their Friend was detrimental during 
difficult times, only that their intervention, suggestions, or advice were occasionally perceived as annoying or not particularly helpful. 


\section{Chapter 9: “It's Okay to be Myself”: The Experience of Identity Development}

Just so you know

This is going back to what I learned.

It's okay to be myself.

What I've learned is

it's okay to be myself

especially with sexual orientation and the way I dress.

I didn't use to dress like this, just so you know.

I used to dress like a total boy,

and that was okay with my mentor.

I learned through them that it's okay to do that anyways,

it's okay to be myself.

That was what moved me.

Even though this thing in my life was telling me it wasn't, it's okay, I could do it.

I could do it, and it would be okay.

Youth in long-term mentoring relationships develop elements of their identities and personalities through their interactions and experiences with their mentors. Identity development has been conceptualized through historical, sociocultural, and narrative lenses, but the current study closely reflects Erikson's psychosocial perspective of identity development that attends to, "the interplay between the individual biology, psychology, and social recognition and response within an historical context” (Kroger, 
2008, p. 206). Of particular interest is Erikson's concept of ego identity, which refers to an individual's striving for psychosocial wellness through individuation and continuity of experience (Kroger, 2008). Some of ego identity’s “most obvious concomitants are a feeling of being at home in one's body, a sense of 'knowing where one is going', and an inner assuredness of anticipated recognition from those who count," (Erikson, 1968, p. 165).

Participants described many experiences of being affirmed by their Friends, feeling a new sense of self-acceptance and self-confidence, realizing that they are unique and valuable individuals with much to offer others. Sometimes participants identified discrete experiences as revelations whose significance was immediately apparent, and other times the identity development process was described as slow and subtle. There were also many nuances to how participants felt that their mentors contributed to their growth as individuals. For some, the mentor made them feel secure and accepted as they are, often in the face of rejection or indifference from other adults in their lives. Participants also described reaching milestones of independence and maturity with the help of their Friends, as well as recognizing aspects of their personalities that they had never noticed or acknowledged before.

Dante had one of the most transformative journeys of any participant. His experiences of psychological abuse and neglect left him feeling disconnected from himself, and his Friend was instrumental in helping him find his identity and his creative voice. He said, “My mom's influence kind of influenced me to be like just this nameless guy, and I was just this body. I didn't feel really, me, you know? But with 
Jesse...I learned how to just be myself, which I think was hard for me to find just because I didn't know who I was. He kind of just put me-like now I'm making music, I'm trying to learn how to play drums, I want to do that. I'm high-energy so it makes sense, you know? And I also make songs, I make poems, I'm more creative now than I was ever before.”

Through his relationship with Jesse, Dante clearly developed a new connection with parts of himself that had been obscured for much of his early childhood by experiences of severe abuse. His traumatic past had not only impeded the development of his personal identity (what Dante refers to as "feeling really me"), but the abuse had dehumanized him to a degree that he felt like a body moving through the world with no person inside. Jesse helped Dante find the person inside the body, and the strengths inside the person.

Dante shared with me that he attempted suicide twice during these dark episodes, the first time when he was only ten years old, "because my mom said something really horrible to me, and did something really horrible to me, and also my brother did a horrible thing to me, too, and I just didn't know how to deal with it." The first attempt was interrupted by his mom, who happened to walk in the room, and the second time he was saved by a stranger who pulled him out of the way of on-coming traffic that Dante had walked out into. Dante said that Jesse was instrumental in helping him recover from these crises, first by sitting in with him during therapy sessions. Dante said, "Jesse helped me, he kind of stood by, he sometimes sat in with the therapist... and I explained to him that something happened at home and it just completely stressed me out so I kind of just 
zombied." Other times when Dante needed to talk, he would sit with Jesse and, "I would tell him everything that was going on in my house, and he would be there to listen and he would try his best to make me feel better... and the way that he does it is laughing and telling jokes, you know, just trying to lighten the mood." The abusive and "military school" environment in his house made Dante's outings with Jesse all the more important. He explained, "I didn't really have fun when I was a kid except for when I was with Friends."

Despite the presence of other important adults in Dante's life, including his child welfare case worker and his school counselor, Dante said there is something different, something special about his relationship with Jesse that allows him to relax and be himself, whereas in relationships with other adults he feels a pressure to be more formal or serious.

It's more laidback just because, like I said, it's just like a friend—not like a Friend as in Friends of the Children, but he's a friend — so I can totally just like, calm down...With my caseworker I don't really have that connection with him so I feel I have to be a little bit more formal, and with [the school counselor] I'm starting to get more casual...what I'm saying, me and Darren's connection, basically, we really bonded.

For Dante, there is an element of authentic friendship to his relationship with Jesse that does not exist with other adult professionals who are important to him. Some of that authenticity is a product of time, as Dante has known Jesse for much longer than he 
has known the case worker or school counselor. The nature of the relationship is important as well, as the counselor and case worker play very specific roles within specific contexts in Dante's life, while Jesse occupies a more central and comprehensive role that includes attention to all aspects of Dante's life. Dante's experience of all of these factors - time, commitment, authenticity, role — seem to have had a profound influence on how he views himself, how he feels about himself, and how he understands his relationship with Jesse.

Karin found strength and validation through her relationship with Therese, and developed the courage to be herself even though she faced potential disapproval from others, "This is going back to what I learned. It's okay to be myself in some aspects, especially with sexual orientation and the way I dress. I didn't use to dress like this, just so you know. I used to dress like a total boy, so that was okay with my mentor. It's not okay with my aunt, but I learned through them that it's okay to do that anyways, like even though this thing in my life was telling me it wasn't, I could do it. And it would be okay." Karin experienced a sense of validation in her relationship with Therese, while she experienced threats, discouragement, and rejection from others.

Karin and her friends experienced intense bullying in middle school because of their sexual orientation. She said other students would:

come on up to us and be like 'Oh, do you think I'm sexy in the locker rooms?' One time, some kid poured Gatorade all through my clothes, my gym clothes, so that I didn't change, and then I got knocked down points...And there's a couple 
times when my friends got pushed down the staircase or something, like it was really harsh stuff, because we were so different and there's a lot of really religious people at the school... So we were bullied on multiple levels, but definitely mostly about our sexual orientations.

Then she further explained what role Therese played during these situations: "She gave me books about stuff like that. There was one book that was about a gay author. It was a gay guy. It was called The Kid. It was by Dan Savage. It was really well done...So she helped me cope with the fact that I was different and like, you know, helped me see that it wasn't a bad thing, and so that was really helpful of her." For Karin, being gay in her school and in her home made her "different" and a target for harassment, rejection, and bullying. Through her relationship with Therese, she was able to find a new and positive understanding of who she was and who she wanted to be.

In more subtle ways, participants connected to their strengths and recognized aspects of themselves that they had not seen or acknowledged before. Gabriel said, "I showed him a video game recently and he's suddenly become addicted to it. Ever heard of Starcraft? Starcraft is a real-time strategy game where basically you're looking from above the battlefield... We play two versus two, me and him versus two other guys online. And so that's a lot of fun 'cause we've come up with a lot of different strategies together...both me and him are big strategy guys.”

For Gabriel, Emmett's involvement and support helped shape his view of himself as "a big strategy guy," a musician, and a videographer. For Sarah, art and poetry were 
the media for finding her positive self, and her relationship with Becca was a part of that discovery process from the day they met. Sarah said, "The first time I met her that was actually really good 'cause the first thing I really learned about her is that she liked art and stuff, which is something I was hoping that my mentor would like. I had a lot in common with her and she's like been very helpful.” More than just a common interest, Sarah and Becca work on projects together, "She likes all kinds of art... She's very creative and resourceful. And she's actually helped me with some things I wanted to make. We do it together."

Sarah's poetry helped her deal with personal challenges, and gave her a vehicle for processing and communicating her resilience and growth. "Most of my poetry," she said, "is about - the characteristics that come out a lot are, first, I start off a point with like, 'This is really depressing' and talking about my past, and then I keep going and it gets brighter and it's talking about how I grow constantly.” Sarah's identity as an artist and poet runs deep and is central to what she wants to do with her life: "I care most about people and how they feel, and basically my art falls into that because what I really want to be able to do, like when I'm older, is I want to be able to take that art and poetry, somehow get out of a hole that I was in-keep going up and then show people that it's not impossible and try to inspire them to keep trying."

Other significant connections between participants and Friends facilitated greater understanding of self and purpose for youth. For Danielle, the key was service to others. For Jacquie, it was a commitment to Christianity and faith in God. Whether youth were discovering and developing their knack for strategy, 
their creative talents, or their care for others, youth found that their mentoring relationships were fertile ground for positive exploration and growth.

\section{Independence and maturity}

Gabriel explained that his relationship with Emmett has helped him "grow up" by preparing him for independence and the increased responsibilities of adulthood, "I'm really going to have to get back on my own two feet, you know? I've always had Mom to fall back on, I've always had friends to fall back on, but I feel like Friends has really helped me to prepare me to get me on my feet - the education and the skills, and the people skills. They prepare you to grow up, as you're growing up." When I asked Gabriel what getting on his own two feet meant to him, he continued,

Well, on my own two feet, as in I'm going to have to be responsible for myself, a lot more than I currently am. And I have to help out a lot more with Mom and things like that. I'm trying to do that, trying not to be so, you know, 'Oh, we have money now.' Trying to pay bills, things like that. Yeah, it doesn't look too scary to me as it would to most people. I don't plan on moving out from Mom yet just 'cause we both kind of need the money. And then also she's my mom. Not only do we need the money also she's Mom. We kind of need each other, and so when I say getting on my own two feet it means being a lot more responsible, knowing that she kind of relies on me as much as I may rely on her.

Me: And you said that's not a scary prospect to you now? 
Gabriel: No, Mom's definitely taught me a lot about that. Emmett's definitely taught me a lot about that. I grew up fast. I've had rough times. You learn life, got to kind of learn life, got to kind of accept things. Emmett and Paul definitely helped me accept some things that I wouldn't have. They've definitely been honest. They've definitely been behind me when I go a direction. They're like personal advisors, 24/7. Yeah, they helped me grow up.

Both Paul and Emmett had a significant influence on Gabriel's ability to understand and respond positively to the challenges he has faced in his life. Gabriel rated the influence of his mentors on par with that of his mother, and indicated that Paul and Emmett helped him develop personal characteristics, such as responsibility and perseverance, that have shaped how Gabriel views himself, his family, and his future.

Kianna said that through her relationship with Trayvia, she developed the knowledge and skills to take care of herself. It is notable, too, that Kianna recognized the importance of being independent and being responsible in her own ways, and not necessarily in the ways that Trayvia is responsible. She said, "It's just that I've learned a lot from Trayvia. How to be a lady, I learned that from my mom-yeah, with so many girls in the house this is how you do-but I learned how to do it a different way, a better way, to take care of myself through Trayvia. I mean, I'm not gonna say I'm as organized as Trayvia 'cause I don't try to be, but I know how to be, and to be on schedule and just how to do certain things. I do admire the things like that, that's one of the reasons why I say she's a leader, because I do admire a lot of things she do as far as taking care of herself, and being organized, and trying to be ahead of the game basically." 
In some cases, youth emulated the positive qualities they saw in their Friends, while in others they looked to Friends for inspiration and validation as they developed their own styles and their own personal strengths. In both cases, it was the certainty that they would be accepted and celebrated for who they are by their Friends that gave participants the confidence to connect with and fully develop their authentic selves.

\section{Care and empathy}

Developing care and empathy for others is another aspect of identity development that participants described as being an important component of their relationship with their Friends. Danielle described this process most fully, and for her, developing care for others happened in several different ways. First, through her relationship with Maria, Danielle developed a sense of responsibility and a commitment to helping others through volunteer work as well as through her future career choices.

Danielle said, "I babysit, I volunteer and...I love children.

Me: "Where do you volunteer?"

Danielle replied, "Du Christ House, it's a retirement center. And I used to do Meals on Wheels and a bunch of different stuff like food shelters and every other Thursday usually I'd go to Northeast Portland under the Hawthorne Bridge and help feed the homeless people. Since I met Maria, we would always do Meals on Wheels and she always wanted us to help the community or go pick up trash, or something to help people, and I have a lot more respect for older people and people that have gone through more stuff-and people that...usually most people 
see a bum and think badly of them, but she taught us that everyone's somebody and everyone has a story

One way Maria taught Danielle about compassion was by example. Maria showed Danielle that, "Everyone's gone through something different and you don't know what they're going through and so you can't judge...I've grown up, and the world I know is not perfect at all, and getting to go somewhere else and help a bunch of people that have never even had... what we take advantage of - I know that they don't get that, and the willingness of us wanting to help them is like Friends of the Children wanting to help us." Danielle described her desire to be, "either a social worker or a counselor for children, and she kind of role-modeled that for me, like, someone can be there for a child without expecting a lot...I know being a social worker, counselors, don't make that much money but, it's worth it to help as much kids as I get to."

Danielle's relationship with Maria certainly encouraged Danielle to engage in a range of volunteer service activities for disadvantaged community members, but it also helped shape Danielle's beliefs about the inherent value of other people and the importance of making a positive contribution to the community. Danielle's commitment to community service began as a series of activities that she engaged in with her Friend, but eventually it became so much a part of her own life that she sought and found ways to volunteer even when Maria was not around: “I do more on my own now because I can't really get to town a lot because I have a job, and school. But we try during the summer, we'll go to the food bank and help out or package food for them - anything we can do." 
Danielle also described the process of learning to be more open to differences through her relationship with Maria. She found herself being less judgmental, able to resist stereotypes, and willing to attempt to see other people's perspectives. Danielle said that although she grew up in an ethnically diverse area, Friends of the Children has given her a perspective on diversity that she wouldn't have had otherwise, "I know there's different races and I grew up around African Americans and Chinese people and Russians, and Friends of the Children has a bunch of African American people, and it teaches you not to be, not necessarily not racist, but to not judge people and not to be like, 'Well she does this so that means this happened,' and it was more like, 'Everyone's someone. Everyone is a different person...And it teaches, the program teaches you not to judge people and to care what happens."

Both Sean and Danielle said that their career paths have been influenced by their mentoring relationships. Danielle said she plans to go to community college for two years, "and "then go to a university to be a social worker. I just want to work with children." As she described previously, Danielle recognizes an explicit link between her desire to be a social worker and her experience with Maria. Following in the footsteps of one's mentor, with the mentor serving literally as a role model, is one way that long-term mentoring relationships can be influential. However, Sean's story was a little different.

Sean didn't see youth work in his future, but said he wanted to have a positive influence in other ways,

I wanna firefight. I definitely wanna do something that positively impacts someone's life, and that could be through a connection of being with Jesse for 
so long. It's just a matter of he's been always a positive influence. I know what it's like to have someone that's a positive influence. I wanna be someone that someone says 'Wow' and looks up to. Maybe not specifically how he has been for me. I don't even know...I have no idea what it even takes to be a mentor. I think I asked him once and it was a college degree, like psychology and stuff. Yeah, no thank you. That sounds crazy. I'll leave that to you. I definitely wanna do something that people look up to.

Sean, like Danielle, identifies the direct influence his relationship with Jesse has had on his desire to make a positive contribution to society through his future career, but Sean sees himself doing it his own way. In fact, Sean has generalized the powerful lesson of his relationship, and simply wants to be respected for making other people's lives better. For Danielle, being "like" her Friend means following a similar path, while Sean's idea of being "like" his Friend means finding his own path and his own way of contributing. As Sean continued to describe the kind of influence that Jesse has had on him, it was apparent that Jesse's contentment and satisfaction with his life and work also made a significant impression, "He's not telling me what I need to do or what I have to do, but just like a role model. I look at him and he's successful. He's not rolling in millions of dollars and he's not driving a Bentley or a Ferrari or anything. He doesn't need to. He's happy. He's got a girlfriend. He's got a house. He's got a car. He's got a job that he enjoys doing and I look up to that. That's something I strive for." 


\section{Social skills and social confidence}

Another important aspect of identity development that youth discussed was feeling increasingly confident in themselves and in their social skills, particularly in their interactions with other adults. This social confidence presented many advantages for participants, from getting jobs to making new friends to staying out of potentially harmful and dangerous situations.

Gabriel said he quickly felt comfortable with his Friends, which not only improved his self-confidence, but gave him the skills to make other people feel comfortable around him. He said that at his job, he

got to talk to a lot of people, got a lot of praise, 'Your music's pretty good. Hey, you're pretty good at talking.' I'm like, 'Really?' I'd say a lot of that is influence from Friends, a lot of being able to speak publicly or speak to people. I thought I'd have a problem being a barista at [work]. We had a café that was open for a while; I was a barista for that. And I was so nervous my first day. Once you figure out people it's not hard to talk. It's just being comfortable around people, and even from the start, Friends of the Children, they were strangers to me at first, but you know I was comfortable with them right off the bat. I kind of learned from that, and I don't quite make a conscious effort, but I try to make people comfortable around me in that way. I take that from Friends...definitely being talkative and social. 
Gabriel's thoughts about the influence of his mentoring relationship on his social skills reflect a couple of important things. First, he learned the importance of making people feel comfortable by experiencing it directly in his mentoring relationship. Gabriel was able to develop a positive relationship experience into a skill, one that now comes to him so naturally it is not "quite" a "conscious effort" to make others feel comfortable with him. Second, the experience of gaining social skills and confidence in this way opened the door to opportunities that would otherwise have been unavailable. Gabriel said he thought he couldn't work in a position that required talking and interacting with people, but with the skills he learned through his relationship with Emmett, he was able to be successful in that position. Third, Gabriel is passing the benefits of his social skill development on to others, making people feel comfortable and in turn teaching them the same lessons that he has been taught.

Gabriel said that his social skills and confidence have improved dramatically due to the influence of his Friends, "From Emmett and Paul I've definitely learned to be around people and talk to people, to be more social." Gabriel credits this development to Emmett consistently challenging him to be more assertive in all types of interactions, 'like we'd be ordering food for lunch, he'd be like, 'You order,' 'Dude, you order.' 'No, you're going to order,' so I got to go up there, got to talk to the person. For the longest time I had a problem with that just 'cause I was shy...Now it's no problem.”

Eventually, the practice with social interactions became a distinct personal strength. "I definitely learned social confidence. I feel like I can talk to anyone. I feel like I could talk to the President and, you know, not sweat to death 'cause I'm talking to the 
President." Gabriel said that some of the most profound lessons he learned seem simple now, "For the longest time I didn't know how to say please and thank you. And then Paul was like, 'Say please, say thank you,' and I was like, 'Okay,' and now I say, 'Sir, please, thank you, Ma'am.' It helps me a lot. I feel like I can talk to people.” These changes for Gabriel came through direct, explicit feedback and eventually became part of his personality. For other participants, the influence was much more subtle, slow, and indirect.

Kianna said that without Trayvia, she believes many things would be different in her life. When her relationship with Trayvia began, Kianna was not happy, “'cause she'd get me in trouble by telling my mom I didn't do my homework or something." During that time, Kianna resisted even seeing Trayvia, and often failed to follow rules at home or at school. She recalled, “I used to leave home when I wasn't supposed to, sneak out the window, go to my cousin's house, stuff like that." Kianna also said that without Trayvia, it's likely she would be on the street:

As far as being out in the streets, I'd probably be just wild, not focused on nothin', not worried about responsibility, or anything like that, 'cause to this day I still have somewhat that same relationship with my mom, so the closest thing to me is Trayvia and my sister, and my sister stays on me, Trayvia stays on me. Without them I'd probably be a whole different kid. I probably wouldn't even be talking to you like this right now. I wouldn't know how to talk to you. It would be so different." 
Kianna believes her identity has been significantly shaped by her relationship with Trayvia - in a way that she is clearly proud of. The lack of support from her mom and the limitations of her other close relationships made Trayvia's role critical in helping her avoid trouble and find happiness and success.

Sean described his relationship experience similarly, also highlighting the slow and gradual nature of the process of identity development that took place for him. Sean said,

The thing is, a lot of it hasn't been directly like that. It's just been subtle. It's been gradual. I've just been with him over time. It wasn't just overnight I was this smart dude and cared and respected for people. It was every day hanging out with him, I learned something new and the next thing I know I'm just, 'Yeah dude, I don't talk to people like that. I don't do this anymore...' My life has been completely influenced by this dude.

For Karin, Therese's willingness to show her faults and be vulnerable was particularly important, as was the reciprocal trust and respect that she encountered in her relationship. She said,

This person's not going to be your best friend at times, and sometimes that's how you know that something's wrong-they're not going to lie to you. And they're people, so they're fallible, and so you just got to learn to trust them on what they say. And I think that's really big for a lot of kids, especially if you come from the background like the kids from Friends of the Children do, because 
there is some reason that they are there, they are chosen for a reason, and so, to have somebody who's going to be there, who's going to believe in them when they can't believe in themselves, is going to help them climb out of holes-that's really powerful. And that's why it's so successful because you're making a pledge to help these children and they see that.

\section{Health and well-being}

Youth participants developed knowledge and habits through their long-term mentoring relationships that improved how they felt about their health and well-being. Many youth went with their Friends to do physical activities, like biking, hiking, and snowboarding. Some integrated healthier foods and drinks into their daily routines. While most participants described the physical benefits of these changes, some also recognized the effects these behaviors had on their psychological well-being and self-confidence.

Gabriel experienced a combination of a healthier diet and increased exercise, saying that:

A lot of motivation comes out of Friends of the Children. I remember when he said, 'I'm not buying you a soda.' That really helped me out 'cause I was round. I was just a big kid. And so I was like, 'He's not going to buy me a soda. Maybe that means I shouldn't drink that soda. Maybe I shouldn't be drinking a two liter or Mountain Dew every two days.' And so that kind of motivated me, made me be a little more healthy. Go on a walk - for a year I was walking from my house to Ethos back and forth- 
every time I went to work. Lost tons of weight, just drink nothing but water, doing that again. I'd gotten in the bad habit all summer of drinking Coke, so drinking water, that's Emmett again, he's like 'Man you shouldn't be drinking that poison.' And I was like, 'Oh fine, I'll drink water. Gosh.” and then it's like, 'Maybe I should just keep drinking water.'

Me: "Sounds like it's been healthy... “"

Gabriel: "It has. Physically and mentally. Emotionally. It's healthy. Friends of the Children has been really healthy for me."

For Sean, it took years for Jesse's influence to really sink in. He said, My transitioning to eating healthy over the last maybe year or so has been influenced by him a little bit. He showed me some things but over the course of a whole six years, he's always had good nutritious treats. It's never really anything like fruit snacks or something like that. He's always 'Hey, you wanna try this?' He has a power bar, energy bar or something. Not like directly protein bar, those nasty ones that weight trainers use, things like Cliff bar. Granola bars and things like that that are actually good for you. I've been accustomed to those kind of things. He's got very good taste.

Danielle said that she was pressured at age 9 to start smoking, and the connection with Maria was one of the primary reasons she quit. She remembered the classmate who offered her the cigarette: 
Well, I remember at the bus stop before school she'd be like, 'Do you want a drag of a cigarette?' And I'd be like, 'No, I don't want to smoke 'cause I grew up around my mom smoking and it made me sick,' but then I ended up being like, 'Okay, I'll take some, whatever.' But Maria would be like, 'You can tell us anything,' and I told her, and she's like, 'It's not healthy,' like, 'You're nine years old, you don't need to be doing that.' And I know now you get really addicted to it really quickly. I stopped because she was worried. She's like, 'I don't want you smoking,' and I didn't want to be caught by my mother, of course-but I haven't smoked since then.

Alex shared his experience of being bullied by peers in late middle school, and described the effect that his relationship with Travis had on his physical health as well as his "psyche" and self-confidence.

Me: "What was Travis's role?"

Alex: "Oh, he was still very much in my life, and that's when we went to the gym a lot. That kind of helped me get out of my head as well. Yeah. Yeah. Just go exercise and just forget about it, you know, because like I said, I used to be kind of the fat kid. Now, as you could see, I'm kind of, you know, big, cut. Yeah. It's not bad at all. Yeah, I actually got better physically. Along with physical fitness, you can also like - I don't know. Physical fitness has some sort of effect on your mind that it also tunes up your mind, you know. Yeah. Helps your brain to function." 
Me: "So you think all of that worked together like to build your self-confidence?"

Alex: "Yeah, pretty much, and my psyche."

Gabriel, Danielle, Sean, and Alex all experienced the physical benefits, and subsequent psychological comfort and encouragement that long-term mentoring relationships can facilitate. Smoking, poor diets, weight problems and obesity, and bullying are common health risks for young people that individually, or especially when experienced simultaneously, can have negative long-term effects. For the youth in this study, the power of a consistent, caring relationship with a Friend over time seems to have helped mitigate these risks and empowered youth to make decisions and behave in ways that support long-term health and well-being. 


\section{Chapter 10: "For Me, It Means Expanded Opportunity": The Experience of Expanded Opportunity}

\section{Good Feeling}

We basically got the whole mountain to ourselves.

It was just me and him,

finding little back routes,

exploring the mountain.

It's quiet.

You can't hear cars,

people screaming or anything.

You don't have to be right next to everyone.

The only noises are the lifts

and just the snow itself.

Especially when there's new snow,

fresh powder.

Its peaceful out there.

Nature.

It's a good feeling.

I wanna go back for that.

When I began talking to Danielle about her relationship with Maria, her description focused on activities that she had an opportunity to participate in, such as spending time at the river, going to the movies, taking a trip to the beach with her Friend and a group of other program participants, and many others. I wondered and asked her which of these stood out to her as opportunities she wouldn't otherwise have had. She answered immediately, “I probably wouldn't have done most of the stuff I've ever done without being in Friends of the Children. She was the first one who took me out to the 
movies, to take me to the river, or the beach, anything. Bowling....all kinds of stuff." For Danielle, her relationship with her Friend means opportunity.

The opportunities participants experienced through their long-term mentoring relationships went well beyond fun activities. Youth described educational and employment-related opportunities that their Friends facilitated, including helping find and apply for scholarships, college, internships, and jobs. Participants also found opportunities to be creative through arts classes, programs, and events. Sports and recreational activities were also important for many participants, with mentors providing access, encouragement, and partnership along the way. Finally, youth were able to connect with peers and adults through social and cultural opportunities that were introduced through the mentoring relationship.

Before describing in detail the opportunities that arose from participants' relationships with their mentors, I think it is important to address the significance of youth experiencing expanded opportunities versus the experience of engaging in an activity itself. Using Danielle's experience in the opening paragraph as an example, there was not a single activity that Danielle identified as the one that exemplified what her relationship with Maria meant to her. Going to the beach was clearly enjoyable and memorable for Danielle, but "going to the beach together" alone does not capture what Danielle finds so special. Rather, it is the fact that "I probably wouldn't have done most of the stuff I've ever done without being in Friends of the Children," that makes all the difference. In other words, it is the opportunity to get out and do things that Danielle values, not just doing one thing or another, regardless of how wonderful those 
experiences might have been. A parallel case can be made for all of the opportunities described in this chapter. With regard to educational opportunities (to offer one more example), while receiving a scholarship is certainly a great achievement, the experience of receiving a scholarship does not adequately capture the experience of having "the opportunity to attend college," which is a collection of knowledge, attitudes, activities, and so on that is greater than the sum of its individual experiential components.

\section{Educational opportunities}

Gabriel said that his relationship with Emmett has been instrumental in helping him find educational opportunities, like, “...finding a good college. Emmett has done tons of research for me, showed me where to go if you want to find a nice college, you know, what I'd be able to qualify for with things that I've done, the education I have. That alone is enough, that's a lot to help me 'cause I wouldn't know the first thing. He's gotten me scholarships and things...Yeah, I'm confident that anything I want to learn he'll always back me up, and always help me learn it." Educational opportunity for Gabriel means having college as an option, but also the flexibility to have assistance and support no matter what or where he wants to learn.

Karin remembered being behind her peers in basic academic skills when her Friend signed her up for a tutoring program. Karin said, "My first mentor, I didn't know how to read very well with, which is shocking now because I read. So she put me in this program where I learned to read better. I had to go to this class once a week. I went there with this other girl that I know, and we both learned to read that way, and we're to 
complete all these steps and it's so annoying, but it helps me learn how to read better. It's like the Sylvan Learning Center. They're set up at the office... at the Friends office." In this case, Karin's educational opportunity was not something she asked for or wanted, so in what way can this even be considered an opportunity?

In Karin's early life, she was denied some of the basic things that most children receive, such as love and affection, nutritious foods, and the opportunity to read books. Being denied the opportunity to read or learn to read has potentially catastrophic developmental consequences. Cunningham and Stanovich (2001) wrote, "Reading has cognitive consequences that extend beyond its immediate task of lifting meaning from a particular passage. Furthermore, these consequences are reciprocal and exponential in nature. Accumulated over time - spiraling either upward or downward - they carry profound implications for the development of a wide range of cognitive capabilities." Therefore, I find it reasonable to suggest that a child who has the experience of being placed in a reading program after being denied the chance to learn to read has been afforded a significant opportunity.

The educational opportunities that Travis helped Alex find constituted a second chance after Alex was expelled from school. Alex said that Travis didn't just find him a school that would take him, but helped him shop around for the school that met Alex's particular needs and interests. Alex said, "Yeah. He went around to different schools like Franklin, Benson, Madison.... and we tried to find one that would fit, you know, because I kind of left up my credits a bit and with some that I needed like credit recovery. So I wanted to go to Focus. That was the one school that I really did like, but they went on 
closing that down. But it was like a blessing in disguise because now I'm in automotive, managing here." Alex's relationship with Travis—characterized by Travis's thorough understanding of Alex's needs, wishes, strengths, and challenges-propelled this experience beyond simply help with re-enrolling in school. Their close relationship, and Alex's trust in Travis, facilitated the opportunity for Alex to find not just a school to go to, but the best educational opportunity for him and his situation.

One of the first activities for many youth with their Friend was a trip to the public library to get a library card and check out some books. Hugo remembered, "I think he took me to the bookstore, or the library, the first day and we got into some books, like I Spy books and stuff, and when we started that, that's what we did often-go to the library. It was pretty cool.” In addition to access to books and library resources, Hugo also experienced Derrick's academic support of checking in with teachers and counselors when no other family members were available to do it. Hugo appreciated homework assistance and keeping track of his academic progress: "Derrick definitely helped me out. I could ask him for help on that whenever, and getting my grades, he helped me check up on my grades sometimes too. So that's probably the main thing, grades, he definitely helps me out with that."

Hugo also knows that Derrick is available to help him explore future educational opportunities as well: "I'm not exactly too sure myself exactly where I want to go or what I plan on doing after high school, but I'm sure if I talk to him... he could probably help me check out some schools or check out some things I can do to help me actually pursue what I want to do." Like Gabriel's experience with Emmett, Hugo's relationship with 
Derrick provided him with resources, support, advice, and practical assistance that greatly enhanced Hugo's past academic experiences and expanded his future educational options. Arts and creative activities

In a previous section, Hugo described art classes that Derrick signed him up for, which wouldn't have been possible otherwise. A number of other participants highlighted the opportunities to pursue artistic and other creative endeavors through the support and encouragement of their Friends. In addition to just having an outlet for creativity, participants also described the opportunity to grow and improve their artistic skills through the engagement, participation, and feedback of their Friends.

Gabriel said, "Emmett definitely influenced my video editing and the video things. At first, since he first became my mentor, we were making videos all the time. He would show me cool tricks, like he showed me editing, showed me the cameras, you know, we did a lot of goofy videos...A lot of like jumping down from something and reversed, jumping back up to something, you know? Pretty funny stuff like that...so it's like I kind of want to do that. I want to see how we did that. From that I now look at movies and TV shows in a different light, like I look at 'how do you do that?' and I look it up, 'Oh that's really interesting.” A strong, trusting relationship also allowed Gabriel's Friends to offer constructive feedback, which enhanced Gabriel's opportunity to improve his craft:

Paul and Emmett are really helpful in that regard. They're honest, tooespecially Emmett—with the summer camp videos and things like that. 
He'll look at the video, he'll be like, 'Hey, you might want to try this or that next time 'cause maybe this shot, you know, if you look at this shot may be a little off,' something like that. And I was like, 'Oh yeah, that's a good point' and so next time I'll do it and it looks a lot better... it helped to get feedback, you know?

Gabriel's Friends have both been actively involved and supportive of his musical endeavors as well: "Both Emmet and Paul were really supportive of my music. They really seem to like it...it's electronic music but I can't quite put a genre on it. It's a little bit house-y, a little bit hip-hop, a little bit techno, you know? Can't quite figure out what it is but, yeah, they both like it. Even when I'd tell them no, 'cause I was shy, they would bring me to the office and play the song on the stereo, I was like "no, don't do that" -and they're all like, 'Man, sounds so good' and I'm like 'really?' So there was a lot of that. Showing off my music..." Emmett also introduced some of the technical aspects of the music industry to Gabriel: "Music production...yeah, a lot of that came from Emmett. A lot of technical skills, a lot of practical skills came from Emmett."

Danielle described the opportunity to make crafts and do art projects as a way to focus her mind and energy on positive, productive things, "I love making bracelets and beading and stuff, and Maria got me into that because she's really crafty. I like to draw and I like to paint and I like to watercolor, and that's about all I like to do." Through her relationship with Maria, Danielle not only developed her interest in creating art and crafts, she was able to connect that "love" with her emerging desire to help people in need. Danielle remembered: 
"When we were younger, Friends of the Children would have group things — and all of the kids and all of the adults would come in and we'd make ornaments for Christmas, or cookies, and hand them out to like a cancer hospital, or we'd made bracelets and sell those for fundraisers...we're actually doing something productive. It's a hobby, but also when I'm drawing or writing poems or a story or something, it's like I'm not thinking of all the stuff that's going on around me. I'm thinking about what I'm doing, at that moment, and I don't have to worry about what's going to happen in two hours or tomorrow or next week. I just want to finish what I'm doing, so it keeps me occupied I guess."

The opportunity for artistic expression and creativity that Danielle found through her Friend became a way for her to find peace and purpose, and turned into a genuine passion that has been rewarding for herself and for others. At the time of my interview with Danielle, she and a friend were almost done writing and illustrating a children's book that they were intending to share through readings at elementary schools. Danielle told me, "The moral of the book I guess is people can have more than one best friend... and we already have the elementary school's permission to read in front of a few classes."

\section{Recreation and exercise}

Participants talked a lot about the opportunities that their mentoring relationships provided for getting out of the house to do physical activities. Gabriel said, "Thanks to 
Emmett mostly, we did a lot of hiking, a lot of biking...We did the Portland to Coast for two years, not in a row, but two separate years - big, big long walk. And that was a lot of fun, a lot of training between that as well. Yeah, Emmett definitely helped me get outdoors a lot more." While for many youth hiking and biking would be fun activities to spend time doing on weekends, Gabriel lived in a household where he said, "I grew up fast," and "got my first job when I was fifteen, and I needed to do that, we needed money. I had to. I had to learn the ropes of work pretty quick. And then on top of that we also had Dad's issues," which included years of drug addiction, and then his father died when he was just 12 years old. After that, "it was just me and mom," and together they experienced a number of housing transitions and periods of homelessness. "It was rough times," Gabriel said, and now, at 16, he worries about helping his mom with the bills because he realizes "that she kind of relies on me as much as I may rely on her."

So, in this context, it is easy to see how experiences like, "hiking up to Mt. Hood...snowshoeing, like, ten miles up a mountain of snow with snowshoes," would be considered a real opportunity by Gabriel; how having a chance to get out in nature, go "biking around up there" on Powell Butte with Emmett and some other youth, crashing his bike, "cracking up...we were all just there dying," and then "biking for another three hours all the way around that place," would be something that Gabriel would not have had an opportunity to do without his relationship with Emmett. In fact, this biking experience in particular took on special significance for Gabriel. "That was one of the most memorable days," he said, "that's the epitome of me and Emmett right there. I get hurt but we laugh about it." 
Danielle described physical activities as part of a larger array of recreational activities that her relationship with Maria made available, "I know during summer we used to do swimming classes and we'd learn how to swim in Mt. Scott Pool... and photography and writing classes, or there's tutoring classes. And I never go on 'em because I'm terrified of drowning in water but they go rafting during the summer, take like week trips to go rafting, and we do cancer runs or a really big run in the summer. Hood to Coast, sometimes we do that." In addition to "support and "schooling," Danielle said the most important thing the program provides is "the adventures or fun times and the activities they provide." Later, she came back to add, "My major thing is the support that they give us, and the opportunities and the stuff that they get us to do," listing among her favorite memories of her relationship with Maria, "going to the park and going out to dinner, and to the river... and we've gone to the beach a few times and I love the beach." When Deion described his experience of doing the 200-mile Seattle to Portland bike ride, there was an unmistakable tone of pride and accomplishment in his voice. Deion said,

There was a thing called the STP. The Seattle to Portland bike race...I did it last year. I've done it three times already. This year we're going for four. It's 200 miles or something. You have to go 1500 miles on your bike, or at least close to like 900 or some weird number, so you can get used to riding. The first time I did it, I didn't do the whole entire thing. I had to get in the van and rest for a little and go, then I came to the finish, but I did over half. The second time I didn't need the van at all. The whole entire 
thing, the whole entire 200-something miles. Third time, I did it again.

Last year when I did it — it's gonna be my fourth this summer-last year when I was doing it, it was the very first time I felt everybody cheering you on. You'll notice everybody clapping for you. I saw them smiling and I got excited.

It is a rare opportunity for any youth, and especially for a youth who has struggled through the kind of adversity that Deion has, to have the experience of completing a 200 mile bike ride with thousands of people lining the streets, clapping, smiling, and cheering them on. This opportunity did not materialize overnight. Deion liked sports as a kid, but he said, "I started doing that a little bit more with Emmett 'cause he's very athletic...we do a whole bunch of athletic stuff... We play basketball, football. We just like to be athletic." Now Deion tries to get other youth more involved in physical activities, including recruiting for another run at the STP: "I talked a couple of people into it. I've been trying to get some more this year "cause we need adventure."

Sean remembered the excitement of his snowboarding trips with Jesse when he was younger. In addition to having fun, Sean said that the trips gave him the opportunity to connect to nature in a way he hadn't done before: "I went snowboarding when I was really young. It was cool. I enjoyed it and I always remember, 'I wanna go back for that.' That'd be cool. Jesse brought it back up not too long ago like, 'Would you be interested in that again?' I'm like, 'Dude, totally'...Yeah, just like fresh powder, it's a good feeling and it's peaceful out there too. There are a lot of people but it's relaxing in a way because you can get away from people. You don't have to be right next to everyone. 
It's not like people are screaming or anything. Most people are just going down the hill. Yeah, the only noises are just the lifts and just the snow itself. Nature. It's awesome."

In a previous section, Alex described how going to the gym gave him an outlet for his anger and frustration towards peers who were bullying him. He also stated that this opportunity was a direct result of his relationship with Travis, inspiring him to start working out and making it logistically possible, too. Alex said, "We started going to the gym when I turned 14. That was pretty good because the majority of my, when I was really little, you know, the problem years, all the way up to about second grade I want to say, I was real skinny, and then from then on, I was like the fat kid, and then when I turned 14, I was allowed to use the gym. So freshman year, the weight just kind of dropped off. Travis, he was the one who hooked me up with the gym card. He's the one who took me there. We worked out together a lot. It was real cool." The opportunity to lose weight, build strength, and improve fitness had a positive effect on Alex's selfconfidence, social relationships, and his "psyche," which makes sense, since, as he pointed out, “...it's pretty well established that exercising makes your brain better.”

\section{Social opportunities}

Long-term mentoring relationships provided participants opportunities to form and strengthen relationships with peers. Sometimes a single Friend would organize events and outings for multiple youth, and other times multiple Friends would bring youth together for activities. Although participants' level of participation in the programming provided at the organization's main office varied greatly—some enjoyed and looked 
forward to weekly events and others rarely attended - almost all participants explicitly recognized and acknowledged the value of the connections they were able to make with others their age through the program.

Jacquie particularly appreciated a group that her mentor created with other FOTC staff with the purpose of getting girls connected to positive peers, "We did overnighters at the beach with this this group we call Girls Worth Watching, and it was her and a few other mentors, and we were all girls at the same grade and age, and we just used to hang out a lot...so I connected with a lot of people my age through her and the other mentors." Like other Friends, Sharon identified and encouraged Jacquie's interests, which created more social opportunities with peers. Jacquie said:

I really was into bracelets in middle school, so she would like buy me bracelet kits and it would be me and some of the other girls, and we would make bracelets, and some of the other girls were with different mentors...Another thing that we did is, I do a lot of church activities with Sharon because we're both Christian, and I'd do little Youth Summits here and there when they have them. Sometimes they're through her church, so I'll just go 'cause I know some of the girls who go too.

For Gabriel the group events at Friends were important, and gave him a chance to connect with peers in a way that he rarely did outside of the program. Gabriel said, "Friends of the Children is really good about, you know, bringing kids together as well. Group events, I like those...I don't talk to a lot of kids usually. I don't get a lot of, you 
know, nice conversation with kids my age. I honestly don't like kids my age. So when I do get a conversation with a kid my age, it's pretty nice. It's a breath of fresh air." As Gabriel's relationships with Paul and Emmett helped him become more and more comfortable with social interactions, he was also able to connect with other kids in his homeschool study group. He mentioned, "doing the lessons and things like that for school, that's pretty fun too. Yeah, learning the same thing as other kids. I was homeschooled for the longest time and getting into the study group is actually pretty fun. Learning together." In this case, the influence of Gabriel's mentoring relationships facilitated an opportunity for positive social interactions that had an indirect, but not insignificant, benefit of helping Gabriel enjoy school more.

Danielle particularly appreciated the opportunities to get together with Maria and other girls from the program, and said that while these outings and trips were fun, they were also important for learning new skills, "We went to the beach and we were all girls so we talked about girly stuff, and then when we get older what will happen - all that fun stuff. And we hung out on the porch and watched movies and walked on the beach and went grocery shopping and learned how to make new foods and how to survive for ourselves. Not necessarily for ourselves, but...

Me: You were learning some independence, some skills...

Danielle: Yeah. And then we just hung out and did crafts and played board games."

Although this description of hanging out, doing crafts, and playing games illustrates the importance of the experience of "being together" with peers, the larger 
opportunity to come together in this way - to go to the beach, to learn how to make new foods, to begin to learn to be independent - this opportunity would not have existed if not for her relationship with Maria.

\section{New foods}

A theme that occurred very frequently when participants talked about why their long-term relationships were meaningful was food. Long-term mentoring relationships gave youth an opportunity to explore foods that they had never tried, often raising their level of awareness about other cultures in the process. Alex talked about how his food explorations with Travis expanded his thinking, "Oh, he also introduced me to exotic food, like really good Chinese food, spicy Asian, spicy Mexican, stuff like that. Stuff I'd never had before. He kind of opened up my view." Opportunities to try new restaurants presented opportunities to experience and appreciate things that were unfamiliar and to explore new perspectives.

For Danielle, trying new foods was related to an increased sense of confidence and a new willingness to take healthy risks and enjoy the moment, "I think the most important thing is the support and the willingness for what they will do for youand the opportunities to try new things, like I would never, ever, ever eat Thai food, ever, and Maria was like, 'Just try it, just try it, just try it,' and she got me into trying new things, and I'm not scared of much other than spiders, and I guess like to go places - to not be afraid of like what could happen and just be happy that what's happening right now is happening, like to go hiking or to go camping or to go swimming in the river, to... anything! They're all adventures.” Danielle experienced Maria's encouragement to 
try new things as a way to learn to not be afraid and to live in the moment, as a series of "adventures," and as valuable "opportunities."

Sean's relationship with Jesse has opened his eyes to various Asian cuisines. He said he had been trying, "Lots of different Asian food. I'd never really been to Asian, any sort of Chinese or Japanese or any type of food like that. I just went to Sushi Land for my first time. A month and a half ago he took me there and I just pigged my face out...he still plans to take me to Chang's Mongolian Grill. I've never been there." Sean experiences these culinary explorations as, "another thing we bonded over. Just food. Good food. Food is my thing. I love food. I know so many good food places.”

Dante was probably the most excited about exploring new foods and restaurants around town, and it was clear that his close relationship with Jesse was intimately related to these new experiences. Dante told me,

"We like to explore new things. Like yesterday, we were hanging out, we went to Mellow Mushroom. Have you been there...we ordered the Funky Q Chicken. You know the barbecue chicken? Bacon, and it's like, oh my god, it was so good. So good, oh. Chang's Mongolian Grill. Delicious again. Love that place too. Ohana's, have you been there, the Hawaiian place? Okay, I'm trying to think of other places we've been recently. Dutch Brothers! Ohhhhhh! Dutch Brothers, but I'm not a coffee guy, so I drink the smoothies. So delicious. Yeah, we tend to go there a lot. It's just 
because, you know, he loves that he knows that I love the place, so he's like, 'Order him the smoothie because you know that's what he wants."

"He knows you well," I said.

Dante laughed, “He does know me well, that's true, he does. We also went to Killer Burger, have you been there? $58^{\text {th }}$ and Sandy, I think. You need to go there, it's great. Yes, order the Black Molly. It's basically a burger with, I think, not cheddar, not provolone, um...Tillamook cheese, and then it was like caramelized onions and it has some Philly cheese steak. So, it's like steak in a burger and there's more ingredients on it, too-I don't remember off the top of my head — but it's just huge, and it's just delicious."

\section{Employment and professional development}

Another significant element of the long-term mentoring relationships for youth was the opportunity to develop job skills and find internships and employment. Some participants took advantage of summer employment and internship programs offered through FOTC, and others used the support and assistance of their Friends to find and apply for available positions.

Danielle said she appreciated that “...there are summer internships, too, and they provide jobs for thirteen-year-olds and above to have a summer job and to get paid and learn how to do work, like interviews and the job process." She also had the good fortune of connecting directly with her potential future profession through her relationship, since 
Maria, as Danielle said, "role-modelled that for me," and demonstrated that "someone can be there for a child without expecting a lot." She said she realized simply, "I just want to work with children."

Hugo found an internship at the Oregon Zoo, and he described the roles Derrick played in helping to make it happen,

He brought this application for me for an internship at the zoo. And then he went over it with me and I filled it out, but he was helping, giving me some ideas of what I could put on the application, and then when the time came, they called me for meetings, and Derrick was the one that took me back and forth to the zoo, but there was like a total of three meetings, so I was really happy when I actually got the internship, and it was cool that Derrick was able to help me out like that. Probably without Derrick I wouldn't have found out about the internship or even tried applying

for it. It lasts for three years-I started in April. It's a paid internship, so I get checks twice a month, and it's also good for job experience.

Derrick alerted Hugo to the opportunity, supported him through the application process, and drove Hugo multiple times for meetings and interviews. In addition to providing this specific opportunity, Hugo said that Derrick also provides motivation and reminders about what it takes to be successful, to have a meaningful career. Hugo used that motivation to explore career options beyond his internship, "I thought it would be really cool to be a surgeon" or "maybe a paramedic." 
Kianna said that sometimes when she is just hanging out with Trayvia, they work on job-related activities together, "Sometimes I just call and be like, 'You at the office? Yeah. I'm on my way.' We just do whatever. She can just work on what she got to work on, I do what I gotta do. We filled out job applications together, she helped me, we did our resume, just spend time really." Working on job and career-related activities is experienced as just part of "spending time" to Kianna, an indication that her relationship with Trayvia includes exploring opportunities for work, or connecting to educational opportunities that will expand her career options. When Kianna quit school after the birth of her son, Trayvia helped her get enrolled in a school that had childcare. Kianna moved steadily toward graduation after that, and told me, "I have so many things I want to do. I was thinking of going to beauty school but...now I want to go to school for forensics."

Sean has found Jesse's support and reminders beneficial in his journey to figure out his plans for after high school graduation,

I was thinking of going into the course for firefighting and then possibly going city firefighting. There's a guy on the board here that maybe has connections to the fire chief or something. So [Jesse]'s been really like, 'Hey, if you still wanna do that, there's a couple more things.' Actually, he just mentioned to me not too long ago, I have to fill out a couple more things if I plan on going directly after high school...He was trying to figure out how I could do that. He told me maybe I should call him and ask him what I should do to go about doing that so it's not too 
late...I wasn't even thinking of it like that. I was just like 'Yeah, I'll put in all that stuff at the beginning of the New Year.'

The journey toward employment and a career can be long and confusing, particularly for youth who have faced significant obstacles along the way. For Sean and others, the commitment of their Friends to helping out through every step of the process was key. Mentors facilitated opportunities to learn about careers, helped find leads for open positions, provided important logistical support during the planning, application, and interview processes, and were encouraging, positive, and supportive from beginning to end. 


\section{Chapter 11: Discussion and Implications}

I came to this project with very little idea about what kinds of stories participants would share with me when I asked them what their relationships with their mentors meant to them. I also had little idea of how my own perspectives on mentoring relationships would evolve as I listened, learned, dug deeper, and synthesized the information. As a professional educator and social worker, with years of experience working with youth in foster care, I know from experience and from the literature that mentoring matters and mentors are important. What I didn't know was what exactly these long-term mentoring relationships really meant to youth.

The previous chapters presented descriptions and interpretations of the most important themes that emerged from my engagement with the youth and the deeply personal experiences they shared with me. For the participants in this study, long-term mentoring relationships meant unconditional support and commitment, consistent and reliable help in difficult situations, the chance to develop and appreciate one's own identity, and a path to expanded opportunities in many facets of life. Each participantwith a unique personality, history, family, and set of values and beliefs_ experienced these aspects of their relationships in different ways, but the four global themes that constitute the essence of the relationship experience were unmistakable.

The poems presented at the beginning of each chapter were intended to provide powerful and complementary illustrations for those themes by capturing some of the emotional content that can be lost in the process of analyzing, categorizing, and describing complex human phenomena. These themes and poems, however, should not 
be regarded as any kind of final word on what the experience of having a long-term mentor is like for youth. Other interpretations, even of the same data, are entirely possible. As van Manen (1990) said, "A phenomenological description is always one interpretation, and no single interpretation of human experience will ever exhaust the possibility of yet another complementary, or even potentially richer or deeper description" (p. 31, italics in original). It is also quite possible that long-term mentoring relationships for youth in other programs differ in some ways from those of the participants in this study. Rather than a definitive answer, I hope the ideas introduced here will serve as a useful and inspiring point of departure for further inquiry into the nature and importance of these unique relationships.

The remainder of this chapter will describe the implications of the findings for youth mentoring practice and research, including specific recommendations for youth mentoring programs and professionals as well as for the field of social work more generally.

\section{Lessons Learned}

Over the course of this study, as I identified and developed the themes that seemed to be at the core of participants' experiences, I also reflected on the significance of those themes for everyone involved in these relationships-youth, Friends, the organization, parents and families, schools, social service agencies, and others. Through these reflections, several important points emerged about long-term youth mentoring relationships that may be important and useful for mentoring professionals, participants, 
researchers, funders, and other stakeholders to understand and consider, and so I believe they are worth further discussion here. These major points include:

- The long-term mentoring relationship is central in a young person's life

- Duration matters: the "long-term" element is key to the power of the mentoring relationship experience for youth

- Long-term mentoring relationships go deep, and likely affect nearly all areas of a youth's life

\section{The Long-term Mentoring Relationship is Central}

One of the most important lessons from this study, one that occurred to me slowly over time, is that long-term mentoring relationships are centrally important to the youth who experience them. This realization took time because the centrality of the relationships for each youth looks quite different. Some participants thought of their Friends as an "aunt" or "big sister" while some said "best friend" and others said "father figure." For several participants who perceived a lack of parental support in their lives, mentors provided many of the supports that parents often provide for kids, including both the social/emotional and the concrete/instrumental types of support described in Chapter 7. For youth with strong parental support, mentors played different but no less important roles, much like a best friend or a sibling is no less important to a teen than their parents.

For many youth, Friends embodied different supportive roles at different times depending on the changing needs of the youth. These relational dynamics described by participants support the assertion by Goldner and Mayesless (2008) that mentors may at 
times play the part of parent, therapist, friend, and teacher, and that "the uniqueness of the mentoring relationship is rooted in the mentor's capacity to move freely in and out of these roles without embodying any of them, as well as to juggle the protégé's diverse set of emotional needs, or the phases of the mentoring relationship," (p. 423). It is likely that this kind of flexibility that mentors demonstrate in order to meet the specific needs of youth is one reason that every youth who participated in this study described a primary role that their Friend has played in their lives.

Friends took youth on their first camping or beach trips, attended their sporting events, worked with them for hours each week on homework, advocated for them in school meetings, helped them find their first jobs, and stayed with them all night when they had surgery or while their siblings were being born. Not one participant said or suggested that their Friend was only important sometimes, or had once been important but was no longer a significant presence. Some youth suggested that their relationship was so important, "mentor" was an inadequate term to describe the relationship. Kianna said, "We have a really close relationship, like beyond her just being my mentor...our relationship is way beyond that." Variation among relationships in this study was not in the level of importance, but in some of the specific ways that Friends were important to each youth.

The significance of Friends in participants' lives was often related to the issues or interests that were most important to the youth. For example, Gabriel valued the engagement of Emmett in his music and video work while Sarah appreciated Becca's involvement in her artistic endeavors. It was important to Jacquie that Sharon attended 
most of her sporting events, and Dante was clearly thrilled that Jesse shared his enthusiasm for discovering and trying new foods and places to eat. Whether the interests were developed independently by youth or together with their Friend through the relationship, participants felt the focus was always on their enrichment and benefit. Keeping the relationship youth-centered, it seems, created the conditions for youth to make a place for Friends in the very inner-circles of their lives.

The focus on youth-centered activities and youth interests is a key component of the Positive Youth Development (PYD) approach described earlier that seeks to promote "thriving" rather than focusing on risk reduction and resilience (Benson, Scales, \& Roehlkepartain, 2010). The PYD framework suggests that mentors help young people find the "sparks" that inspire them, "providing energy, joy, purpose, and direction." For the youth in this study, the long-term mentoring relationship with their Friend gave them ample time and opportunity to identify, explore, and pursue their "sparks," with one result being that youth perceived the mentoring relationship as being transformative and central to their development. It is beyond the scope of the current study to examine how Friends facilitated participants' connections to their sparks, but it is clear that the lived experience of connecting with a mentor through common interests provided depth and meaning to the mentoring relationship from the youths' point of view.

\section{"I don't know what I would have done..."}

Another indication that Friends occupied a centrally important space in participants' lives was that many youth couldn't imagine where they would be or what 
they would be doing in their lives without their Friend. When we think of our most important relationships, we are so close and so connected to those people that life without them would literally be a completely different life. Many participants said in one way or another, “I don't know where I'd be" or "I don't know what I would have done" without a Friend or without the program. Karin was so grateful for the support and opportunities she had in the program that she wrote a letter to FOTC's founder, Duncan Campbell, to thank him. She told me, "I seriously don't know what I would have done if I didn't have this program. There were just so many times when I was so close to the breaking point when my mentors picked me up again that, without the program I just - that was what moved me to write a letter...I was just thanking him for it because without it, I'd just be in such a different place."

Other participants did have an idea of where they would be without a mentor, and those hypothetical situations were grim. Jacquie said, "I would not be here right now, I would probably have run away somewhere," while Dante said, "Just him not being there for me...I would have been on the street...I'd be homeless." Others said they would likely be addicted to drugs, involved with gangs, and possibly dead. Of course there's no way to know what would have happened for these youth under other circumstances, but their unequivocal responses demonstrate how essential long-term mentoring relationships feel to youth, and help to explain why youth feel that Friends occupy such a key spot in their lives. 


\section{Implications of Centrality}

The fact that long-term mentoring relationships are centrally important to youth has important implications for mentoring programs, case workers, teachers and school staff, and others who work with youth. First, if a mentor is a central figure in a young person's life, then it may suggest that mentors should be included in important events and decisions as often as it is appropriate. Mentoring programs that have pairs in long-term relationships can ask parents' and guardians' permission for mentors to contact schools and teachers, and request that mentors be invited to conferences, IEP meetings, and special school events. Considering Candace's smile when she recalled Naomi's presence at the births of both of her younger siblings, it may be misguided under the circumstances to view or treat mentors as outsiders in terms of school and family when the youth see them very clearly as insiders in their lives.

Participants' descriptions of their relationships with Friends largely reflected the characteristics of the "hybrid" type mentoring relationships that Keller and Pryce (2010) described in their study, involving a combination of friendship and adult guidance. For Sarah, what set her relationship with Becca apart from other relationships was that unlike with her parents, friends, and teachers, she could talk to Becca about the widest range of important topics, "personal, academic, everything." She could talk with Becca about her relationship with her boyfriend one minute, and shift to planning for college the next. The "hybrid" characteristics of the mentoring relationships mean that other professionals, such as case managers, can potentially connect with youth through the mentoring relationship to better understand youth and their situations, as well as their strengths, 
challenges, and goals. As Dante said, he doesn't expect the same kind of depth and commitment from his relationships with school counselors or case workers that he does from Jesse, but his relationships with those other professionals in his life have been strengthened by the support he receives from Jesse daily.

Another important implication of understanding that long-term mentoring relationships are central for youth is that it suggests that programs must be intentional about facilitating successful transitions out of the program. A number of participants said that they believe their relationships will last "forever." While it is understandable that a relationship that has lasted five, ten, or twelve years might seem eternal to a young person, it is important to ask to what extent it is realistic, or even desirable, for youth to expect the mentoring relationship to continue beyond graduation from the program and indefinitely beyond? Programs that have invested so much in creating and maintaining strong relationships over time seem to have an obligation to make sure that the transition out of the formal part of the program includes honesty, clarity, support, and resources for youth who might not be prepared for the feelings of loss or uncertainty that might occur.

\section{Long-term is Key}

While the youth made it clear that Friends "being there" for them was a vitally important aspect of the mentoring relationships, it is also apparent that the "long-term" element was similarly important for cultivating the sense of trust and connection on which "being there" relied. A few participants talked about the long period of time that it took for trust to develop, for them to believe that their Friend was reliable and had their 
best interests genuinely and consistently in mind. Nathan said, for example, "I didn't really know what to think or what to make of him for like the first year, two years. After that, I realized that he's genuinely a good guy." The fact that deep, trusting relationships between Friends and youth take time to develop may help to explain findings such as those of Grossman and Rhodes (2002) introduced in Chapter 2, which found that longer relationships predicted improvements in academic, psychosocial, and behavioral outcomes.

Karin suggested that she would be reluctant to invest herself in a relationship that was not going to last. She said, “....if you know somebody is limited you're not going to put your effort into that as much. Like if you think it's forever or for even 12 years or more, then you'll be like, 'Okay, yeah.' But if you think, 'I'm willing to have you for like 3 months or 2 years,' there's going to be this block. You're not going to want to go the distance all the way. If you have somebody who's there for 12 years, like, 'Uh, fine. If you can be around for 12 years, I might as well put some effort into this." Pederson's (2009) study of extraordinary mentoring relationships duration as one element that made relationships special, highlighting the story of one particular mentor who was matched with an 11 year-old girl, and many years later with that mentee's children, committing more than 29 years of her life to mentoring the youth in one family.

In addition to youth needing time to connect and feel comfortable with mentors, it sometimes took parents and family members a significant amount of time to trust their child's Friend. Alex said, "My grandma, you know, she's always gotten along with Travis. It took my dad like 2 or 3 years to kind of get acquainted with him. And my mom, 
for like 4 or 5 years, she was kind of distant, but after that she was just fine." There is evidence to suggest that parental involvement in mentoring relationships helps support positive outcomes for youth (Mentoring Resource Center, 2005), and a study that explored the pathways of influence for mentoring in adolescence found that improved relationships with parents mediated positive outcomes for mentored youth (Rhodes, Grossman, and Resch, 2000). Derrick took the time to connect with Hugo's family, and Hugo said, "Derrick talking to my mom...or getting to know my brothers is something that really helps him understand us I think." The long-term nature of the relationships explored in this study allowed youth plenty of time to get to know and trust their Friends, and in some cases Friends were able to take the time to make genuine and meaningful connections with participants' families, which made the experience of the relationship for youth even stronger.

With regard to the duration of the mentoring relationships, it important to remember that many of the youth who participate in the FOTC program, and certainly many of the youth who participated in this study, had challenging and often traumatic experiences that made trusting people extremely difficult. Alex, Danielle, and Nathan all stated explicitly that they had to overcome a general distrust of adults to form a close connection with their Friends, and that process clearly happened slowly over time. Nathan went so far as to say that distrust had become an ingrained part of his personality. Sean said that the trust that built over time allowed him to accept constructive criticism from Jesse without getting upset. When Sean made a comment one day that Jesse found offensive, Jesse let Sean know how he felt. Sean told me, "It was just a life lesson 
because I trusted him. It's been a year and a half, two years that I'm with him now. I can take criticism from him... so it was alright. It's gotta be serious if he's actually gone out of his way to tell me... When he told me, I was just like I'm sorry. I apologized and I thought about it and he was completely right."

\section{Implications of the Importance of Duration}

The significance of duration in long-term mentoring relationships is important for mentoring professionals and programs, as well as participants and parents, to understand. Since trust develops gradually, especially for those youth who have histories of trauma, loss, and other challenges, mentoring programs must recognize that there is no short cut to developing strong, authentic relationships. Programs that wish to realize the benefits of long-term connections between youth and adults should create programs that are structured and adequately resourced to provide consistency and support over the longterm. One way FOTC has tried to accomplish this is by requesting long-term commitments from those who are hired to be Friends, and paying competitive salaries so that remaining a Friend is a feasible and attractive option for many people (Lakind, Eddy, $\&$ Zell, 2014). Although these commitments are not contracts and are not legally binding, they do set a standard and an expectation that relationships at FOTC are meant to last. Indeed, retention among Friends is strong, with an average tenure of over seven years, and with a handful of Friends who have been with the program 15 years or more.

Programs can also maximize the potential benefits of long-term mentoring relationships by anticipating and planning for transitions and endings. It is inevitable, 
even with relatively long-term commitments, that relationships will change and likely end at some point. As with any other professional position, Friends leave FOTC for any number of reasons. The promotions of several Friends to team and program leader positions at FOTC meant that a number of kids on each of their caseloads had to be reassigned to other Friends. Even the longest lasting relationships at FOTC are officially terminated when youth graduate from high school. Knowing that trust-building takes time and that some youth are more vulnerable to loss than others due to their histories and life circumstances, it seems essential that programs develop intentional, youth-centered processes to help youth anticipate, understand, and successfully navigate inevitable relationship transitions.

Another reason for programs to consider the importance of duration for the development of deep, meaningful mentoring relationships is that program structures and policies can be designed to nurture - or hinder — the trust-building process. Since trust can take a significant amount of time to develop, programs should provide adequate time, space, and support to facilitate the relationship development process. Early expectations should not be set too high, nor should relationships that encounter early struggles be discounted or written off. As discussed earlier, involving parents, grandparents, guardians, teachers, and other significant positive adults in the mentoring process can help ensure strong and comprehensive support is provided throughout the relationship. As suggested by Keller's (2005a) systemic model that highlights the importance of collaboration between mentors, families, and professionals, long-term support for mentoring relationships from multiple caring adults also means that challenges are likely 
to be addressed more effectively. Sarah said that when she and Becca talk to Sarah's mom together, “That feels amazing because my mom is actually listening to me...she's hearing my thoughts." Focusing explicitly and intentionally on fostering longer-term relationships can provide participants significant advantages that would be less likely to occur or develop in relationships of shorter duration.

\section{The Experience of Long-Term Mentoring Relationships is Deep and Broad}

Another important point suggested by the findings of this study is that long-term mentoring relationships affect youth deeply and in many different aspects of their lives. By “depth” I am referring to fundamental developmental processes that long-term mentoring relationships seem to influence. The chapter on identity development provides many examples of participants whose personalities, values, confidence, goals, and beliefs were shaped in significant ways by the experience of having a long-term mentor. Lakind, Atkins, and Eddy (2015) describe Friends' perceptions of environmental risks and challenges that youth in the Friends of the Children program encountered that made success so difficult to imagine for many participants. Youth who had learned to expect disappointment and rejection instead experienced trust and compassion from their mentors. Kianna "never felt loved at home," and through her relationship "learned how to be loved." Sean said he's learned a lot of "life lessons" from being with his Jesse, "down to things like language and how I carry myself.” Dante shared his experience of selfdiscovery, from feeling literally like "nobody" to a young man who "learned just how to be myself...I make songs, I make poems, I'm more creative now than I ever was before." Alex went from seeing himself as "a deadbeat pretty much" who "probably still would be 
if it wasn't for [Travis]," to a confident entrepreneur and one of the few 18 year olds "who can tell you about hydrogen fuel cell technology." These are not small changes or minor improvements. These are truly transformative lived experiences that happened because youth had mentors committed to them for the long-term.

By "broad," I am referring to the extremely wide variety of ways that participants found support, comfort, meaning, and inspiration in their relationships with Friends. Danielle experienced a new appreciation for cultural diversity and found a passion for social work. Dante writes and performs songs and Sarah writes stories and poems. Jacquie discovered in Maria a spiritual guide and her number one cheerleader for basketball, volleyball, and track. Sean wants to be someone that other people look up to like he looks up to Jesse. Kianna "learned how to be a lady...how to do it a different way, a better way, to take care of myself." Karin came out as gay to her Friend and found an adult ally who "was there for me during that time, like a lot, like I just don't know what I would have done without her there." The examples go on and on, from bonding over food and exercise to conversations about God and evolution. There is practically no limit to the ways in which participants and mentors connected, created, bonded, celebrated, mourned, planned, and grew together. So what kind of lessons can be gleaned from such a menagerie of experiences?

For one, the variation in activities and areas of focus along with the consistency in depth and significance suggests that each relationship is as unique as the two individuals who make up the pair. There is no formula for "how to be a great mentor," at least as far as types of activities are concerned. Kianna enjoyed running errands and hanging around 
the office while Deion liked to bike 200 miles from Seattle to Portland with Emmett. Most relationships, because they lasted for so long, went through stages of focusing on fun and hobbies, academics and healthy relationships, health and nutrition, finding ways to cope with adversity, and celebrating life achievements and successes. For participants, mentoring relationships influenced their lives and relationships at home; affected their grades, academic skills, behavior, and attitudes about school; connected them to their "sparks," whether that was sports, music, religion, physics, or service to others; helped them become themselves and develop confidence, social skills, compassion, and a positive vision for the future.

None of these wide ranging influences are likely to occur without the trust that develops in the mentoring relationship over the long-term. The depth and strength of the interpersonal connection is the foundation on which many of these other developments and achievements are built. I believe there is profound truth in a statement that I heard from a speaker at a mentoring conference one summer, which said, "When it comes to mentoring, the relationship is the intervention." It is the vehicle through which profound change happens, and those profound changes reflected in the experiences of the participants in this study appear to rely largely on the power of the long-term relationship with Friends.

\section{Further Implications for Social Work Practice}

The information and understandings generated through my interactions with the twelve youth participants in this study are necessarily colored by the subjectivity of our 
individual experiences as well as the unique dynamic that developed between me and each youth during the couple of hours that we met. Despite the unique quality of my interactions with these 12 youth, I believe the findings have relevance for social work professionals and potential applications for the youth mentoring field in particular.

First, a general takeaway from this project is that it is important for those who work with youth to take the opportunity to hear the stories of youth participants and understand their perspectives in order to provide programs and services that are responsive to their needs. In contexts outside of youth mentoring-including child welfare, schools, and other community organizations - research has demonstrated that youth voice can be instrumental in guiding changes in practice and policy that yield better outcomes for youth (Friesen, Koroloff, Walker, \& Briggs, 2010; Mitra, 2004; Zeldin, 2010). Until now, youth perspective has been almost completely absent from the youth mentoring literature, yet this study demonstrates the depth and significance of youth contributions to the conversation about what mentoring is, what it can be, what it does, and what it can do. In this case, the youths' voices and stories reflect the essence of longterm mentoring relationships, and bring a number of elements of those relationships that were once assumed or unknown to the surface for us to explore, analyze, and learn from.

Another implication of this study's findings is that it may be necessary to utilize multiple approaches to "knowing" to get a deeper, more nuanced understanding of youth experience. The themes identified in the process of coding, grouping, and interpreting the interview transcripts using a logical and categorical approach (i.e. Theme A and Theme B seem to be related and both belong in Category C) described in prose in Chapters 7-10 
yielded important insights into the nature of youth experience in long-term mentoring relationships. Yet, these categories and prose descriptions cannot adequately capture the emotional content that is communicated through the poems that are presented at the beginning of Chapters 7-10. We can only imagine the loss and loneliness Candace experienced while her mom was incarcerated when it is mentioned in Chapter 8, but the short, sharp phrasing and repetition of "it was kind of hard when I was little" brings the vulnerable quality of her voice directly to the reader. That vulnerability and Candace's knowledge that "I know I'm nice, good to get along with," is intentionally juxtaposed with her ability to "be really mean, like I don't even care" to illustrate the struggle of being left to one's own devices at a young age, a time when, she tells us, "all I really had was a dog."

There is power and richness in the meanings that can be discovered through poetic and other creative approaches to inquiry — qualities that can be diminished, misconstrued, or lost when explored in other ways. This is not to say that transcript poems or arts-based inquiry are always necessary or are in some way superior to other methods of exploring human phenomena. Rather, they should be considered as viable, and potentially complementary, options for understanding human experience from a unique and emotionally resonant perspective.

For mentoring programs, this study provides clues for facilitating relationships that are deep, authentic, and transformative. Unconditional support and a sense of trust are key, and patience is often required as youth and families may take months, and sometimes years, to feel that a mentor is truly committed to the relationship. Youth value 
the sense that a mentor is "there" for them, and "being there" is particularly important in times of crisis or difficulty. Another important point is that mentoring relationships can help youth connect with their "sparks," the things that motivate and inspire them, and can help youth feel good about who they are and the direction they are going. At the same time, mentoring relationships can influence a young person's identity, help them develop social skills, guide them toward healthy choices and new experiences. All of these things that mentoring relationships can do, however, appear to be invariably built upon a foundation of genuine, trusting relationships that develop gradually over time.

\section{Implications for Future Research}

The findings of this study may provide a compelling point of departure for further research on long-term youth mentoring relationships. Future research could address the experiences of youth in long-term mentoring relationships with volunteer rather than professional mentors, or youth in programs other than Friends of the Children. Another area the current study did not explore was the experiences of youth who dropped out or did not successfully complete the program. All of the participants in the current study were in the FOTC program and actively engaged in a long-term mentoring relationship at the time of the interview, but what is it like to experience a long-term mentoring relationship that ends earlier than anticipated? Also, these long-term relationships constitute long-term personal and professional commitments for mentors. It is important to understand the experiences of mentors as well, including the potential effects of longterm relationships on job satisfaction, health and well-being, family functioning, and more. 
Of course one of the most obvious research questions that this study raises, and one that is currently being explored through a federally-funded randomized controlled trial, is: what are the effects of long-term mentoring relationships for youth? The findings of this study suggest that participants experience long-term mentoring relationships as transformative and helpful in many different ways, but it is important to understand just what influence these relationships have on confidence and other attitudes of self; educational achievement; physical and mental health; cognitive, social, emotional, and identity development; peer and adult relationships; and long-term outcomes related to family, career, and other aspects of well-being.

\section{Limitations}

There are several limitations to the current study that should be noted and considered. First, as the earlier Max van Manen quote reminded us, interpretive phenomenology offers only a single interpretation of a phenomenon, and future studies may support, expand upon, or challenge my interpretations as described in this work. Also, although qualitative work is not intended to produce generalizable results, the current study has a particularly limited focus in that all of the youth participants were engaged in the same mentoring program. It is quite possible that the theoretical approach and the unique characteristics of the Friends of the Children program produced findings that would be somewhat different if the relationships developed elsewhere.

Two other limitations of this study are related to intended efforts to ensure trustworthiness that did not work out as originally planned. It was my intention to engage 
each participant in at least one member-checking session to solicit their feedback on my interpretations as well as my poems. Due to significant delays in analyzing the transcripts and writing up the findings, most of the participants had graduated from the program by the time I was ready to share the work with them. Several Friends who had initially put me in touch with youth had also left the organization. As a result, my member checking was limited to just two participants, both of whom very graciously took the time to review the major aspects of my work and offer guidance and suggestions. I had also intended to enlist a volunteer to engage in "peer debriefing" sessions specifically to get feedback on the quality and resonance of the transcript poems. Unfortunately, the two skilled and accomplished poets I contacted were both unable to provide the assistance I was seeking. I am fortunate, however, that my dissertation committee members played an active role in providing guidance, support, critique, and feedback throughout the research process. 


\section{References}

Akkerman, S., Admiraal, W., Brekelmans, M., \& Oost, H. (2008). Auditing quality of research in social sciences, Quality \& Quantity, 42, 257-274.

Anderson-Nathe, B. (2010). Youth workers, stuckness, and the myth of supercompetence: Not knowing what to do. New York: Routledge.

Arnett, J. J. (1999). Adolescent storm and stress, reconsidered. American Psychologist, $54,317-326$.

Bailey, C.A. (2007). A guide to qualitative field research. Thousand Oaks, CA: Sage Publications.

Barrera, M., Jr., \& Bond, D. (2005). Social support, social networks, and mentoring. In D. DuBois \& M. Karcher (Eds.), Handbook of youth mentoring (pp. 133-142). Thousand Oaks, CA: Sage.

Bassett, S. E. (1920). That young prig Telemachus. The Sewanee Review, 28, 160-171.

Benner, P. (Ed.) (1994). Interpretive phenomenology: Embodiment, caring, and ethics in health and illness. Thousand Oaks, CA: Sage Publications.

Benson, P. L., \& Scales, P. C. (2009). The definition and preliminary measurement of thriving in adolescence. Journal of Positive Psychology, 4, 85-104.

Berg, L., Skott, C., \& Danielson, E. (2006). An interpretive phenomenological method for illuminating the meaning of caring relationship. Scandinavian Journal of Caring Sciences, 20, 42-50. 
Beyer, C. (2011). Edmund Husserl. In E. N. Zalta (Ed.), The Stanford encyclopedia of philosophy (Summer 2011 Edition). Accessed May 13, 2011 from http://plato.stanford.edu/archives/sum2011/entries/husserl.

Big Brothers Big Sisters of America (n.d.). Our programs get things started. What we do. Retrieved October 16, 2011 from http://www.bbbs.org/site/c.9iILI3NGKhK6F/b.5968193/k.5031/Our_programs_g et_things_started.htm

Blakeslee, J. E., \& Keller, T. E. (2012). Building the youth mentoring knowledge base: Publishing trends and co-authorship networks. Journal of Community Psychology, 40, 845-859.

Boyd, C. O. (2001). Phenomenology: The method. In P. L. Munhall (Ed.), Nursing research: A qualitative perspective (pp. 93-122). New York: NLN Press.

Boyer, P. S., Clark, C. E., Halttunen, K., Kett, J. F., \& Salisbury, N. (2010). The enduring vision: A history of the American people. Belmont, CA: Wadsworth.

Butler-Kisber, L. (2002). Artful portrayals in qualitative inquiry: The road to found poetry and beyond. The Alberta Journal of Educational Research, 48, 229-239.

Butler-Kisber, L., \& Stewart, M. (2009). The use of poetry clusters in poetic inquiry. In M. Prendergast, C. Leggo and P. Sameshima (Eds.), Poetic inquiry: Vibrant voices in the social sciences (pp. 3-12). Rotterdam: Sense Publishers.

Catalano, R. F., Berglund, M. L., Ryan, J. A. M., Lonczak, H. S., \& Hawkins, J. D. (1998). Positive youth development in the United States: Research findings on 
evaluations of positive youth development programs. Retrieved September 13, 2010 from: http://aspe.hhs.gov/hsp/positiveyouthdev99/index.htm\#toc.

Chan, C. C., \& Ho, W.C. (2008). An ecological framework for evaluating relationshipfunctional aspects of youth mentoring. Journal of Applied Social Psychology, 38, (4), 837-867.

Charity Organization Society of the City of New York. (1883). Hand-book for friendly visitors among the poor. New York: Putnam's.

Chinman, M. J., \& Linney, J. A. (1998). Toward a model of adolescent empowerment: Theoretical and empirical evidence. Journal of Primary Prevention, 18, 393-413.

Classen, L. (2011). Building youth/mentor relationships. Retrieved June 3, 2011 from http://ctb.ku.edu/en/tablecontents/sub_section_main_1208.aspx.

Conroy, S. A. (2003). A pathway for interpretive phenomenology. International Journal of Qualitative Methods, 2(3). Article 4. Retrieved January 30, 2010 from http://www.ualberta.ca/ iiqm/backissues/2_3final/pdf/conroy.pdf.

Cope, J. (2005). Researching entrepreneurship through phenomenological inquiry: Philosophical and methodological issues. International Small Business Journal, 23, $163-189$.

Coulter, E. K. (1913). The children in the shadow. New York: McBride, Nast and Company. Retrieved June 22, 2011 from http://openlibrary.org/books/OL13521171M/The_children_in_the_shadow. 
Coulter, E. K. (1917). The Big Brothers. Journal of the National Institute of Social Sciences, 3, 102-106.

Creswell, J. W. (1998). Qualitative inquiry and research design: Choosing among five traditions. Thousand Oaks, CA: Sage.

Cunningham, A. E. \& Stanovich, K. E. (2001). What reading does for the mind. Journal of Direct Instruction, 1, 137-149.

Dall'Alba, G. (2009). Introduction to diverse approaches to phenomenology and education. In G. Dall'Alba (Ed.), Exploring education through phenomenology: Diverse approaches, (pp. 1-3). West Sussex: Wiley-Blackwell.

Denzin, N. K., \& Lincoln, Y. S. (2003). Collecting and interpreting qualitative materials. Thousand Oaks, CA: Sage.

Denzin, N. K., \& Lincoln, Y. S. (2005). Introduction: The discipline and practice of qualitative research. In N. K. Denzin \& Y. S. Lincoln (Eds.), The Sage handbook of qualitative research, 3rd ed. (pp. 1-33). Thousand Oaks, CA: Sage.

DeWitt, L., Ploeg, J., \& Black, M. (2010). Living alone with dementia: An interpretive phenomenological study with older women. Journal of Advanced Nursing, 66, $1698-1707$.

DuBois, D. L., Holloway, B. E., Valentine, J. C., \& Cooper, H. (2002). Effectiveness of mentoring programs: A meta-analytical review. American Journal of Community Psychology, 30, 157-197. 
DuBois, D. L., Portillo, N., Rhodes, J. E., Silverthorn, N., \& Valentine, J. C. (2011). How effective are mentoring programs for youth? A systematic assessment of the evidence. Psychological Science in the Public Interest, 12, 57-91.

DuBois, D. L., \& Neville, H. A. (1997). Youth mentoring: Investigation of relationship characteristics and perceived benefits. Journal of Community Psychology, 25, $227-234$.

DuBois, D. L., Neville, H. A., Parra, G. R., \& Pugh-Lilly, A. O. (2002). Testing a new model of mentoring. In J. E. Rhodes (Ed.), A critical view of youth mentoring (pp. 21-57). San Francisco: Jossey-Bass.

DuBois, D. L., \& Rhodes, J. (2006). Introduction to the special issue: Youth mentoring: Bridging science with practice. Journal of Community Psychology, 34, 647-655.

Dukes, S. (1984). Phenomenological methodology in the human sciences. Journal of Religion and Health, 23, 197-203.

Eby, L. T., Allen, T. D., Evans, S. C., Ng. T., \& DuBois, D. L. (2008). Does mentoring matter? A multidisciplinary meta-analysis comparing mentored and non-mentored individuals. Journal of Vocational Behavior, 72, 254-267.

Freedman, M. (1988). Partners in Growth: Elder mentors and at-risk youth. Philadelphia, PA: Public/Private Ventures.

Furman, R., Shears, J., \& Badinelli, M. (2007). Mexican men and their fathers: Analyzing and representing data through the research poem. Journal of Poetry Therapy, 20, $141-151$. 
Furrer, C. J., \& Kissick, K. (2008). Friends of the Children-Portland Annual Evaluation, July 2007-June 2008. Portland, OR: NPC Research.

Furrer, C. J., \& Kissick, K. (2009). Friends of the Children-Portland Annual Evaluation, July 2008-June 2009, Milestones Report. Portland, OR: NPC Research.

Gadamer, H. G. (2004). Truth and method (Joel Weinsheimer \& Donald G. Marshall, Trans.). New York: Continuum. (Original work published 1960).

Ganeson, K., \& Ehrich, L. C. (2009). Transition into high school: A phenomenological study. In G. Dall'Alba (Ed.), Exploring education through phenomenology: Diverse approaches, (pp. 66-84). West Sussex: Wiley-Blackwell.

Goldner, L. \& Mayesless, O. (2008). Juggling the roles of parents, therapists, friends and teachers - a working model for an integrative conception of mentoring. Mentoring and Tutoring: Partnership in Learning, 16, 412-428.

Grant, R. W., \& Sugarman, J. (2004). Ethics in human subjects research: Do incentives matter? Journal of Medicine and Philosophy, 29, 717-738.

Groenewald, T. (2004). A phenomenological research design illustrated. International Journal of Qualitative Methods, 3, 1-26.

Grossman, J. B., \& Rhodes, J. E. (2002). The test of time: Predictors and effects of duration in youth mentoring relationships. American Journal of Community Psychology, 30, 199-219.

Grossman, J. B., \& Tierney, J. P. (1998). Does mentoring work? An impact study of the Big Brothers Big Sisters program. Evaluation Review, 22, 403-426 
Hall, G. S. (1904). Adolescence: Its psychology and its relations to physiology, anthropology, sociology, sex, crime, religion and education. New York: Appleton.

Hays, T., Minichiello, V., \& Wright, P. (2000). Mentorship: The meaning of the relationship for musicians. Research Studies in Music Education, 15, 3-14.

Hein, S. F., \& Austin, W. J. (2001). Empirical and hermeneutic approaches to phenomenological research in psychology: A comparison. Psychological Methods, 6, 3-17.

Herrera, C. (2004). School-based mentoring: A closer look. Philadelphia: Public/Private Ventures.

Herrera, C., Sipe, C. L., \& McClanahan, W. S. (2000). Mentoring school-age children: Relationship development in community-based and school-based programs. Philadelphia: Public/Private Ventures.

Holmbeck, G. N. (1996). A model of family relational transformations during the transition to adolescence: Parent-adolescent conflict and adaptation. In J. A. Graber, J. Brooks-Gunn, \& A. C. Petersen (Eds.), Transitions through adolescence: Interpersonal domains and context (pp. 167-199). Mahwah, NJ: Erlbaum.

Husserl, E. (1983). Ideas pertaining to a pure phenomenology and to a phenomenological philosophy: First book: General Introduction to a pure phenomenology. (F. Kersten, Trans.). Boston: Martinus Nijhoff Publishers. (Original work published 1913). 
Jekielek, S., Moore, K. A., \& Hair, E. C. (2002). Mentoring programs and youth development: A synthesis. Washington, DC: Child Trends.

Jennings, L. B., Parra-Medina, D., Messias, D. K. H., \& McLoughlin, K. (2006). Toward a theory of critical social youth empowerment. Journal of Community Practice, $14,29-54$

Jones, K. R. (2009). “It's all about the children”: From vision to success at Friends of the Children-Portland. Portland, OR: Friends of the Children.

Karcher, M. J. \& Nakkula, M. J. (2010). Youth mentoring with a balanced focus, shared purpose, and collaborative interactions. New Directions for Youth Development, $126,13-32$.

Keller, T. E. (2005a). A systemic model of youth mentoring intervention. Journal of Primary Prevention, 26, 169-188.

Keller, T. E. (2005b). The stages and development of mentoring relationships. In DuBois, D.L, \& Karcher, M. (Eds.) The Handbook of Youth Mentoring (pp. 82-99). Thousand Oaks, CA: Sage Publications.

Keller, T. E., \& Pryce, J. M. (2010). Mutual but unequal: Mentoring as a hybrid of familiar relationship types. New Directions in Youth Development, 126, 33-50.

Kim, S., Crutchfield, C., Williams, C., \& Hepler, N. (1998). Toward a new paradigm in substance abuse and other problem behavior prevention for youth: Youth development and empowerment approach. Journal of Drug Education, 28, 1-17. 
Kockelmans, J. J. (1989). Heidegger's "Being and Time": The analytic of Dasein as fundamental ontology. Lanham, MD: University Press of America

Kogler, H. H. (1996). The self-empowered subject: Habermas, Foucault and hermeneutic reflexivity. Philosophy and Social Criticism, 22, 13-44.

Kroger, J. (2008). Identity development during adolescence. In G. R. Adams, \& M. C. Berzonsky (Eds.), Blackwell Handbook of Adolescence (pp. 205-226). Oxford, UK: Blackwell Publishing.

Lakind, D., Atkins, M., \& Eddy, J. M. (2015). Youth mentoring relationships in context: Mentor perceptions of youth, environment, and the mentor role. Children and Youth Services Review, 53, 52-60.

Lakind, D., Eddy, J. M., \& Zell, A. (2014). Mentoring youth at high risk: The perspectives of professional mentors. Child and Youth Care Forum, 43, 705-727.

Larkin, M., Watts, S., \& Clifton, E. (2006). Giving voice and making sense in interpretative phenomenological analysis. Qualitative Research in Psychology, 3, $102-120$.

Laverty, S. M. (2003). Hermeneutic phenomenology and phenomenology: A comparison of historical and methodological considerations. International Journal of Qualitative Methods, 2, 21-35.

Lerner, R. M. (2009). Adolescence: Development, diversity, context, and application. Upper Saddle River, NJ: Prentice Hall.

Levinson, D. (1978). The seasons of a man's life. New York: Ballantine. 
Liang, B., \& Rhodes, J. (2007). Guest editorial: Cultivating the vital element of youth mentoring. Applied Developmental Science, 11, 104-107.

Lietz, C., Langer, C., \& Furman, R. (2006). Establishing trustworthiness in social work research: Implications from a study regarding spirituality. Qualitative Social Work, 5, 441-458.

Lincoln, Y. S., \& Guba, E. G. (1985). Naturalistic inquiry. Beverly Hills, CA: Sage Publications.

Lipsey, M. W., \& Wilson, D. B. (1993). The efficacy of psychological, educational, and behavioral treatment. American Psychologist, 48, 1181-1201.

Lucas, G. (2001). The Meaning of Mentoring: We're Never Too Old—or Young—to Learn. Retrieved August 19, 2011 from http://www.edutopia.org/meaningmentoring.

Luce-Kapler, R. (2004). Writing with, through, and beyond the text: An ecology of writing. Mahwah, NJ: Lawrence Erlbaum.

MacBeth, D. (2001). On reflexivity in qualitative research: Two readings, and a third. Qualitative Inquiry, 7, 35-68.

Macquarrie, J. (1973). Existentialism: An introduction, guide, and assessment. New York: Penguin.

McIntyre, R., \& Smith, D. W. (1989). Theory of Intentionality. In W. R. McKenna \& J. N. Mohanty (Eds.), Husserl's phenomenology: A textbook. University Press of America. 
Merleau-Ponty, M. (1962). Phenomenology of perception (Colin Smith, Trans.). New York: Humanities Press. (Original work published 1945).

Mentoring Resource Center (2005). Mentoring Fact Sheet \#6. Washington, D.C.: U.S. Department of Education.

MENTOR/National Mentoring Partnership (n.d.). Waiting for Superman messaging document. Retrieved December 1, 2011 from http://www.mentoring.org/program_resources/waiting_for_superman_campaign. MENTOR/National Mentoring Partnership. (2004). Community mentoring for adolescent development trainer's manual. Waco, TX: Baylor University. Retrieved May 6, 2010 from http://www.mentoring.org/downloads/mentoring_1328.pdf.

Miller, A. (2007). Mentoring students and young people: A handbook of effective practice. New York: Taylor \& Francis.

Moran, D. (2000). Introduction to phenomenology. New York: Routledge.

Morrow, K. V., \& Styles, M. B. (1995). Building relationships with youth in program settings: A study of Big Brothers/Big Sisters. Philadelphia: Public/Private Ventures.

Morrow, S. L. (2005). Quality and trustworthiness in qualitative research in counseling psychology. Journal of Counseling Psychology, 52, 250-260.

Muhammed, M., Wallerstein, N., Sussman, A. L., Avila, M., Belone, L., \& Duran, B. (2014). Reflections on researcher identity and power: The impact of positionality on Community Based Participatory Research (CBPR) processes and outcomes. Critical Sociology, online first edition, DOI: 10.1177/0896920513516025 
Nakkula, M. (2009, July). Closeness and complexity in adult-youth mentoring relationships [PowerPoint slides]. Paper presented at the 2009 Summer Institute on Youth Mentoring, Portland State University, Portland, OR.

Neilsen, L. (2004) Aesthetics and knowing: Ephemeral principles for a groundless theory. In A. L. Cole, L. Neilsen. J. G. Knowles, \& T. C. Luciani (Eds.), Provoked by art: Theorizing arts-informed research (pp. 44-49). Halifax/Toronto: Backalong Books/Cetre for Arts-informed Research.

Offer, D., \& Schonert-Reichl, K. A. (1992). Debunking the myths of adolescence: Findings from recent research. Journal of the American Academy of Child \& Adolescent Psychiatry, 31, 1003-1014.

Parra, G. R., DuBois, D. L., Neville, H. A., \& Pugh-Lilly, A. O. (2002). Mentoring relationships for youth: Investigation of a process-oriented model, Journal of Community Psychology, 30, 367-388.

Patton, M. Q. (1990). Qualitative evaluation and research methods (2nd ed.). Newbury Park, CA: Sage.

Pedersen, P. J., Woolum, S., Gagne, B., \& Coleman, M. (2009). Beyond the norm: Extraordinary relationships in youth mentoring. Children and Youth Services Review, 31, 1307-1313.

Pittman, K. (1999, September). The power of engagement. Washington, DC: The Forum for Youth Investment. Retrieved March 17, 2011 from http://www.forumfyi.org/node/500. 
Pittman, K., Irby, M., \& Ferber, T. (2001). Unfinished business: Further reflections on a decade of promoting youth development. In P.L. Benson and K.J. Pittman (Eds.), Trends in youth development: Visions, realities and challenges (pp. 4-50). Norwell, MA: Kluwer Academic Publishers.

Pittman, K., Irby, M., Tolman, J., Yohalem, N., \& Ferber, T. (2003). Preventing problems, promoting development, encouraging engagement: Competing priorities or inseparable goals? Washington, DC: The Forum for Youth Investment, Impact Strategies, Inc.

Polkinghorne, D. (1989). Phenomenological research methods. In R. Valle, \& S. Halling (Eds.), Existential-phenomenological perspectives in psychology (pp. 41-60). New York: Plenum.

Prendergast, M. (2009). “Poem is what?” Poetic inquiry in qualitative social science research. International Review of Qualitative Research, 1, 541-568.

Pryce J., \& Keller, T. (2011). An investigation of volunteer-student relationship trajectories within school-based youth mentoring programs. Journal of Community Psychology, 29, 1-21.

Raingruber, B. (2009). Asilomar and other interpretive poems. In M. Prendergast, C. Leggo and P. Sameshima (Eds.), Poetic inquiry: Vibrant voices in the social sciences (pp. 259-274). Sense Publishers, Rotterdam.

Reece, R. L. (2000). Preserving the soul of medicine and physicians: A talk with David Whyte. The Physician Executive, 26, 14-19. 
Reynolds, J. (2004). Merleau-Ponty and Derrida: Intertwining Embodiment \& Alterity. Athens, OH: Ohio University Press.

Rhodes, J. E. (1994). Older and wiser: Mentoring relationships in childhood and adolescence. Journal of Primary Prevention, 17, 187-196.

Rhodes, J. E. (2005). A theoretical model of youth mentoring. In D. L. DuBois \& M. J. Karcher (Eds.), Handbook of youth mentoring (pp. 30-43). Thousand Oaks, CA: Sage.

Rhodes, J. (2008). Improving youth mentoring through research-based practice. American Journal of Community Psychology, 41, 35-42.

Rhodes, J. E., \& DuBois, D. L. (2008). Mentoring relationships and programs for youth. Current Directions in Psychological Science, 17, 254-258.

Rhodes, J. E., Grossman, J. B., \& Resch, N. R. (2000). Agents of change: Pathways through which mentoring relationships influence adolescents' academic adjustment. Child Development, 71, 1662-1671.

Rhodes J., Reddy, R., Roffman, J., \& Grossman, J. B. (2005). Promoting successful youth mentoring relationships: A preliminary screening questionnaire. The Journal of Primary Prevention, 26, 147-167.

Rhodes, J. E., Spencer, R., Keller, T. E., Liang, B., \& Noam, G. (2006). A model for the influence of mentoring relationships on youth development. Journal of Community Psychology, 34, 691-707. 
Richardson, L. (1993). Writing: A method of inquiry. In Y. Lincoln and N. Denzin (Eds.), Handbook of Qualitative Research (pp. 516-529). Thousand Oaks, CA: Sage.

Rodgers, B. L., \& Cowles, K. V. (2007). The qualitative research audit trail: A complex collection of documentation. Research in Nursing and Health, 16, 219-226.

Scala, A. A. L. (2014). About Photography. Raleigh, N.C.: Lulu Press.

Search Institute. (2006). 40 Developmental Assets for Adolescents (ages 12-18).

Retrieved January 13, 2011, from: http://www.searchinstitute.org/system/files/40AssetsList.pdf.

Sinha, D. (1963). Phenomenology and positivism. Philosophy and phenomenological research, 23, 562-577.

Sipe, C. L. (1996). Mentoring: A synthesis of P/PV's research, 1988-1995. Philadelphia: Public/Private Ventures.

Sipe, C. L. (2002). Mentoring programs for adolescents: A research summary. Journal of Adolescent Health, 31, 251-260.

Sipe, C. L. (2005). Toward a typology of mentoring. In D. L. DuBois \& M. J. Karcher (Eds.), Handbook of youth mentoring (pp.65-79). Thousand Oaks, CA: Sage.

Smith, D. W. (2011). Phenomenology, The Stanford Encyclopedia of Philosophy, Retrieved December 2, 2011 from http://plato.stanford.edu/archives/fall2011/entries/phenomenology/.

Smith, J. A. (2005). Merleau-Ponty and the phenomenological reduction. Inquiry, 48, $553-571$. 
Smith, J.A., Flowers, P., \& Larkin, M. (2009). Interpretative phenomenological analysis: Theory, method, and research. London: Sage.

Smith, J. A., \& Osborn, M. (2007). Interpretative phenomenological analysis. In J.A. Smith (Ed.) Qualitative Psychology. London: Sage.

Smith, T. J. (2004). Guides for the journey: supporting high risk youth with paid mentors and counselors. Philadelphia, PA: Public/Private Ventures.

Spencer, R. (2006). Understanding the mentoring process between adolescents and adults. Youth and Society, 37, 287-315.

Spencer, R. (2007). “I just feel safe with him'”: Close and enduring male youth mentoring relationships. Psychology of Men and Masculinity, 8, 185-198.

Spencer, R. (2007). "It's not what I expected": A qualitative study of youth mentoring relationship failures. Journal of Adolescent Research, 22, 331-354.

Spencer, R., \& Liang, B. (2009). "She gives me a break from the world": Formal youth mentoring relationships between adolescent girls and adult women. Journal of Primary Prevention, 30, 109-130.

Spencer, R., \& Rhodes, J. E. (2005). A counseling and psychotherapy perspective on mentoring relationships. In D. L. Dubois \& M. J. Karcher (Eds.), Handbook of youth mentoring (pp. 118-132). Thousand Oaks, CA: Sage.

Strauss, L. (2006). The gardening analogy. Retrieved February 21, 2010, from http://www.lizstrauss.com/2010/10/13/everyones-business/the-gardeninganalogy/. 
Strauss, A., \& Corbin, J. (1990). Basics of qualitative research: Grounded theory procedures and techniques. Newbury Park, CA: Sage Publications, Inc.

Tierney, J. P., Grossman, J. B., \& Resch, N. L. (1995). Making a difference: An impact study of Big Brothers/Big Sisters. Philadelphia: Public/Private Ventures.

Todres, L., \& Galvin, K. T. (2008). Embodied interpretation: A novel way of evocatively re-presenting meanings in phenomenological research. Qualitative Research, 8, 568-583.

Van Manen, M. (1997). Researching the lived experience: Human science for an action sensitive pedagogy. London, Ontario, Canada: The Althouse Press.

Van Manen, M. (2011). Experiential phenomenology. Phenomenology Online. Retrieved May 29, 2011 from http://www.phenomenologyonline.com/inquiry/orientationsin-phenomenology/experiential-phenomenology/.

Van Manen, M., \& Adams, C. (2009). The phenomenology of space in writing online. Educational Philosophy and Theory, 41, 10-21.

Vasseleu, C. (1998). Textures of Light: Vision and Touch in Irigaray, Levinas and Merleau-Ponty. New York: Rutledge.

Werner, E. E., \& Smith, R. S. (1992). Overcoming the odds: High risk children from birth to adulthood. Ithaca and London: Cornell University Press. 


\section{Appendix A: Reflections on the Use of Poetry in Interpretive Phenomenological}

\section{Analysis}

The use of poetry in qualitative research is relatively rare, and this project may be the first to use poetry writing as a method for analyzing data in IPA. Therefore, it seems appropriate to provide this addendum to reflect briefly on some of the lessons I learned through the poetry writing process, including the advantages and challenges associated with using poetry in phenomenology. The four main points, which I will describe in more detail below, are:

1. Poetry can capture the emotional content of participant experiences that thematic approaches and prose descriptions tend to miss.

2. Poetry must be allowed to speak for itself — attempts to explain the meanings of poems will recreate the same limitations as using prose.

3. Poetry has potential as a stand-alone method or as an approach that complements other data analysis techniques.

4. A researcher using poetry in IPA must be comfortable and familiar with engaging with the world through poetry.

The primary purpose of using poetry writing as an approach to data analysis was to uncover and communicate the emotional experiences of youth in a way that traditional approaches to qualitative research cannot. So, the first and perhaps the most important lesson I took away from this project is that poetry can successfully identify and reflect emotional content of participant experiences that thematic approaches and prose descriptions tend to miss. Dante's story, and the poem that it inspired ("A Long Story" at 
the beginning of Chapter 8), provides a good example of how poetry can facilitate a qualitatively different kind of understanding than lists, descriptions, and quotes. In the thematic analysis, themes associated with "help in difficult situations" included the mentor being available for emotional support and giving youth an outlet to share their experiences in the context of difficult relationships with peers and family. However, Dante's situation included a number of these characteristics, all of which combined to create unique and powerful personal experiences for Dante that cannot be adequately summed up by listing the individual or collected themes presented in Chapter 8 . The essence of Dante's experience — of having a long-term mentor in difficult life situations - is also not conveyed fully by providing a few quotes that are removed from the context of the rich and complex story Dante shared with me during the interview. The poem serves to put important bits and pieces of Dante's experiences back in context, and in relation to each other, so that the moments and events of his life come alive with emotion and deeper meaning.

The second important point that occurred to me as I created the poems from the interview transcripts was that the poems must be allowed to speak for themselves. In other words, the poems are, like other methods of understanding, organizing, and presenting qualitative data, interpretive products that cannot be explained through prose without losing some of the value, and ultimately undermining the purpose, of the reader's engagement with the poems. The photographer Ansel Adams once said, "A true photograph need not be explained, nor can it be contained in words," (Scala, 2014), and my feelings about poems are similar. Poetry is a singular mode of communication 
that derives its power as much from how it is presented as from the actual words that are used. People often wonder about the "meaning" of poems, wanting to understand what was in the poet's mind as the work was created. To me, this misses the point of poetry entirely. The poem is what was in the poet's mind at the time the work was created. The poem $i s$ the story, with all of the information the reader needs to understand what that moment in time was like — cognitively and emotionally_ for the poet. Even a paragraph of explanation, I believe, would effectively signal a fundamental lack of confidence in the adequacy of poetry — one of the world's oldest and most universal methods of written communication - to convey the essential aspects of human experience, which is its primary purpose.

Poetry should speak for itself in qualitative research, but at the same time there is no reason it can't be successfully complemented by other methods or approaches. This third point - that poetry has the potential to yield important phenomenological findings in its own right, or can be used as a complementary or supplementary research strategyhas important implications for future research that uses poetry as an interpretive tool. On their own, transcript poems (and other research poems) offer a phenomenological interpretation of experience that can inform theory development, identify and illustrate aspects of human experience that may be overlooked or unaccounted for by other qualitative and quantitative methods, and provide insight for both researchers and professionals who are looking for a unique perspective on participants' lives and experiences. 
Using poetry in research, like any research method, requires training, skill, and experience in order for the approach to be effective. The fourth and final lesson I learned through this process is that a researcher using poetry in IPA must be comfortable and familiar with engaging with the world through poetry. It is unlikely that a novice poet will have the confidence or necessary tools to create rich and resonant poems that honor the experiences of participants and that offer significant insight into the phenomenon being considered. With transcript poems, particularly when the transcripts are words from youth who have been through significant difficulty, the researcher/poet must take responsibility to use the participants' contributions ethically and competently, taking full advantage of the opportunity to help participants become known in a way they never have before. Ineffective poetry, on the other hand, is often heavy-handed, uneven, and causes confusion and uncertainty. While most everyone has the capacity (as opposed to the skill) to write strong and beautiful poems, it is important that researcher poets come to their work with the skill and dedication that is likely to be required to understand, interpret, and reflect upon these dynamics, and to use the resulting information in a positive way. 


\section{Appendix B}

\section{Parent/Guardian Consent for Participation in: An Interpretive Phenomenological Analysis of Long-Term Youth Mentoring Relationships from the Youth Perspective}

Your child has been invited to participate in a research study conducted by Kevin Jones, a doctoral candidate from Portland State University, School of Social Work. The researcher hopes to learn about long-term mentoring relationships at Friends of the Children. This study is being conducted by a student researcher under the supervision of Dr. Thomas Keller (dissertation chair) from the Portland State University School of Social Work.

Your child was selected as a possible participant in this study because of his/her experience as a present or past participant at Friends of the Children. If your child participates in the study, he/she will be asked to participate in one or more interviews about his/her experiences in the organization.

Interviews may be audio-taped. While participating in this study, it is possible that your child may feel uncomfortable or upset by one or more of the interview questions, and your child may at any time decline to answer questions or end the interview. Neither you nor your child may receive any direct benefit from taking part in this study, but the study may help to increase knowledge which may help others in the future.

Real names will not be used in reporting the findings of the study and every effort will be made to protect the identity and confidentiality of your child and your family. However, there is a small possibility that your child may be identifiable through anecdotal details contained in the report. Your child will have the opportunity to review, prior to publication, any material referring to or provided by your child in the report. Research findings from this study may be published in the form of a paper, dissertation, journal article, book, or conference presentation. Names of participants and all field notes, transcripts, and audio-recordings will be kept confidential by storage in a locked file cabinet or in password-protected computer files at the researcher's office for five years following completion of the study.

** Participation in this study is voluntary. You do not have to give permission for your child to take part in this study, and your decision will not affect your child's status or relationship with Friends of the Children. You may also withdraw your child from this study at any time without affecting your or your child's relationship with Friends of the Children.

If you have concerns about your child's participation in this study or your child's rights as a research subject, please contact the Human Subjects Research Review Committee, Office of Research and Strategic Partnerships, 1600 SW $4^{\text {th }}$ Ave, Suite 620, Portland State University, (503) 725-3423 / 1800-547-8887. If you have questions about the study itself, contact Kevin Jones at: School of Social Work, Portland State University, P.O. Box 751, Portland, Oregon, 97207; or by phone at (503) 4901823 .

Your signature indicates that you have read and understand the above information and agree to your child's participation in this study. Please understand that you may withdraw your consent at any time without penalty, and that, by signing, you are not waiving any legal claims, rights or remedies. The researcher will provide you with a copy of this form for your own records.

Parent/Guardian Name (printed)

Parent/Guardian Signature
Child's name

Date 


\section{Appendix C}

\section{Consent for Participation in: An Interpretive Phenomenological Analysis of Long-Term Youth Mentoring Relationships from the Youth Perspective}

You have been invited to participate in a research study conducted by Kevin Jones, a doctoral candidate from Portland State University, School of Social Work. The researcher hopes to learn about long-term mentoring relationships at Friends of the Children. This study is being conducted by a student researcher under the supervision of Dr. Thomas Keller (dissertation chair) from the Portland State University School of Social Work.

You were selected as a possible participant in this study because of your experience as a present or past participant at Friends of the Children. If you participate in the study, you will be asked to participate in one or more interviews about your experiences in the organization. Interviews may be audio-taped. While participating in this study, it is possible that you may feel uncomfortable or upset by one or more of the interview questions, and you may at any time decline to answer questions or end the interview. Participants will receive a one-time $\$ 20$ cash payment to thank you for your participation. Besides the $\$ 20$ payment, you may not receive any direct benefit from taking part in this study, but the study may help to increase knowledge which may help others in the future.

Real names will not be used in reporting the findings of the study and every effort will be made to protect the identity and confidentiality of you and your family. However, there is a small possibility that you or your story may be identifiable through anecdotal details contained in the report. You will have the opportunity to review, prior to publication, any material referring to or provided by you in the report. Research findings from this study may be published in the form of a paper, dissertation, journal article, book, or conference presentation. Names of participants and all field notes, transcripts, and audio-recordings will be kept confidential by storage in a locked file cabinet or in password-protected computer files at the researcher's office for five years following completion of the study.

** Participation in this study is voluntary. You do not have to take part in this study, and your decision will not affect your status or relationship with Friends of the Children. You may also withdraw from from participation in this study at any time without affecting your relationship with Friends of the Children.

If you have concerns about your participation in this study or your rights as a research subject, please contact the Human Subjects Research Review Committee, Research and Strategic Partnerships (http://www.rsp.pdx.edu), $1600 \mathrm{SW} 4{ }^{\text {th }}$ Ave, Suite 620, Portland State University, (503) 725-3423 / 1-800-547-8887. If you have questions about the study itself, contact Kevin Jones at: School of Social Work, Portland State University, P.O. Box 751, Portland, Oregon, 97207; or by phone at (503) 4901823.

Your signature indicates that you have read and understand the above information and agree to participate in this study. Please understand that you may withdraw your consent at any time without penalty, and that, by signing, you are not waiving any legal claims, rights or remedies. The researcher will provide you with a copy of this form for your own records.

Participant's Name (printed)

Parent/Guardian Signature

Date 


\section{Appendix D}

\section{Sample Semi-Structured Interview Questions}

Project: An Interpretive Phenomenological Analysis of Long-Term Mentoring Relationships from the Youth Perspective

1. What's it like having a Friend? (How would you describe your relationship?)

2. Tell me about some of the things you and your Friend do together.

3. What are the best parts about having a Friend?

4. Please describe a time when your relationship with your Friend was difficult.

5. What are some ways that your Friend helps you?

6. What are some other things you wish your Friend would help you with?

7. Tell me about the first time you remember meeting with your Friend.

8. How is having a Friend different now than when you were younger?

9. What is your favorite memory of you and your Friend?

10. What would you say are the difficult things about having a Friend? 


\section{Appendix E}

\section{Transcriptionist Confidentiality Form}

$\mathrm{I}$, , transcriptionist, agree to maintain full confidentiality in regards to any and all audiotapes and documentation received from related to his doctoral study on

Furthermore, I agree:

1. To hold in strictest confidence the identification of any individual that may be inadvertently revealed during the transcription of audio taped interviews, or in any associated documents;

2. To not make copies of any audiotapes or computerized files of the transcribed interview texts, unless specifically requested to do so by

;

3. To store all study-related audiotapes and materials in a safe, secure location as long as they are in my possession;

4. To return all audiotapes and study-related documents to in a complete and timely manner.

I am aware that I can be held legally liable for any breach of this confidentiality agreement, and for any harm incurred by individuals if I disclose identifiable information contained in the audiotapes and/or files to which I will have access.

Signature

Date 